Aus der Königl. Universitäts-Frauenklinik zu Kiel.

Direktor: Prof. Dr. Stoeckel.

\title{
Ueber die anatomischen Veränderungen an den Bauch- und Brustorganen, insbesondere am Peritoneum von lieren nach intraperitonealer Kampferölinjektion.
}

\author{
Von \\ Dr. med. Kawasoye (Formosa). \\ (Hierzu Tafe] VII-VIII.)
}

Der Erste, der die resorptionshemmende Wirkung des Oels im Cavum peritonei von Tieren nachgewiesen hat, war Glimm, während Martin schon 1895 steriles Oel bei Bauchhöhlenoperationen aus ganz anderem Grunde angewandt hatte, nämlich um die Entstehung von Adhäsionen zu verhüten.

Glimm hatte bei Kaninchen Olivenöl, Kampferöl, Adeps lanae, Vaselin, Mohnöl und Kokosöl mit Bacterium coli in die Bauchhöhle eingespritzt. Es zeigte sich dabei eine beträchtliche Hemmung der Bakterienresorption derart, dass nur wenig Keime in die Blutbahn gelangten, und peritoneal mit 0 el behandelte Tiere am Leben blieben, während die entsprechenden Kontrolltiere, die nicht mit Oel behandelt waren, zugrunde gingen. Glimm erklärte diese resorptionshemmende Fähigkeit des Oels gegenüber den von ihm angewandten Kolibakterien als eine rein mechanische Wirkung. Nach seiner Auffassung verstopft das Oel die aus dem Peritonealkavum abführenden Lymphbahnen und hindert dadurch die peritoneale Resorption von Bakterien.

Eine Reihe von Autoren, wie Hirschel, Borchard, Krecke u. a. folgten der von Glimm gegebenen Anregung und verwandten das Kampferöl als Heilmittel bei bestehender Peritonitis. Gleichzeitig, aber ganz unabbängig von diesen rein therapentischen Bestrebungen stellten Pfannenstiel "klinische Versuche" und Hoehne "experimentelle Versuche" zur Prophylaxe der Peritonitis an. Während Pfannenstiel die postoperative Oelbehandlung 
bei "unreinen" Bauchhöhlenoperationen übte, fand Hoehne bei seinen entsprechenden experimentellen Versuchen, dass das peritoneal angewandte Oel nicht, wie Glimm meinte, durch Verlegung der Lymphbahnen die Bakterienresorption aulhebt bzw. hemmt, sondern durch die hervorgerufene reaktive Reizperitonitis. Hoehne wies nach, dass es sich bei dieser Oelperitonitis garnicht um eine spezifische 0el- bzw. Kampherölwirkung handelt, sondern um einen durch die verschiedensten Reizmittel auslösbaren entzündlichen Reaktionszustand des Peritoneums. Eine im Tierversuch gleichzeitig mit der peritonealen Infektion erfolgende Oelinjektion erkannte Hoehne nicht nur als nutzlos, sondern sogar als schädlich, weil bei solcher Versuchsanordnung die peritoneale Bakterienresorption nicht gehemmt, sondern sogar beschleunigt wird. Diese exakten Beobachtungen im Tierexperiment führten Hoehne zu Vorstellungen, die von der Glimm'schen Anschauung der Lymphbahnverlegung durch Oel völlig abwichen und liessen ihn den entzündlichen Reaktionszustand des Peritoneums als den wirksamen Schutz gegen Peritonitis erkennen. Die Frucht dieser Erkenntnis war die anteoperative Reizbehandlung des Peritoneums vor "unreinen" Bauchhöhlenoperationen, die. Hoehne als Erster beim Menschen vor einer abdominalen Carcinomoperation anwandte und die Pfannenstiel übernahm und an Stelle seiner postoperativen Peritonitisprophylaxe setzte.

Hoehne wies nach, dass es sich nach der Oelbehandlung um eine aseptische Bauchfellentzündung in gleicher Weise handle, wie bei der Fremdkörperperitonitis, ja er hat sogar selbst analoge Veränderungen des Peritoneums nach der Einführung verschiedener Fremdkörper in die Bauchhöhle beobachtet. Nach Hoehne zeigt das Peritoneum nach der Oelbehandlung in seiner ganzen Ausdehnung, besonders am Zwerchfell und an den tiefstgelegenen Partien der Bauchböhle mehr oder weniger dicke Auflagerungen, welche aus einem emulgiertes Oel einschliessenden Maschenwerk von Fibrin und Endothelzellen bzw. Peritonealepithelzellen bestehen. Er vergleicht diese Auflagerungen in ihrer Wirkung mit dem Granulationswall von Wunden, der ebenso wenig wie diese Auflagerungen eine Resorption von Bakterien zulässt. Ausserdem konnte er auch nachweisen, dass die obige reaktive peritonitische Veränderung bei Tier und Mensch 24 Stunden nach der Oelbehandlung noch minimal ist, später jedoch stärker wird und beim Menschen ihre stärksten Grade, 6, 7, 10, 11, 12, 14 und 
15 Tage der Oelbehandlung erreicht. Selbst nach 7 Wochen konstatierte er noch deutliche Spuren der aseptischen Peritonitis. Die anatomischen Veränderungen, die von Hoehne gefunden wurden, sind später von Novak und Wilkie gleichfalls beim Kaninchen deutlich beobachtet, während Heimann bei weissen Mäusen weder makroskopisch noch mikroskopisch Abweichungen von einem nicht mit Oel behandelten Peritoneum fand.

Wilkie hatte Paraffin eingespritzt und nach 2-3 Wochen die Bauchhöhle eröffnet. Er bemerkte darin eine Auflagerung "like creamcheese", wie er schreibt. Bei der mikroskopischen Untersuchung fand er darin Fibrin, degenerierte Leukozyten, Oelkugeln und Bakterien, die er für Infektionsversuche eingespritzt hatte. Ausserdem berichtet er, seien die Lymphgefässe des Zwerchfells mit Fett angefüllt gewesen.

Norak benutzte 4 Kaninchen zu seinen Versuchen und untersuchte das 1. Tier am 33., das 2. Tier am 20., das 3. Tier am 14., das 4. Tier am 26. Tage nach der Oelbehandlung. Der Hauptzweck seiner experimentellen Untersuchung war; die von anderer Seite behauptete adhäsionshemmende Wirkung des Oels zu studieren. Seine Beobachtungen am Kaninchenperitoneum nach Oelinjektion entsprechen sowohl makroskopisch als auch mikroskopisch grösstenteils den von Hoehne gefundenen Resultaten. Er beschreibt in der Auflagerung verschiedene Arten von Zellen, über deren Herkunlt er jedoch keine Vermutungen äussert. Novak's Befunde sind, wenn ich mich möglichst an seine eigene Darstellung halte, etwa folgende: Bei dem 1. Tier (nach 33 Tagen) bemerkte N. ausser der Verwachsung des Darmes an der Operationswunde im zusammengerollten Netze eingeschlossenes Oel und teils gestielte, teils flache Auflagerungen an der Oberfläche der Leber. Das mikroskopische Bild der Auflagerung zeigte ein gefässreiches Bindegewebsnetz. Das Fett lag in den Hohlräumen dieses Netzes. Ausserdem findet es sich in den Hohlräumen des Gewebes selbst, die rundlich und scharf begrenzt und mit Haufen ron Zellkernen und von einem nicht in einzelne Zellen gegliederten Protoplasma erfüllt waren. Die tiefere Schicht der Auflagerung war fibrinreicher, und die fetthaltigen Hohlräume erschienen grösser und regelmässiger. Die Innenflächen der Hohlräume werden nach Novak von Zellen überzogen, welche teilweise niedrig sind, z. T. aber ein hohes feinschaumiges Protoplasma zeigen; und schliesslich sieht man auch sehr grosse Zellen, welche mehrkernig sind und 
gleichsam ein von Vakuolen durchsetztes Synzytium bilden. Alle intra- und extrazellulären Hohlräume sind mit Fett erfüllt. Eine gestielte Auflagerung auf der Leber zeigt ein junges, mit protoplasmareichen Zellen ausgestattetes Bindegewebe; darin findet man Hohlräume, welche Fett enthalten und an den Innenflächen mit ein- und vielkernigen Zellen ausgekleidet sind.

Bei dem 2. Tier (nach 20 Tagen) sah Novak ausser der Verwachsung in der Gegend der Operationswunde noch zahlreiche, schleierartige, mattglänzende, schleimähnliche Beläge auf der Darmoberfläche, besonders am Dickdarm. Eine grosse und dicke Auflagerung bemerkte er am Peritoneum parietale. Ausserdem konnte er vielfach lockere Verklebungen zwischen den Darmschlingen nachweisen. In diesem Falle schildert er die histologischen Veränderungen der Auflagerung am Netz und am Peritoneum parietale folgendermassen: Das Knötchen im Netze zeigt ein mit Fett erfülltes Bindegewebsgerüst. Im Bindegewebe sieht man polygonale Zellen mit feinschaumigem Protoplasma und Riesenzellen. In der Mitte findet man einen kleinen Abszessherd, der mit nekrotischen Leukozyten erfüllt ist. Die peritoneale Auflagerung besteht aus einem zell- und gefässreichen Bindegewebe, in dem man hier und da Maufen von Leukozyten wahrnimmt. In der Umgebung der fetthaltigen Hohlräume befinden sich Riesenzellen.

Bei dem 3. Tiere (nach 14 Tagen) bemerkte er die strangförmige Verwachsung nur auf der Strecke zwischen dem Blasenscheitel und der medianen Laparotomiewunde. Im Bereiche der Peritonealdefekte selbst bestand keine Adhäsion. In der Bauchhöhle fand er an verschiedenen Stellen, speziell in der Gegend des Beckenbauchfelles, an der Leberoberfläche und im Netz sehr zahlreiche, gelblich-weisse, opake Auflagerungen mit fettglänzender Oberfläche. Er schilderte die histologische Veränderung der Auflagerung der Leber wie folgt: Sie besteht aus einem fetterfüllten Maschenwerke. Im Septum desselben sah er sehr dicht gedrängte polygonale Zellen mit hellem, feinschaumigem Protoplasma und zahllose Riesenzellen, von denen einzelne mit in Vakuolen eingeschlossenen Fetttropfen erfüllt sind. Oft bemerkte er Uebergangsformen von einkernigen Zellen bis zu den Riesenzellen.

Bei dem 4. Falle (nach 26 Tagen) fand er wieder vom Bereiche der Peritonealdefekte und der Laparotomienarbe ausgehende Verwachsungen zwischen der vorderen Bauchwand und einem 
Konvolut von Darmschlingen. In der Bauchhöhle sah er ebenfalls zahlreiche, weisslich-grane Auflagerungen auf der Milz, sowie dem Peritoneum parietale, in geringerem Grade an der Leberoberfläche und zottige Rauhigkeiten am parietalen Blatt des Peritoneums. Der histologische Befund der Auflagerung an der Leber, an der Milz und auf dem Peritoneum parietale war folgender: Das Lebergewebe selbst war normal, die Leberkapsel verdickt und von Hohlräumen durchsetzt, die mit synzytiumähnlichen Zellkomplexen ausgekleidet waren. Es fand sich eine mässige Infiltration des Gewebes mit Leukozyten. Stellenweise sieht man Gruppen von rundlichen, mit einem blassgelben Inhalt erfüllten, vakuolisierten Zellen vom Typus der sogenannten Pseudoluteinzellen. Die gestielte Auflagerung, welche durch einen dünnen Stiel mit der oben geschilderten Leberkapsel in Verbindung steht, zeigt dieselbe Struktur wie die Leberkapsel. Die laterale Partie besteht aus dem mit rundlichen Hohlräumen durchsetzten riesenzellenreichen Bindegewebe. Das Septum und die Hohlräume selbst waren mit schon vorgeschrittene Nekrose aufweisenden Leukozyten infiltriert. Auf der Milz zeigten sich dieselben bindegewebigen Hohlräume. Die zottige Auflagerung an dem Peritoneum parietale bestand aus einem gefässreichen Bindegewebe und war an der Oberfläche mit Endothelzellen überzogen.

Aus diesen Befunden am Peritoneum der 4 urtersuchten Kaninchen schliesst Novak, dass es sich bei der Veränderung des Peritoneums nach intraperitonealer Oelbehandlung um eine Fremdkörperperitonitis handelt.

Im wesentlichen deckt sich das Untersuchungsresultat Novak's mit den Befunden Hoehne's am tierischen (Kaninchen) und menśchlichen Peritoneum. Wenn nun von einzelnen Autoren nach intraperitonealen Oel- bzw. Kampferölinjektionen beim Menschen eine Peritonitis mit reichlichem serösem oder gar eitrigem Exsudat vermisst wurde, so waren es falsche und unbegründete Erwartungen, welche an die Oelinjektion geknüpft wurden. Freilich lässt sich nach Hoehne die Oelperitonitis beim Kaninchen durch Zusatz reizender Stoffe zum Oel beliebig bis zu schwerster fibrinöseitriger-hämorrhagischer Exsudation steigern (Dieses Arch., Bd. 93, S. 569 ff.), aber die Kampferölwirkung bei Anwendung kleinerer Dosen äussert sich nach Hoehne im Peritonealkavum nicht in dem Auftrețen grösserer Mengen serösen oder eitrigen Exsudates, sondern markiert sich als eine mit spärlicher Exsudation einher- 
gehende Reizperitonitis, die zur Abkapselung der als Fremdkörper wirkenden Oelkügelchen führt.

Da systematische Untersuchungen über die verschiedenen Stadien der Kampferölreizperitonitis bisher nicht vorliegen, habe ich, angeregt durch Professor Hoehne, die Einwirkung des Kampferöls auf den Tierkörper, speziell auf das Tierperitoneum, in allen einzelnen Phasen studiert. Zugleich mit Erhebung des anatomischen Befundes habe ich auch stets darauf geachtet, wie das Kampferöl auf das Befinden des Tieres wirkt, um mich über die von Rübsamen und Happich behauptete und kürzlich von Esser abgelehnte giftige Wirkung des Kampfers zu orientieren. Hoehne selbst hatte auch nachgewiesen, dass 10 proz. Kampferöl bei schwächeren Patienten Blässe, Schweissausbruch und Ohnmachtsgefühl hervorruft. Zugleich habe ich bei der Sektion besonderen Wert darauf gelegt, zu untersuchen, ob eine Verwachsung an irgend einer Stelle der Bauchhöhle vorhanden ist, weil Hirschel und Borchard der Oelbehandlung eine adhäsionshemmende Wirkung zuschrieben, während Novak kürzlich seine abweichenden experimentellen Resultate publizierte. Letzterer hatte bei einigen Tieren grosse Defekte des Peritoneums und der oberflächlichen Muskelschichten zurückgelassen und erwartete nun, dass infolge der Oelung die Verwachsung ausbleiben würde. Weil die Verwachsung aber trotz der Oelung eintrat, lehnte er die Annahme einer adhäsionshemmenden Wirkung des Oels ab. Hinsichtlich der adhäsiven Veränderungen hatte Hoehne auf Grund seiner experimentellen und klinischen Erfahrungen bereits erklärt, dass die intraperitonealen Oelinjektionen von Adhäsionen nicht gefolgt sind, wenn wirklich aseptisch gearbeitet wird.

Herrn Professor Stoeckel bin ich zu grossem Danke verphichtet, dass ich mit seiner gütigen Erlaubnis die Arbeit in dem Institute ausführen durfte.

\section{Eigene Versuche.}

Als Versuchstiere benutzte ich zunächst Kaninchen, weil Glimm, Hoehne, Novak und Wilkie beim Kaninchen Veränderungen nach der Oelbehandlung sicher nachgewiesen haben und ich hieraus den Schluss zog, dass die Veränderungen nach der Oelung beim Kaninchen besonders deutlich in Erscheinung treten.

Unter streng aseptischen Kautelen öffnete ich ohne Narkose die Bauchhöhle des Tieres in der Mittellinie durch je einen ganz 
kleinen, 1 em langen I,ängssehnitt, welcher gerade in der Mitte zwischen Proc. xiphoideus und der Schamfuge angelegt wurde. Die Oeffnung der Bauchhöhle habe ich deswegen ausgeführt, weil man so sicher und ohne irgend eine Verletzung der Baucheingeweide das Oel in die Bauchhöhle hineinbringen kann. Bei Injektionen mit stumpfer Kanüle ohne Eröffnung des Peritoneums ist ein Einspritzen des Oels in die Bauchwand nicht mit absoluter. Sicherheit ausgeschlossen. Nachdem die Bauchhöhle geöffnet worden war, habe ich vorsichtig eine sterilisierte Kanüle in die Bauchhöhle eingeführt und fixierte diese Kanüle durch eine einmalige Abschnürung der Naht, welche um die Peritonealwunde herum tabaksbeutelartig ausgeführt wurde. Diese Fixation ist sehr wichtig, um das Herausfliessen des in die Bauchhöhle eingespritzten Oels zu verhindern. Dann habe ich steriles und auf Körpertemperatur erwärmtes Kampferöl langsam in die Bauchhöhle hineingespritzt. Das Kampferöl, welches ich benutzte, war immer 1 prozentiges, weil eine grosse Menge von Kampfer, wie ich geschildert habe, von einigen Autoren als giftig angesehen, 1 proz. Kampferöl aber nach dem Vorgang von Hoebne gegenwärtig allgemein ohne irgend eine schädliche Wirkung angewandt wird. Was die Menge 'des Kampferöls anbetrifft, so richtete ich mich nach dem Körpergewicht des Tieres, und zwar nahm ich für je $100 \mathrm{~g}$ Körpergewicht des Tieres $0,5 \mathrm{ccm}$, weil diese Menge von Hoehne auf Grund seiner eingehenden Untersuchungen als gefahrlos nachgewiesen wurde. Sobald nun die Einspritzung beendet und die Känüle wieder herausgenommen war, schnürte ich die tabaksbeutelartige Naht des Peritoneum fest, dann wurde geknotet. Hierauf wurde die Bauchwunde zweischichtig gleichfalls durch tabaksbeutelartige Naht geschlossen und mit Dermatolpulver gepudert.

Die Tiere wurden in ihrem Befinden, ihrer Bewegungs- und Fresslust genau beobachtet. An bestimmten, der systematischen Untersuchung der Oelwirkung entsprechenden Tagen worden sie durch Nackenschlag getötet und sofort seziert. Bei der Sektion notierte ich genau die Veränderungen der Brust- und Bauchorgane. Ausserdem wurde aus der Bauchhöhle abgeimpft und das Material in Bouillon und auf Agar übertragen, um zu kontrollieren, ob die Operation aseptisch ausgelührt worden war.

Nach der Beendigung der makroskopischen Untersuchung fixierte ich einen Teil der verschiedenen Organe der Brust- und 
Bauchhöhle in 4 proz. Formalinlösung, andere Stückchen dieser Organe in Alkohol. Von den mit Formalin behandelten Organstückchen wurden einige Teile in Gefrierschnitte zerlegt und dann mit Sudan III gefärbt. Andere Teile der mit Formalin vorbehandelten Stuicke sämtlicher Organe, sowie die in Alkohol fixierten Stücke wurden in Paraffin eingebettet und in düne Schnitte zerlegt. Für die Schnittfärbung benutzte ich HämatoxylinEosin. Das Fibrin wurde nach Weigert, das Bindegewebe nach van Gieson und auf Bakterien nach Gram oder mit Methylenblau gefärbt.

Die Organe der ausser Kaninchen zu den Experimenten benutzten Tiere (Meerschweinchen und Mäuse) wurden ebenso verarbeitet und mikroskopisch genau untersucht.

Um eine eventuelle Nachprüfung meiner Tierexperimente zu ermöglichen, gebe ich meine Versuchsprotokolle in allen Einzelheiten wieder:

\section{Experimente an Kaninchen:}

\section{Gruppe.}

Tötung der beiden Tiere (Nr. 1 und 2) 6 Stunden nach der intraperitonealen Kampferölinjektion.

Nr. 1. Männliches Kaninchen, $1020 \mathrm{~g}$ schwer.

Oelinjektion um 9 Uhr vormittags am 14. XI. 1912. Die Menge des Kampferöls betrug $5 \mathrm{ccm}$.

Verlauf: Das Tier wird nur etwas still, aber es frisst bald wieder.

Sektion: Um 3 Uhr nachmittags am 14. XI. 1912.

Befund: In der eröffneten Bauchhöhle findet man zum Teil noch nicht emulgiertes Oel in geringer Menge. Mikroskopisch sieht man in diesem Oel weder Kügelchen noch andere besondere Bestandteile.

Das Peritoneum ist überall glatt und spiegelnd, nirgends ist eine Auflagerung bemerkbar. Adhäsive Veränderungen sind natürlich nicht nachweisbar. Die Mesenterialgefässe sind deutlich injiziert. Das Zwerchfell zeigt sich an der abdominalen Seite sowohl wie nach der Pleura zu ganz glatt und spiegelnd. An der Leber, am Magen, am Netz, an der Milz sowie am Dünn- und Dickdarm findet man gar keine Abweichungen von der Norm. - Die Pleura ist glatt. Die Lunge ist gleichfalls normal.

Die bakteriologische Untersuchung der. Bauchhöhle ergibt Keimfreiheit.

Mikroskopische Untersuchung: Auf der abdominalen Seite des Zwerchfells findet man an einigen Stellen eine starke Erweiterung und Füllung der Blutgefässe, im subserösen Gewebe und in deren Umgebung eine geringfügige Infiltration mit Leukozyten. Hier und da sind auf dem Endothelüberzug kleine Anhäufungen von Leukozyten anzutreffen. Die Endothelzellen sind an diesen Stellen, besonders auf dem Centrum tendineum, ziemlich stark aufgequollen und zeigen ein feinkörniges Protoplasma von mehr rundlicher Form. Ihre Kerne sind ver- 
grössert, aber ihre Struktur ist regelmässig und zeigt eine gute Färbung. An der Pleuraseite des Zwerchfells findet man aber keine Veränderung der Endothelzellen und eine Infiltration mit Lenkozyten ist anch nicht nachweisbar. Bei der Fettfärbung des Zwerchfells sieht man an der abdominalen Seite desselben selten feine Fettkïgelchen zwischen den Endothelzellen oder in den subendothelial gelegenen Lymphgefässen. Ebenso selten trifft man hier ganz feine Fettiröpfchen in dem Protoplasma der Endothelien und der Leukozyten selbst.

Am Dickdarm findet man hier und da aufgequollene Endothelzellen und Injektion von Blutgefässen im subserösen Gewebe.

An der Bauchwand, an der Leber und an der Milz findet man keine nennenswerten Veränderungen, nur an einigen Stellen sieht man deutlich aufgequollene Endothelzellen.

Am Netz sieht man aber an vielen Stellen Mehrschichtigkeit der aufgequollenen Endothelzellen und kleine Haufen von Leukozyten auf der Oberfläche. In der oberen Partie des Grundgewebes des Netzes haben wir eine deutliche Erweiterung und Füllung der Blutgefässe, sowie Infiltration mit einer geringen Menge Leukozyten. Bei der Fettfärbung des Netzes sieht man in dessen Grundgewebe dasselbe Fett in grösserer als normaler Menge. An der Oberfläche des Netzes ist jedoch Fett in feinsten Tröpfchen intra- und interzellulär liegend in Endothelzellen und Leukozyten nachweisbar. Die Pleura und die Lunge sind vollkommen normal. Bei der Fettfärbung der Lunge kann man Fett in den Lungengefässen nicht nachweisen.

Nr. 2. Männliches Kaninchen, $1050 \mathrm{~g}$ schwer.

Oelinjektion 10 Uhr vormittags am 13. XI. 1912. Menge des Kampferöls $5,2 \mathrm{ccm}$.

Verlauf: Ungestört.

Sektion: 4 Uhr nachmittags am 14. November 1912.

Befund: In der Bauchhöhle findet man gleichfalls noch nicht emulgiertes Oel in geringer Menge, welches mikroskopisch ein analoges Bild zeigt wie bei $\mathrm{Nr}$. 1. Das Peritoneum ist sowohl parietal wie viszeral glatt und spiegelnd; wie zu erwarten, finden sich keine adhäsiven Veränderungen. Die Mesenterialgefässe sind deutlich injiziert. Das Zwerchfell ist normal, An der Leber und an der Milz findet man ebenso, wie an den anderen Eingeweiden keine Abweichungen von der Norm. Die Pleura ist glatt und spiegelnd, der Lungenbefund ist gleichfalls normal.

Der Keimzuichtungsversuch aus der Bauchhöhle fällt negativ aus.

Mikroskopische Untersuchung: Das mikroskopische Bild ist ganz analog wie in $\mathrm{Nr}$. 1, so dass sich eine abermalige Schilderung erübrigt. Nur die Veränderung des Netzes ist noch stärker, besonders die Leukozytenansammlung an der oberen Partie des Grund gewebes.

Der Befund der Lunge ist normal. Bei der Fettärrbung findet man hier und da kleine Fettropfen in den Lungengefässen: Infiltration ist nicht nachweisbar.

Epikrise: 6 Stunden nach der intraperitonealen Kampferölinjektion zeigen sich makroskopisch, abgesehen von der Injektion der Mesenterialgefässe, keine Veränderungen. Mikroskopisch aber kann man schon Veränderungen an einigen Bauchorganen, besonders deutlich am Netz nachweisen. Diese Veränderungen: Aufquellung and Wucherung der Endothel- 
zellen, deutliche Injektion der Blutgefässe und kleine Anhäufungen von Leukozyten, sowohl im subserösen Gewebe als auch auf der Oberfläche der Serosa, sind ohne Zweifel durch den Reiz des Kampferöls verursacht, da ich sie am nicht geölten Kaninchenperitoneum in dem Maasse nie gefunden habe.

\section{Gruppe.}

Tötung der beiden Tiere (Nr. 3 und 4) 12 Stunden nach der intraperitonealen Kampferölinjektion.

Nr. 3. Männliches Kaninchen, $1010 \mathrm{~g}$ schwer.

Oelinjektion 8 Uhr vorm. am 14. XI. 12. Menge des Kampferöls 5 cem.

Verlauf: Ungestört.

Sektion: 8 Uhr abends am 14. November 1912.

Befund: In der Bauchhöhle findet man eine öltropfenhaltige, ziemlich klare Flüssigkeit in geringer Menge. Diese Flüssigkeit zeigt mikroskopisch Leukozyten in mässiger Anzahl und Fettkügelchen von verschiedener Grösse. Ausserdem bemerkt man in der Flüssigkeit spärliche aufgequollene Endothelzellen. Letztere zeigen zuweilen einen oder mehrere Fortsätze. Das Protoplasma der Endothelzellen ist stark granuliert. Die Kerne sind vergrössert, aber sie tingieren sich meistens gut und gleichmässig.

Die Mesenterialgefässe sind im allgemeinen stark injiziert. Adhäsive Veränderungen sind in der Bauchhöhle nirgendwo angedeutet. Am Peritoneum bemerkt man im allgemeinen einen tauartigen Belag. An der Serosa des Dickdarms sieht man einen sehr beträchtlichen, dicken, weissen, feucht glänzenden Belag, der sich bald als zottige, bald als flache, teils fest, teils lose an der Serosa haftende Auflagerung darstellt. An einigen Stellen der Serosa des Dickdarms bemerkt man feinste punktförmige, subseröse Blutungen,

In der Bauchhöhle finden sich vereinzelte freiliegende, weissliche Flöckchen, die ohne Zweifel als losgerissene Beläge zu deuten sind.

Ausser dem Dickdarm findet man einen gleichartigen dicken Belag am Netz und an der Milz. An dem Mesenterium ist der Belag in nur geringer Menge und in dünnerer Schicht vorhanden. An der Leber, am Dünndarm und an der parietalen Bauchwand findet man nur hier und dort kleine, weisse Auf lagerungen. An der abdominalen Seite des Zwerchfells bemerkt man in seiner ganzen Ausdehnung verstreut zahlreiche, herdförmige, weissliche Auflagerungen. durch welche die Oberfläche des Zwerchfells ein leicht getrübtes Aussehen bekommt. Die Pleuralseite des Zwerchfells dagegen ist glatt und spiegelnd wie die übrige Pleura. Die Lunge ist normal.

Die bakteriologische Prüfung der Bauchhöhle ergibt Keimfreiheit.

Mikroskopische Untersuchung: Bei Betrachtung der abdominalen Zwerchfellserosa zeigt sich, dass die Endothelzellen, welche bei den Tieren der vorigen Gruppe die Oberfläche gleichmässig überzogen und nur ein wenig aufgequollen waren, bei diesem Tiere stärker ausgequollen sind und ein stark granuliertes Protoplasma aufweisen. Ihr Höhendurchmesser hat bedentend zugenommen, ihre Gestalt ist rundlich geworden. An der lateralen, muskulären Partie des Zwerchfells zeigen diese aufgequollenen Endothelzellen stellenweise infolge ihrer Wucherung eine Mehrschichtigkeit, und wir finden hier eine starke, bis zur 
Oberfläche reichende Durchsetzung der Zwerchfellserosa mit Leukozyten. Im subserösen Gewebe findet man starke Erweiterung und Fïllung der Blutgefässe und eine Infiltration mit weniger zahlreichen Leukozyten. Die Lymphgefässe sind hier ebenfalls erweitert und bei der Fettfärbung sind darin rotgefärbte Fettröpfchen nachweisbar.

Wenn man nun die Gegend des Centrum tendineum betrachtet, dann wird man die Wucherung der Endothelzellen noch viel deutlicher als an den muskulären $Z$ werchfellpartien gewahr. Besonders bemerkenswert ist hier ein Maschenwerk, gebildet von gewucherten Endothelzellen und von Leukozyten, Die zahlreichen Hohlräume dieses Maschenwerkes sind mit Fettropfen erfüllt und werden von Zellen begrenzt, vom Aussehen der Endothelzellen. welche die Oberfläche des Zwerchfells überziehen und, wie oben beschrieben, an vielen Stellen mehrschichtig geworden sind. Das Maschenwerk zeigt sich stark mit Leukozyten durchsetzt. An manchen Stellen des Maschenwerkes ist die Leukozytenanhäufung so stark, dass diese Partien lediglich aus Leukozyten zu bestehen scheinen. Hier und da trifft man Haufen von Leukozyten im Maschenwerk; von denen ein Teil schon nekrotische Veränderungen aufweist. Man sieht hier Leukozyten mit zerfallenen Kernen oder auch isolierte freigew ordene Kerntrümmer. Die grossen Hohlräume des Maschenwerkes zeigen in ihrer Wand länglich gestreckte bandartige Endothelzellen. Wenn man aber diese Zellen uach beiden Richtungen hin verfolgt, so kann man oft bemerken, dass diese gestreckten Zellen nach und nach höher werden und schliesslich das Bild gequollener Endothelzellen bieten. Im subserösen Gewebe des Centrum tendineum findet man eine starke Infiltration mit Leukozyten sowie Erweiterung und Füllung der Blutgefässe. Ausserdem sieht man hier dicht unter den vermehrten Endothelzellen stark erweiterte Lymphgefässe. Manchmal ragen die letzteren in die untere Partie des Maschenwerkes hinein und beteiligen sich an der Maschenwerkbildung.

Fibrin findet man als ein feines Netz im Maschenwerke und im subserösen Gewebe, und zwar in geringer Menge. Bei der Fettfärbung des Zwerchfells sieht man ein die Hohlräume des Maschenwerkes und die Lymphgefässe erfüllendes Fett in beträchtlicher Menge derart, dass die Oberfläche des Zwerchfells vollständig mit dem Fett bedeckt zu sein scheint. Andererseits liegt auch Fett in feinen Tropfen intra- und interzellulär im Peritonealepithel sowie in und um die Leukozyten im Maschenwerke. In den muskulären Partien des Zwerchfells findet man Fett intramural gar nicht oder nur in geringer Menge und nur stellenweise in den Lymphgefässen.

Am Dickdarm sieht man gleichfalls starke Erweiterung und Füllung der Blutgefässe im subserösen Gewebe, besonders stark an der Stelle, wo die Oberfläche des Dickdarmes hochgradige Wucherung resp. eine Maschenbildung der Endothelzellen zeigte. Ausser der Erweiterung: und Füllung der Blutgefässe bemerkt man im subserösen Gewebe auch eine starke Infiltration mit Leukozyten, und zuweilen trifft man gleichzeitig eine Infiltration mit roten Blutkörperchen. Solche Infiltrationen beschränken sich grösstenteils auf das subseröse Gewebe, bisweilen jedoch dringen sie bis in die Muskularis des Dickdarms hinein. Die Lymphgefässe im subserösen Gewebe des Diclidarms sind ebenfalls an der Stelle, wo die Oberfläche eine starke Wucherung und ein Maschenwerk der Endothelzellen zeigte, stark erweitert und zeigen bei der Sudanfärbung eine Fïllung mit Fett, während an den anderen Stellen, 
wo die Oberfläche kein deutliches Maschenwerk zeigt, nur hier und da eine mässige Erweiterung der Lymphgefässe sowie eine nur geringe Infiltration mit Leukozyten im subserösen Gewebe bemerkt wird. An der Oberfiäche des Dickdarms findet man im allgemeinen aufgequollene Endothelzellen, welche an vielen Stellen mehrschichtig sind und in grosser Ausdehnung ein Maschenwerk von beträchtlicher Dicke bilden. Dieses Maschenwerk besteht, wie ich schon beim Zwerchfell geschildert habe, aus den gewucherten Endothelzellen, welche zahllose Hohlräume von verschiedener Grösse bilden (vergl. Fig. 1 und 2). Die kleineren Hohlräume werden dadurch gebildet, dass die aufgequollenen Endothelzellen dicht aneinanderliegen, während die grösseren Hohlräume von den langgestreckten Endothelzellen begrenzt werden. Im Lumen der grossen Hohlräume sieht man Reste von Septen, welche offenbar dadurch zustande gekommen sind, dass mehrere kleinere Hohlräume zu einem grösseren konfluiert sind. Im Maschenwerke sieht man ausserdem auch hier am Dickdarm an einigen Stellen noch Haufen von Endothelzellen sowie eine starke Infiltration mit Leukozyten. Diese Infiltration ist so hochgradig. dass die Endothelzellen dadurch in den Hintergrund treten und das Maschenwerk nur aus den das Gewebe durchsetzenden Leukozyten zu bestehen scheint.

Im Maschenwerke selbst findet man keine Blutgefässe, nur sieht man am Grunde des Maschenwerkes, da, wo es dicht dem subserösen Gewebe aufliegt, einige in das Maschenwerk hineindringende Kapillargefässe, die mit Blutzellen erfüllt sind. Fibrin ist im Maschenwerke des Dickdarms noch in ganz geringer Menge als ein feines Netz nachweisbar. Bei der Sudanfärbung der Dickdarmselnitte kann man Fett in grossen Tropfen in den Hohlräumen des Maschenwerkes und in feineren Tröpfchen intra- und interzellulär genau wie im Maschenwerke des Zwerchfells nachweisen.

Am Omentum majus findet man ebenfalls sehr starke Veränderungen. Im Grundgewebe des Omentum bemerkt man, dass seine Maschen hochgradig erweitert und mit Fett erfüllt sind. Die Blutgefässe sind hier stark erweitert und strotzend mit Inhalt erfïllt. Gleichfalls findet man hier eine starke Infiltration mit Leukozyten. Hier und dort ist auch Fibrin nachweisbar und zwar ziemlich deutlich.

An der Oberfläche des Omentum sieht man überall Veränderungen derart, dass man normale Endothelzellen nicht mehr nachweisen kann. Die Endothelzellen sind im allgemeinen stark aufgequollen und zeigen an vielen Stellen durch ihre mehrschichtige Wucherung Polypen- oder Zottenbildungen, auch hier findet man eine starke Durchsetzung mit Leukozyten. Auf weite Strecken hin findet man ausgeprägtes Maschenwerk, welches einen ähnlichen Aufbau zeigt wie am Zwerchfell und am Darm. In der Grundschicht des Maschenwerkes bemerkt man auch hier erweiterte Lymphgefässe. Dort findet man auch erweiterte und gefüllte Kapillargefässe, die ihre Ausläufer in das Maschenwerk hineinsenden. An der Stelle, wo verschiedene Teile des Netzes durch die Faltenbildung an seiner Oberfläche aneinanderliegen, kommt eine Vereinigung der beiden Oberflächenteile dadurch zustands, dass die Oberflächen des beiderseitigen Maschenwerkes konfluieren.

Der Befund hinsichtlich des Fibrins und Fettes ist ganz gleich wie an den anderen beschriebenen Stellen. Das Grundgewebe des Netzes ist so fettreich, dass es bei Anwendung der Fettfärbung nur aus Fett zu bestehen scheint. 
Am Mesenterium sieht man ebenfalls eine Erweiterung und Füllung der Blutgefässe und ziemlich deutlich erweiterte Lymphbahngefässe, aber sie sind weniger zahlreich als die des Netzes. Eine Infiltration mit Leukozyten ist gleichfalls nur spärlich nachweisbar. An der Oberfläche des Mesenteriums bemerkt man nur hier und dort an einigen Stellen mehrschichtige Wucherungen der Endothelzellen. Das Maschenwerk derselben ist nur selten und dann nur in geringer Ausdehnung vorhanden.

Am Dünndarm sieht man ebenfalls die Wucherung und das Maschenwerk der Endothelzellen, jedoch nicht beträchtlich. Im subserösen Gewebe findet man an der Stelle, wo es unter dem Maschenwerk liegt, ganz dieselben Veränderungen, wie anderwärts beschrieben, also eine starke Infiltration mit Leukozyten und eine hochgradige Erweiterung der Blut- und Lymphgefässe. An anderen Stellen der Oberfläche des Dünndarms, wo keine Wucherung der Endothelzellen vorhanden ist, zeigt das subseröse Gewebe keine nennenswerten Veränderungen, nur hier und da in der Umgebung der Gefässe findet man kleine Ansammlungen von Leukozyten. Das Maschenwerk am Dünndarm findet man besonders stark an der Stelle entwickelt, wo die Serosa des Dünndarms auf das Mesenterium übergeht. Im allgemeinen ist die Veränderung am Dünndarm viel schwächer als am Dickdarm.

An der Bauchwand, an der Leber, am Magen und an der Milz findet man nur geringe Veränderungen; bisweilen sieht man eine mehrschichtige Wucherung der Endothelzellen. Ausserdem war an der Milz ein ganz kleines Maschenwerk von dem bekannten Bau vorhanden. An den anderen genannten Organen dagegen war ein Maschenwerk überhaupt nicht nachzuweisen, obwohl bei der Sektion doch ein dicker Belag gefunden worden war. Es war vielleicht bei den verschiedenen Manipulationen, z. B. der Fixation, der Färbung usw. entfernt worden. Jedenfalls waren die Veränderungen an den zuletzt genannten Organen nicht sehr auffallend.

Der mikroskopische Befund der Lunge ist normal. Bei der Fettfärbung findet man in den Lungengefässen hier und da kleine Fetttropfen in so spärlicher Menge, dass man denselben keine pathologische Bedeutung zuschreiben kann.

Nr. 4. Weibliches Kaninchen, $1000 \mathrm{~g}$ schwer.

Delinjektion $81 / 4$ Uhr vorm. am 14. Xl. 1912. Menge des Kampferöls $5 \mathrm{ccm}$.

Verlauf: Ungestört.

Sektion: 81/4 Uhr abends am 14. November 1912.

Befund: In der Bauchhöhle findet man eine öltropfenhaltige, ziemlich klare Flüssigkeit, in welcher bei mikroskopischer Betrachtung wie bei Nr. 3 Fettkugeln, Leukozyten und Endothelzellen in mässiger Menge nachzuweisen sind. Verklebungen werden nicht gefunden. Der tauartige Ueberzug am Peritoneum und die Injektion der Mesenterialgefässe entsprechen genau den Befunden bei Nr. 3. Den weissen, dicken, feuchtglänzenden Belag findet man besonders stark an der Milz entwickelt. Ausserdem sieht man denselben Belag auch noch am Netz. An der abdominalen Seite des Zwerchfells bemerkt man gleichfalls wie bei Nr. 3 kleine punktförmige, weisse Auflagerungen in seiner ganzen Ausdehnung, jedoch etwas schwächer als dort. Am Mesenterium, an der parietalen Bauchwand, an der Leber und am Dickdarm findet man stellenweise kleine weisse Auflagerungen, während am Dünndarm solche 
nicht zu bemerken sind. Die PleuraIseite des Zwerchfells ist glatt und spiegelnd wie der übrige Teil der Pleura. Der Lungenbefund ist normal. Die bakteriologische Prüfung der Bauchhöhle ergibt Keimfreiheit. Mikroskopische Untersuchung: In diesem Falle sieht man auch am Peritoneum stark aufgequollene Endothelzellen, mehrschichtige Wucherung derselben und auch das Maschenwerk, welches bereits bei Nr. 3 genau geschildert wurde. Nur ist in diesem Falle ein gradueller Unterschied zu konstatieren. Man findet hier nämlich die Veränderungen viel schwächer als bei Nr. 3. Das stark entwickelte Maschenwerk sieht man nur an der abdominalen Seite des $\mathrm{Z}$ werchfells und am Netz, während ein solches an den anderen untersuchten Peritonealabschnitten nur vereinzelt, und zwar an einigen Stellen des Dickdarms, an der Milz und an der Bauchwand nachweisbar ist. Am Dünndarm, am Mesenterium und am Magen jedoch fehlt, abgesehen von der Aufquellung der Endothelzellen und der melirschichtigen Wucherung derselben, jegliches Maschenwerk. Die Struktur des Maschenwerks am Zwerchfell und am Netz ist ganz analog wie in Nr. 3, so dass mir eine nochmalige Beschreibung überflüssig erscheint. Der Befund der Lunge ist ebenso wie bei Nr. 3 ohne Belang.

Epikrise: Im Gegensatz zu den beiden Tieren der ersten Gruppe zeigt sich bei der zweiten Versuchsgruppe (Nr. 3 u. 4), 12 Stunden nach der intraperitonealen Kampferölinjektion, schon eine deutliche Veränderung am parietalen und viszeralen Peritoneum, nämlich eine ausgesprochene Wucherung und Mehrschichtang der stark aufgequollenen Endothelzellen und eine Maschenwerkbildung derselben, eine starke Infiltration des subserösen Gewebes und des Maschenwerkes mit Leukozyten, eine hochgradige Erweiterung und Füllung der Blutgefässe. Fibrin ist nur in geringer Menge als feines Netz vorhanden. Das emulgierte Oel liegt hauptsächlich in den Hohlräumen des Maschenwerkes; in den Lymphbahnen dagegen ist es, abgesehen von dem Grundgewebe des Netzes, erst in geringer Menge nachweisbar.

Die Veränderungen finden sich am stärksten ausgeprägt am Netz und am Zwerchfell, während sie an anderen Stellen der Bauchhöhle verschieden stark waren, z. B. am Dickdarm bei Nr. 3 sehr stark, bei Nr. 4 jedoch nur schwach.

\section{Gruppe.}

Tötung der beiden Tiere (Nr. 5 und 6) 24 Stunden nach der intraperitonealen Kampferölinjektion.

Nr. 5. Männliches Kaninchen, $1570 \mathrm{~g}$ schwer.

Oelinjektion 18. X. 1912. Menge des Kampferöls $8 \mathrm{ccm}$.

Verlauf: Ungestört.

Sektion: 19. Oktober 1912, $1520 \mathrm{~g}$ schwer (50 g Gewichtsabnahme) 
Befund: In der Bauchhöhle findet man wenig, ziemlich klares Oel. Mikroskopisch zeigt dies noch nicht emulgierte Oel nur spärliche Leukozyten. Adhäsive Veränderungen in der Bauchhöhle sind nirgends vorhanden.

Das Peritoneum ist überall tauartig von Oeltröpfchen bedeckt. Den weissen, dicken, feucht glänzenden Belag findet man am stärksten gleichfalls am Netz und an der abdominalen Seite des Zwerchfells. Ausserdem sieht man einen solchen dicken Belag auch deutlich am Dickdarm, an der Leber und an der hinteren Bauchwand, doch auch am Magen, am Dündarm und an der Milz ist er vorhanden, wenn auch nicht so stark wie an den anderen genannten Stellen. Am Mesenterium findet man solchen Belag besonders deutlich an der Radix mesenterica. Er haftet auf der Serosa der Organe zottenartig oder als flache Auflagerung, und zwar teilweise fest, während ein anderer Teil nur lose der Oberfläche des betreffenden Peritonealabschnittes anliegt. Aber auch in der Banchhöhle findet man freiliegende Flöckchen, die sicher von der Oberfläche der Organe losgerissene Beläge sind. Das Netz selbst ist sehr fettreich. An seiner Oberfläche findet man ausser den weissen, dicken Belägen zahllose weisse, polypenartige Wucherungen. An der abdominalen Seite des Zwerchfells bemerkt man inselartig weisse, dicke Beläge, welche besonders hochgradig an dem Centrum tendineum entwickelt sind. Die Pleura des Zwerchfells ist glatt und spiegelnd wie die ubrige Pleura. An der lange zeigen sich keine Besonderheiten.

Die bakteriologische Prüfung der Bauchhöhle fält negativ aus.

Mikroskopische Untersuchung: Was zunächst das parietale Peritoneum betrifft, so findet man hier sehr deutliche Veründerungen. Das subperitoneale Gewebe ist im allgemeinen stark gelockert. Die Blutgefässe sind hier stark erweitert und strotzend gefüllt. Die Lymphgefässe sind gleichfalls stark erweitert und enthalten, wie die entsprechende Färbung ergibt, zahlreiche Oeltröpfchen. Ausserdem findet man im subperitonealen Gewebe eine mächtige Infiltration mit Leukozyten besonders hochgradig in der Umgebung der Gefässe. Die Endothelzellen des parietalen Peritoneums zeigen verschiedene Veränderungen. Die stark aufgequollenen Endothelzellen sind mehrschichtig gewuchert und bilden an vielen Stellen ein Maschenwerk. Das Maschenwerk besteht aus den dicht nebeneinander liegenden aufgequollenen Endothelzellen mit feinschaumigem Protoplasma oder aus langgestreckten Endothelzellen von gleicher Struktur des Protoplasmas. Die massenhaften Hohlräume im Mlaschenwerk sind ausgefüllt von Oeltropfen verschiedener Grösse. Die Leukozyten im Maschenwerk sind noch zahlreicher wie bei den Tieren der vorigen Gruppe, so dass das Maschenwerk, besonders die obere Partie desselben überhaupt nur ans Leukozyten zu bestehen scheint. Ausser den Leukozyten findet man bei der Färbung nach Pappenheim hier und da vereinzelte protoplasmareiche Zellen mit wandständigen, radförmig gefärbten Kernen. Diese letzteren Zellen findet man auch sehr spärlich im subperitonealen Gewebe.

Die Oberfläche des Maschenwerkes ist fast iuberall von den gewucherten Endothelzellen überzogen. Nur hier und da sieht man an der Oberfläche des Maschenwerkes solche Stellen, wo eine kleine Strecke weit der endotheliale Ueberzug fehli und das mit Leukozyten hochgradig durchsetzte Maschenwerk frei liegt. Fibrin findet sich in geringer Menge als feines Netz im Maschenwerk und im subperitonealen 
Gewebe. Bei der Fettärbung der Bauchwand findet man das injizierte Oel hauptsächlich als Tropfen von verschiedener Grösse in den Hohlräumen des Maschenwerkes. In den Lymphgefässen des subperitonealen Gewebes lassen sich ebenfalls Oeltropfen in mässiger Menge nachweisen. Feine Fettröpfchen werden auch intra- und interzellulär im Maschenwerk bzw. in den gewucherten Endothelzellen bemerkt. Am Netz zeigt sich gleichfalls eine weit verbreitete, starke Wucherung der Endothelzellen und ein aus Endothelzellen gebildetes Maschenwerk. An \den Stellen, wo das Maschenwerk besonders stark entwickelt ist, sieht man an seiner Basis dicht über dem Grundgewebe des Netzes einige in das Maschenwerk hineindringende Kapillargefässe, daneben auch sehr deutlich erweiterte Lymphgefässe. Die Blutgefässe im Grundgewebe des Netzes sind stark erweitert und strotzend mit Inhalt erfüllt. Eine Infiltration mit Leukozyten findet man deutlich an der Oberfläche des Netzes und in der Umgebung der Blutgefässe.

Die Rampferölreaktion ist an der Abdominalseite des Zwerchfells besonders hochgradig. Man findet hier die Oberfläche in weiter Ausdehnung mit dem Maschenwerk bedeckt. Im allgemeinen ist die Wucherung der Endothelzellen an dem Centrum tendineum stärker als an dem peripheren muskulären Abschnitt des Zwerchfells.

Bezüglich seiner Struktur verhält sich das Maschenwerk am Zwerchfell genau so wie an anderen Stellen der Bauchserosa. Auch die Verteilung von emulgiertem Oel und von Fibrin entspricht der am Bauchwandperitoneum beschriebenen Verteilung. Das Maschenwerk ist von grossen Leukozytenmengen durchsetzt, besonders stark nach der Oberfläche zu. Hier und da reichen Haufen von Leukozyten bis zur Oberfläche des Maschenwerkes, während der grösste Teil der Oberfläche von Endothelzellen überzogen ist. An der Basis des Maschenwerkes bemerkt man einige in dasselbe dringende Blutgefässe und daneben deutlich erweiterte Lymphgefässe, wie sie gleichfalls in der Grundpartie des Maschenwerkes an anderen Stellen gefunden wurden. Im subserösen Gewebe ist an der abdominalen Seite des Zwerchfells eine Lockerung des Gewebes, starke Erweiterung und Füllung der Blut- und Lymphgefässe und Infiltration mit Leukozyten vorhanden, während an der Pleuraseite solche Veränderungen fehlen. Das Mesenterium zeigt eine fast analoge Veränderung; ebenso das Netz, wenn auch nicht so ausgeprägt. Die Infiltration mit Leukozyten im Maschenwerk und im Grundgewebe ist im Mesenterium und im Netz gleich stark vorhanden. Am Dünudarm sieht man die Wucherung und das Maschenwerk der Endothelzellen sowie die Leukozytendurchsetzung in gleicher Weise wie an anderen Stellen. In der Wand des Dünndarms sieht man im allgemeinen eine starke Frweiterung und Füllung der Blut- und Lymphgefässe, besonders im subserösen Gewebe; hier findet man die Leukozyteninfiltration in mässigem Grade. Bei der Fettfärbung der Dünndarmabschnitte liegen die Oeltropfen ebenfalls hauptsächlich in den Hohlräumen des Maschenwerkes, aber auch intra- und interzellulär. Ausserdem findet man geringe Mengen emulgierten Oels in den Lymphgefässen des subserösen Gewebes. An einer Stelle der Oberfläche des Dünndarms bemerkt man ein grosses Maschenwerk, das enorme Mengen von Fettropfen enthält. In der Mitte dieses Maschenwerkes zeigen sich nekrotische Vorgänge an den Zellen, sowohl an den Leukozyten wie an den Endothelzellen. Am Dickdarm sind die Veränderungen ganz 
übereinstimmend mit den am Dünndarm gefundenen. Hier sieht man ebenfalls teils die mehrschichtige Wúcherung, teils das Maschenwerk der Endothelzellen, beides mit Leukozyten stark durchsetzt. Die Oeltropfen und das Fibrin verhalten sich wie an anderen Stellen. Im subserösen Gewebe findet man auch eine starke Leukozyteninfiltration; starke Erweiterung und Füllung der Gefässe.

An der Oberfläche der Leber zeigt sich ein ausgedehntes Maschenwerk. Dieses Maschenwerk besteht ebenfalls ans Endothelzellen und ist mit Leukozyten stark durchsetzt. In einigen Partien ist die Menge der Leukozyten so gross, dass das Maschenwerk dort lediglich aus Leukozyten und Fibrin zu bestehen scheint. Da. wo das Maschenwerk besonders kräftig entwickelt ist, findet man in seinem basalen Abschnitt erweiterte und prall gefüllte Kapillargefässe, welche aus dem subendothelialen Gewebe und dem oberen Leberparenchym in das Maschenwerk eingedrungen sind. Betreffs des Fettes im Maschenwerke ist der Befund ein gleicher wie bei den anderen Bauchorganen; es ist in grosser Menge vorhanden. Trotz des Vorhandenseins von beträchtlichen Mengen emulgierten Oels im Maschenwerk der Leberoberfläche ist es im Lebergewebe selbst, auch in den Lymphgefässen desselben noch nicht deutlich nachweisbar. Am Magen sieht man die Wucherung und das Maschenwerk der Endothelzellen nur in geringerem Grade ausgebildet, sonst verhält es sich jedoch genau wie bei den anderen Organen.

In den Gefässen der Lungen sieht man vereinzelte feine Fetttropfen, die aber keine pathologischen Veränderungen des Lungengewebes veranlasst haben.

Nr. 6. Männliches Kaninchen, $950 \mathrm{~g}$ schwer.

Oelinjektion 18. X. 1912. Menge des Kampferöls $5 \mathrm{ccm}$.

Sektion 19. X. 1912, $890 \mathrm{~g}$ schwer (60 g Gewichtsabnahme).

Befund: In der Bauchhöhle findet man keine Verklebungen. Emulgiertes Oel ist in ziemlich reichlicher Menge vorhanden. Bei der mikroskopischen Untersuchung dieses Oels sieht man viele Fetttropfen von sehr verschiedener Grösse, abgestossene aufgequollene Endothelzellen in geringer Anzahl und massenhafte Leukozyten. An der ganzen Oberfläche des Bauchfells findet man einen tauartigen Ueberzug von Oeltropfen. Als Hauptlagerungsstätten des dicken, weissen Belags zeigen sich die Abdominalseite des Zwerchfells, das Netz, das Mesenterium, der Dickdarm, die hintere Bauchwand, der Leberrand und die Milz. Am Magen, am Dickdarm und an der vorderen Bauchwand ist der Belag nur spärlich vorhanden. Besonders hochgradig ist der Belag am Zwerchfell, und zwar wieder stärker am Centrum tendineum als an den lateralen muskulären Teilen des Zwerchfells. Aber auch da, wo an der Abdominalseite des Zwerchfells kein deutlicher Belag sichtbar ist, zeigt sich das Peritoneum diaphragmaticum verändert, nämlich weisslich getrübt. Die Pleura diaphragmatica dagegen ist spiegelnd und glatt wie die übrigen Abschnitte der Pleura.

Die Lunge ist beiderseits nicht in gewöhnlichem Grade retrahiert. An beiden Lungen erkennt man inselartig grosse dunkelrot gefärbte Flecke. Auch auf der Schnittfläche zeigt die Lunge an der Stelle, wo die Oberfläche eine dunkelrote Farbe hat, ausgebreitete dunkelrote Herde. Im allgemeinen ist die Lunge blutreicher als normal.

Die bakteriologische Prüfung der Bauchhöhle ergibt ein negatives Resultat. 
Mikroskopische Untersuchung: Der Befund an der Peritonealserosa entspricht ganz dem des Paralleltieres Nr. 5. Am Bauchwandperitoneum sieht man ein beträchtlich ausgebildetes Maschenwerk. Das Maschenwerk ist sehr stark mit Leukozyten durchsetzt. Die Aufquellung, die mehrschichtige Wucherung und die Maschenwerkbildung der Endothelzellen, die Infiltration mit Leukozyten im Maschenwerk und im subperitonealen Gewebe, die Erweiterung und Füllung der Gefässe an den verschiedenen Bauchorganen sind genau so wie bei Nr. 5. Nur sind bei diesem Tiere die Veränderungen an der Bauchwand in stärkerem und an der Leber in geringerem Grade als bei Nr. 5 vorhanden. Die Lunge zeigt bei Kaninchen Nr. 6 eine bemerkenswerte Veränderung. Man findet hier und dort ausgedehnte Herde einer Infiltration mit Leukozyten und roten Blutkörperchen, Die Lungenalveolen sind in diesen Herden mit gleichen Infiltrationsmassen erfüllt. Bei der Sudanfärbung sieht man in den Infiltrationsgebieten reichliche Fetttropfen im Lumen der Blutgefässe. In der Umgebung der Infiltrationsherde sind die Lungenalveolen stark erweitert.

Epikrise. Die Veränderungen am Peritoneum sind 24 Stunden nach der intraperitonealen Kampferölinjektion im allgemeinen analog denen der vorigen Versuchsgruppe (12 Stunden nach der Oelung). Die Hauptveränderung besteht also in der starken Wucherung und in der Maschenwerkbildung der Endothelzellen und in der enormen Leukozyteninfiltration. Beide Zellarten umscheiden die in den Hohlräumen des Maschenwerkes eingeschlossenen Oeltropfen und bilden dadurch eine mehr oder weniger dicke Auflagerung auf dem Peritoneum. Fibrin ist nur in mässiger Menge vorhanden. Hervorzuheben sind die bei Kaninchen Nr. 6 gefundenen Lungenveränderungen, die nur als fettembolische Herde aufgefasst werden können und die ohne Zweifel auf die Resorption von Oel aus der Bauchhöhle zurückgeführt werden müssen. Dieser Lungenbefund ist um so auffallender, als die 5 anderen bisher beschriebenen Tiere keine Lungenveränderungen pathologischer Art aufwiesen.

\section{Gruppe.}

Tötung der beiden Tiere (Nr. 7 und 8) 48 Stunden nach der intraperitonealen Kampferölinjektion.

Nr. 7. Männliches Kaninchen, $1300 \mathrm{~g}$ schwer.

Oelinjektion 18. X. 1912. Menge des Kampferöls $7 \mathrm{ccm}$.

Verlauf: Ungestört.

Sektion 20. X. 1912, $1170 \mathrm{~g}$ schwer (130 g Gewichtsabnahme).

Befund: In der eröffneten Bauchhöhle findet man kein freies Exsudat. Adhäsive Veränderungen sind nirgends nachweisbar. Die Mesenterialgefässe sind stark injiziert. Die Oberfläche des ganzen Bauchfells zeigt ein tauartiges Aussehen und ist wie mit einem Schleier bedeckt. Ausser diesem diffusen Ueberzug des Peritoneums sieht man 
noch weit verbreitet dicke, weisse, feuchtglänzende Beläge. Sie sind entweder polypenartig oder flach und haften teilweise auf dem Peritoneum sehr fest, teilweise jedoch. lose, so dass sie sich von der Oberfiäche leicht entfernen lassen. Freiliegende Flöckchen findet man sehr reichlich, besonders auf der hinteren Beckenwand.

Der dicke, weisse Belag findet sich hauptsächlich auf der Abdominalseite des Zwerchfells, am Netz und am Dickdarm. Er ist auch deutlich an der Leber, an der Milz, an der hinteren Banchwand und am Mesenterium vorhanden. Am Dünndarm, am Magen und an der vorderen Bauchwand bemerkt man allerdings auch einen solchen Belag, jedoch ist er hier viel spärlicher als an den oben genannten Stätten.

An der Leber findet man einen entsprechenden Belag besonders stark an den Rändern entwickelt, welche beim Kaninchen sehr reichlich vorhanden sind, weil die Leber dieses Tieres in viele Lappen geteilt ist. Am Dickdarm ist der Belag besonders stark an den Einsenkungen zwischen je zwei Ausbuchtungen. Am Netz zeigen sich viele grössere und kleinere polypenartige Auflagerungen. Sehr oft sind solche Auflagerungen in den Falten des Netzes eingekapselt vorhanden.

Ausserdem kann man hier und dort an der vorderen und hinteren Bauchwand und auch stellenweise am Dickdarm subseröse punktförmige Blutungen beobachten. Am Dünndarm findet man solche subseröse Petechien nur an einer Stelle in geringer Anzahl.

Die Pleura diaphragmatica ist ebenso glatt wie die übrige Pleura.

Die Lunge ist ganz normal.

Die bakteriologische Prüfung der Bauchhöhle ergibt kein Bakterienwachstum.

Mikroskopische Untersuchung: Bei diesem Tier zeigen sich wieder sehr starke Veränderungen am parietalen und viszeralen Peritoneum. Am Bauchwandperitoneum findet man überall beträchtliche Veränderungen der Endothelzellen, so dass die Oberfläche an keiner Stelle mehr ein normales Bild bietet. Ueberall sind die Endothelzellen stark aufgequollen und mächtig gewuchert. Die Wucherung ist zum Teil mehrschichtig, zum Teil sehen wir ein deutliches Maschenwerk. Der Zustand des Maschenwerkes zeigt aber bei diesem Tier eine bemerkenswerte Abweichung gegenüber dem bisher Beschriebenen. Es fällt sofort eine starke Vermehrung des Fibrins in die Augen. Fibrin liegt im Maschenwerk entweder netzförmig sich den Maschen anschliessend oder in breiten Streifen, besonders deutlich ist es an der Oberfläche dicht unter dem endothelialen Ueberzug des Maschenwerkes. Im subperitonealen Gewebe findet man auch vermehrte Fibrinmengen. Während somit das Fibrin im Maschenwerk deutlich vermehrt ist, sind die Leukozyten in demselben Gewebe deutlich vermindert. An einigen Stellen des Maschenwerkes bemerkt man Anhäufungen, welche aus den nekrotisch gewordenen Leukozyten und den freiliegenden zerfallenen Kernen derselben bestehen. Die Kerne zahlreicher Leukozyten sind in Körnchen zerfallen: ihr Protoplasma ist unregelmässig und schwach gefärbt. Man trifft noch im Maschenwerk hier und da Haufen von Endothelzellen an, welche ein schaumartiges Protoplasma und grosse, aber regelmässig und gut tingierte Kerne enthalten. Manchmal bemerkt man auch nekrotisch gewordene Endothelzellen mit nekrotisierten Leukozyten untermischt. Die Endothelzellen enthalten an solchen Stellen blasse Kerne, teilweise sind sie sogar nur noch schattenartig ohne Kerne vorhanden. Während die Leukozyten im Maschenwerke durch Nekrose 
nach und nach verschwinden, bemerkt man in der Grundpartie des Maschenwerkes, wo erweiterte und prall gefüllte Kapillargefässe in das Maschenwerk selbst eingedrungen sind, noch gut erhaltene Leukozyten und gewucherte Endothelzellen.

Blutgefässe und Bindegewebsfasern kann man im Maschenwerk selbst, abgesehen von der Grundpartie desselben, noch nicht nachweisen. In der Grundschicht aber sind an einigen Stellen Ausläufer des subperitonealen Bindegewebes eingedrungen, welche erweiterte Blut- und Lymphgefässe enthalten.

Am. Netze findet man ebenfalls eine starke Wucherung und Maschenwerkbildung der Endothelzellen. Im Maschenwerk sieht man im Vergleich zu den Tieren der 3 ersten Versuchsgruppen stark vermehrte Menge von Fibrin, Haufen von Lenkozyten, die grösstenteils nekrotisch geworden sind, und Haufen von freigewordenen Kernen und Kerntrümmern. Die Oberfläche des Maschenwerkes ist wie sonst von proliferierenden Endothelzellen überzogen. In der Grundpartie des Maschenwerkes findet man ebenso wie am Parietalperitoneum in das Maschengewebe eingedrungene Blut- und Lymphgefässe.

An der Abdominalseite des $\mathrm{Z} w$ erchfells sind die reaktiven Veränderungen wieder sehr deutlich. Man findet hier, besonders stark wieder am Centrum tendineum, ein ausgedehntes Maschenwerk. Die Vermehrung von Fibrin, die nekrotischen Veränderungen und gleichzeitige Verminderung von Leukozyten sind auch hier deutlich nachweisbar. In dem aufgelockerten subserösen Gewebe zeigt sich eine starke Gefässfüllung; die Lymphgefässe enthalten reichlich resorbiertes Oel. Ebenso sind die Lymphgefässe des Zwerchfellgrundgewebes mit Oeltropfen erfüllt. An der pleuralen Seite des Zwerchfells sieht man keine nennenswerten Veränderungen der Endothelzellen.

Am Mesenterium findet man ebenfalls die Wucherung und das Maschenwerk der Endothelzellen, das grosse Mengen von Fibrin und Haufen von untergegangenen Leukozyten aufweist

Am Dickdarm finden wir eine hochgradige Zellwucherung und auch das Maschenwerk ist in grosser Ausdehnung an seiner Oberfläche vorhanden. Die Struktur des Maschenwerkes ist ganz entsprechend dem Befund an den anderen Stellen, nur sieht man hier wieder viele noch gut erhaltene Leukozyten auf der Oberfäche des Maschenwerkes, welche spärliche Gruppen von Endothelzellen enthalten. Im Maschenwerk ist eine noch grössere Menge von Fibrin als an den anderen Peritonealabschnitten dieses Tieres ausgeschieden, so dass ein Teil des Maschenwerkes lediglich aus Fibrinmasse zu bestehen scheint. An der Basis des Maschenwerkes sind ebenfalls Blut- und Lymphgefässe eingedrungen.

Am Dünndarm trifft man nur hier und da auf Maschenwerkbildung. Wo es vorhanden ist, ist es ebenso wie an den auderen Stellen gebaut. Die mehrschichtige Wucherung der Endothelzellen ist hier in geringerem Umfange vorhanden. An der Leber sind die Veränderungen wieder stark ausgeprägt. Im Maschenwerk finden sich sehr reichliche Fibrinmengen und Massentod von Leukozyten. Jedoch kann man an der Leber 2 Arten von Maschenwerk unterscheiden: Die eine Art des Maschenwerkes zeigt nur Wachstum nach aussen, ohne das Leberparenchym zu berühren. Bei der anderen Art dagegen scheint nicht nur ein Wachstum nach aussen, sondern auch nach innen nach dem Leberparenchym zu erfolgt zu sein, so dass dadurch das Lebergewebe einen starken Druck erfahren hat, der Ursache einer teilweisen 
Degeneration von Leberzellen geworden ist. Bei der zweiten Art von Maschenwerk ist besonders bemerkenswert, dass ein aus Leukozyten und mehrkernigen Riesenzellen bestehender Zellwall gegen das Leberparenchym hin vorhanden ist. Die Oberfläche des Leberparenchyms ist an solchen Stellen muldenförmig und zeigt direkt unterhalb des Infiltrationswalles starke Erweiterung und Füllung der Gefässe. Bei der Sudanfärbung der Leberschnitte findet man Fett nicht nur im Maschenwerk, sondern auch in Form von strahlenartig ins Leberparenchym hineingedrungenen roten Streifen, die den Lymphgefässen der oberen Partie des Leberparenchyms entsprechen. Ausser den erweiterten Lymphgeiässen in den oberen Schichten des Leberparenchyms bemerkt man hier auch eine starke Erweiterung und Füllung der Blutgefässe.

An der Milz findet man nur an einigen Stellen der Oberfläche eine mehrschichtige Wucherung der Endothelzellen mit intra- und interzellulär gelegenen Fetttropfen. Das Maschenwerk kann man aber nirgends nachweisen. Am Magen ist die mehrschichtige Wucherung der Endothelzellen in geringem Umfange vorhanden. An einigen Stellen der Oberfläche des Magens aber zeigt sich ein wie an anderen Stellen gebautes Maschenwerk.

Der Lungenbefund bietet auch mikroskopisch nichts Pathologisches. Bei der Fettfürbung sieht man geringe Mengen von Fetttröpfehen in den Blutgefässen.

Nr. 8. Männliches Kaninchen, $1850 \mathrm{~g}$ schwer

Oelinjektion 18. X. 1912. Menge des Kampferöls $9 \mathrm{ccm}$.

Verlauf: Ohne Störung.

Sektion: 20. X. 1912.

Befund: Keine adhäsiven Veränderungen und keine freie Flüssigkeit in der Batchhöhle. Das Peritoneum ist parietal sowohl wie viszeral grösstenteils glatt und spiegelnd. Ein tauartiger oder schleierartiger Ueberzug ist nirgends nachweisbar. Der weisse, dicke, feucht glänzende Belag findet sich nur an einigen Stellen am Leberrand, aber nur in geringerer Ausbreitung und stellenweise an der hinteren Bauchwand. Das Netz ist sehr fettreich, aber man sieht keinen Belag und auch keine polypenartige Wucherung. Auch die Abdominalseite des Zwerchfells ist frei von Belag, sowohl der muskuläre Abschnitt als auch das Centrum tendineum. Die Mesenterialdrüsen sind aber deutlich injiziert.

Die Lunge ist normal, ebenso die Pleura. Die bakteriologische Prüfung der Bauchhöhle ergibt Keimfreiheit.

Mikroskopische Untersuchung: An der hinteren Bauchwand und an der Oberfläche der Leber findet man hier und da Wucherung und Maschenwerk der Endothelzellen, jedoch sind diese Veränderungen nur in geringem Grade vorhanden. Die Struktur des Maschenwerkes ist aber eine ganz gleiche wie bei den anderen Nummern, nur die Erweiterung und Füllung der Blutgefässe im subperitonealen Gewebe ist viel geringer als dort. Der Befund betreffs des Fettes, des Fibrins und der Leukozyten ist ein gleicher wie in $\mathrm{Nr}$. 7 . An der abdominalen Seite des Zwerchfells findet man an einigen Stellen kleine Fortsätze der wuchernden Endothelzellen. Die gleiche Wucherung der Endothelzellen ist auch an der Oberfläche des Netzes nachweisbar, aber vom Maschenwerk findet sich keine Andeutung, weder an der Oberfläche des Netzes noch des Zwerchfells. An den übrigen untersuchten Bezirken 
des Peritoneums sieht man nur aufgequollene Endothelzellen, weder mehrschichtige Zellwucherung noch Maschenwerkbildung.

Lunge und Pleura weisen auch mikroskopisch keine Besonderheiten auf.

Epikrise. Die auffälligsten Veränderungen in dieser Versuchsgruppe 2 Tage nach der intraperitonealen Kampferölinjektion sind das in grosser Menge auftretende Fibrin und der Untergang der Leukozyten durch nekrotische Veränderungen im Maschenwerk. Jedenfalls ist die Blutversorgung des Maschenwerkes bis zu diesem Zeitraum eine noch mangelhafte. Blntgefässe sind nur in die unteren Partien des Maschenwerkes eingedrungen, so dass nur dieser Teil gut ernährt wird, während die darüber liegenden oberen Schichten des Maschenwerkes noch keine direkte Blutversorgung erhalten haben.

Bemerkenswert ist noch in dieser Versuchsgruppe, dass bei Nr. 7 die peritoneale Oelreaktion sehr stark, bei Nr. 8 dagegen nur gering und nur an einigen Organen ausgeprägt war, wenn auch das histologische Bild der Veränderungen bei beiden Tieren keine nennenswerten Unterschiede bot. Die reaktiven Veränderungen stellen sich' also regelmässig ein, aber es sind dabei graduelle Unterschiede bei verschiedenen Tieren derselben Gattung und auch an den verschiedenen Peritonealabschnitten desselben Tieres zu beobachten.

\section{Gruppe.}

Tötung der beiden Tiere (Nr. 9 und 10) 3 Tage nach derintraperitonealen Kampferölinjektion.

Nr. 9. Männliches Kaninchen, $1210 \mathrm{~g}$ schwer.

Oelinjektion 18. X. 1912. Menge des Kampleröls $6 \mathrm{ccm}$.

Verlauf: Ohne Zwischenfall.

Sektion: 21. X. 1912, $1230 \mathrm{~g}$ schwer (20 g Gewichtszunahme).

Befund: In der Bauchhöhle keine freie Flüssigkeit und keine adhäsiven Veränderungen. Die ganze Oberfläche des parietalen und viszeralen Peritoneums ist glatt und spiegelnd; es ist kein tauartiger Ueberzug und nichts von einem weissen, dicken Belag zu sehen. An der abiominalen Seite ist das Zwerchfell ebenso glatt und spiegelnd wie an der Pleuralseite. Auch an dem fettreichen Netz ist kein Belag vorhanden.

Die Lunge ist ganz normal, ebenso die Pleura. Die bakteriologische Prüfung der Bauchhöhle ergibt ein negatives Resultat.

Mikroskopische Untersuchung: An den Serosaabschnitten, die ich untersucht habe, konnte ich gar keine Veränderung nachweisen, weder Wucherung noch Maschenwerkbildung der Endothelzellen. Die, Erweiterung und Füllung der Lymph- und Blutgefässe des subperitonealen Gewebes sind auch nicht deutlich ausgesprochen. Bei der Sudan- 
färbung findet man dann und wann an einzelnen Stellen geringe Mengen kleiner Fetttröpfchen in den subperitonealen Lymphgefässen.

In der Lunge zeigen sich ebenfalls vereinzelte kleine Fetttropfen in den Gefässen, sonst aber keinerlei Besonderheiten.

Nr. 10. Männliches Kaninchen, $1770 \mathrm{~g}$ schwer.

Oelinjektion 18. X. 1912. Menge des Kampferöls $9 \mathrm{ccm}$.

Verlauf: Ungestört.

Sektion: 21. X. 1912, $1580 \mathrm{~g}$ schwer (190 g Gewichtsabnahme).

Befund: Keine freie Flüssigkeit und keine adhäsiven Veränderungen in der Bauchhöhle. Auf der ganzen Oberfläche des parietalen und viszeralen Peritoneums findet man einen tauartigen, schleierartigen Ueberzug. Die Hauptablagerungsstätte des weissen, dicken Belags sind die Abdominalseite des Zwerchfells, das Netz, die parietale Bauchwand, der Dickdarm, die Leber und das Mesenterium. Am Magen, am Dünndarm und an der Milz konnte man einen entsprechenden weissen, dicken Belag nicht finden. Die Beläge haften, wie früher mehrfach geschildert, zum Teil fest, zum Teil sitzen sie nur lose auf der Serosa. Sie sind bald polypös, bald mehr flach gestaltet. Auch von der Serosa abgelöste freie Flöckchen finden sich im Abdominalkavum.

Die Pleuralseite des Zwerchfells ist ebenso glatt wie die übrigen Abschnitte der Pleura.

An der Lungenoberfläche sieht man an vielen Stellen dunkelrote Flecke.

Bei der bakteriologischen Untersuchung erweist sich die Bauchhöhle als keimfrei.

Mikroskopische Untersuchung: An der Bauchwand findet man starke Wucherung und Maschenwerkbildung der Endothelzellen. Das Maschenwerk wird teils von den sehr lang gestreckten schmalen Endothelzellen, teils von einem Fibrinnetz gebildet. Fibrin lässt sich an verschiedenen Stellen in grossen Mengen nachweisen, vor allem in den oberen Partien des Maschenwerkes. Im Maschenwerk sieht man ausserdem Haufen von degenerierten Zellen, von freigewordenen Kernen und von Kerntrïmmern, Resten von Leukozyten und gewucherten Endothelzellen. Im subperitonealen Gewebe zeigt sich noch deutliche Erweiterung und pralle Füllung der Blut- und Lymphgefässe, aber eine nur mässige Infiltration mit Lenkozyten.

Am Netz trifft man auf starke Endothelwucherung und Maschenwerkbildung. Das Maschenwerk ist stark mit Leukozyten durchsetzt wie bei den Tieren der früheren Gruppen, unterscheidet sich aber von jenen durch die bedeutende Zellnekrose und die Anhäufung von Kerntrümmern. Fibrin ist entweder als Netz oder in Form von breiten Streifen im Maschenwerk in grosser Menge nachzuweisen. Auch im Grundgewebe des Netzes bemerkt man reichliche Fibrinmassen. Die erweiterten Lymphgefässe sind hier strotzend mit Fett erfüllt. Es besteht hier eine beträchtliche Infiltration mit gut erhaltenen Leukozyten.

An der abdominalen Seite des $\mathrm{Zwerchfells} \mathrm{ist} \mathrm{besonders} \mathrm{im}$ Bereiche des Centrum tendineum ein reichliches Maschenwerk vorhanden, das aber im Vergleich zu dem des Netzes leukozytenarm ist. Das Maschenwerk besteht ebenfalls aus langgestreckten Endothelzellen und .aus reichlichem, teils netzförmig, teils in breiten Streifen angeordnetem Fibrin. In den Fibrinmassen sieht man viele nekrotisch gewordene Kerntrümmer. Neugebildete Kapillaren sind erst in geringer Menge in 
die unteren Partien des Maschenwerkes eingedrungen. Hier und da trifft man im Maschenwerk grosse Zellen mit vielen Kernen, vakuolenhaltige Riesenzellen, die offenbar durch Konfluieren degenerierter Zellen entstanden sind. Da man dicht nebeneinander Schatten von Zellen mit undeutlichen Zellgrenzen und auch noch gut erhaltene Endothelzellen sieht, liegt die Annahme nahe, dass die Riesenzellen zum Teil dem Zusammenfliessen von degenerierten Endothelzellen ihre Entstehung verdankten, zum anderen Teil aber der Verschmelzung degenerierter Leukozyten. Da, wo am Zwerchfell kein Maschenwerk gebildet ist, findet man eine mehrschichtige Wucherung der Endothelzellen. Die Erweiterung und Füllung der Blut- und Lymphgefässe in dem subserösen Gewebe des Peritoneum diaphragmaticum ist deutlich ansgeprägt. Die Pleuralseite des Zwerchfells weist keine Veränderungen auf.

Am Mesenterium sind nur schwache reaktive Veränderungen, geringe Wucherung von Endothelzellen und minimale Maschenwerkbildung. In seinem Grundgewebe findet man eine geringfügige Leukozyteninfiltration.

Am Dünndarm sieht man gar kein Maschenwerk, nur hier und dort ist eine mehrschichtige Wucherung der Endothelzellen nachzuweisen. An der Leber sieht man die Wucherung und das Maschenwerk der Endothelzellen deutlich. Das Maschenwerk besteht auch an der Leberoberfläche aus langgestreckten Endothelzellen und aus einem Fibrinnetz. Fibrin ist besonders reichlich in den oberen Partien des Maschenwerkes zu finden. Zell- und Kerndetritus bemerkt man an vielen Stellen im Maschenwerk, besonders aber da, wo Fibrinmassen angehäuft sind. Auch Riesenzellenbildungen sind vielfach im Maschenwerk zu konstatieren.

Im allgemeinen kann man in diesem Stadium das Maschenwerk in drei Zonen einteilen. Die obere Zone besteht aus dem Epithelüberzug und der darunterliegenden Fibrinschicht. Die mittlere Zone nimmt den grössten Teil des Maschenwerkes ein. Sie besteht aus den von Endothelzellen und Fibrin gebildeten Fächern. Die verschieden grossen Hohlräume sind hier mit Fett dicht erfüllt. Diese Schicht umschliesst auch viele Detritusmassen, Reste von Zellen und Kerne. Die dritte Zone des Maschenwerkes endlich besteht aus dem Infiltrationswall der Leukozyten. In - dieser Schicht findet man stark erweiterte Blut- und Lymphgefässe, während in der mittleren Zone solche nur in geringer Zahl vorhanden sind.

Bei der Fettfärbung der Leberschnitte sieht man nicht nur Fettkugeln in den Hohlräumen des Maschenwerkes, sondern auch in den Lymphgefässen des basalen Maschenwerkes und des subendothelialen Gewebes. Ausserdem findet man in der oberen Partie des Leberparenchyms, direkt unter dem Maschenwerk, strahlenartige rote Streifen, welche den mit Fett gefüllten Lymphgefässen entsprechen.

An der Milz sieht man nur mehrschichtige Wucherungen der Endothelzellen in grosser Ausdehnung, dagegen kein Maschenwerk.

Am Dickdarm findet man ebenfalls starke Wucherungen der Endothelzellen und ein mächtiges polypöses Maschenwerk.

Am Magen ist nur an vereinzelten Stellen die Wucherung der Endothelzellen zu bemerken.

Die frei in der Bauchböhle liegenden Flöckchen zeigen genau denselben Aufbau wie das an der Peritonealserosa haftende Maschenwerk, einschliesslich des Fibrinnetzes und reichlicher Detritusmassen. 
124 Kawasoye, Veränderungen der Bauchorgane nach Kampferölinjektion.

Nur Kapillargefässe fehlen vollkommen. Die Oberfläche des Maschenwerkes ist von Endothelzellen bekleidet. Das Verhalten des Fettes ist analog dem des Serosamaschenwerkes.

Der Befund der Lunge ist normal. Bei der Fettfärbung findet man ziemlich viele Fetttröpfchen in den Lungengefässen, ohne dass sie pathologische Veränderungen im Lungengewebe hervorgerufen hätten.

Epikrise: 3 Tage nach der intraperitonealen Kampferölinjektion sind die reaktiven Veränderungen bei Kaninchen Nr. 10 analog denen der vorigen Versuchsgruppe. Nur weist die Fibrinbildung und die Zellnekrose mit Anhäufung von Detritusmassen eine weitere bedeutende Steigerung auf. Ausserdem macht sich das Auftreten grosser vakuolenhaltiger Riesenzellen im Maschenwerk bemerkbar. Blut- und Lymphgefässe sind in grösserer Zahl, vor allem an der Leber, in die basalen Abschnitte des Maschenwerkes eingedrungen.

Auffallenderweise fehlen bei dem 1. Tier dieser Versuchsgruppe, bei Kaninchen Nr. 9, reaktive Veränderungen am Peritoneum vollkommen.

\section{Gruppe.}

Tötung der beiden Tiere (Nr. 11 u. 12) 4 Tage nach der intraperitonealen Kampferölinjektion.

Nr. 11. Männliches Kaninchen, $1520 \mathrm{~g}$ schwer.

Oelinjektion 30. IX. 1912. Menge des Kampferöls $=8 \mathrm{ccm}$.

Verlauf: Ungestört.

Sektion: 4. X. 1912.

Befund: In der eröffneten Bauchhöhle findet man noch ziemlich reichlich trübe, ölhaltige Flïssigkeit. Mikroskopisch sieht man in dieser Flüssigkeit viele Fettkugeln von verschiedener Grösse, grosse Mengen von Leukozyten und spärliche aufgequollene Endothelzellen.

Die gesamte Oberfläche des parietalen und viszeralen Peritoneums ist wie von einem Oeltau bedeckt und wie in einen Schleier gehüllt. Hier und da sind subseröse Blutungen am Dickdarm und am parietalen Peritoneum zu beobachten. Die Hauptablagerungsstelle für den weissen, dicken Belag ist die Abdominalseite des Zwerchfells, die hintere Bauchwand, die Leber und der Dickdarm. Das Zwerchfell zeigt den Belag besonders stark am Centrum tendineum. An der Leber ist der Belag lokalisiert an den Rändern sowie in den hinteren Partien auf den Flächen in der Nähe der Ränder. An der Milz kann man an den unteren Partien derselben einen ziemlich deutlichen weissen Belag nachweisen. Am Magen, am Dünndarm und an der vorderen parietalen Bauchwand ist der Belag anch in geringer Ausdehnung vorhanden.

Die Pleura ist überall glatt und spiegelnd, auch die Pleura diaphragmatica.

Die Lunge ist ganz normal.

Die Bauchhöhle erweist sich als keimfrei. 
Mikroskopische Untersuchung: Am parietalen Peritoneum findet man weit verbreitet eine mehrschichtige Wucherung von Endothelzellen, die an verschiedenen Stellen polypenartige Hervorragungen bildet. Die stark erweiterten Lymphgefässe des subserösen Gewebes enthalten reichlich resorbiertes Oel. Ausser der mehrsehichtigen Wucherung findet man an dem parietalen Peritoneum stark entwickeltes Maschenwerk von dem bekannten Bau. In der basalen Zone des Maschenwerkes ist eine starke Erweiterung und pralle Füllung der Blutgefässe sowie eine Frweiterung und Fettfüllung der Lymphgefässe zu sehen. Die Oeltropfen sind in den Hohlräumen des Maschenwerkes eingekapselt, das Maschenwerk selbst von Endothelzellen überzogen. Bei der Fibrinfärbung findet sich Fibrin vor allem in der oberen Zone unter dem oberen Endothelüberzug, aber auch in den anderen Partien des Maschenwerkes und auch im subserösen Gewebe. Die Endothelzellen an der Oberfläche des Netzes sind stark gewuchert, an vielen Stellen so stark, dass kleine polypöse Hervorragungen sichtbar werden. Im Grundgewebe des Netzes findet sich reichlich Fibrin und starke Leukozyteninfiltration.

An der abdominalen Seite des $Z$ werchfells sieht man das bekannte Maschenwerk in beträchtlicher Ausdehnung. In die unteren Partien des Maschenwerkes ist aus der Serosa gefässhaltiges Bindegewebe eingedrungen. Hier bemerkt man auch stark erweiterte Oeltropfen enthaltende Lymphgefässe. Die unteren Partien des Maschenwerkes gehen ohne scharfe Grenze in das Gewebe der Serosa über, das ebenfalls eine starke Erweiterung und Füllung der Blut- und Lymphgefässe zeigt. Eine starke Anhäufung von Fett in den Lymphgefässen kann man übrigens in der ganzen Zwerchfellwand nachweisen.

Am Dünndarm sieht man nur an einigen Stellen eine Wucherung der. Endothelzellen. Dagegen ist sie am Dickdarm stark ausgeprägt, ebenso die Maschenwerkbildung.

Ganz besonders stark sind die reaktiven Veränderungen an der Leber. Hier liegt das Maschenwerk in grosser Ausdehnung auf der Oberfiäche. In dem Maschenwerk findet sich ein deutliches Fibrinnetz. Fibrin liegt aber ausserdern noch als ein breites Band direkt unter dem Endothelzellenüberzug des Maschenwerkes (s. Fig. 3). Die Leukozyten des Maschenwerkes sind infolge von Nekrose an Zahl vermindert. Unterhalb des Maschenwerkes enthält das gewucherte subendotheliale Gewebe erweiterte und stark gefüllte Blutgefüsse sowie mit Fett erfülltte Lymphgefässe. Aus dem subendothelialen Gewebe sind Lymph- und Blutgefässe führende Bindegewebszüge in dis unteren Partien des Maschenwerkes in reichlicher Zahl eingedrungen, wodurch die Grenze zwischen Maschenwerk und subendothelialem Gewebe verwischt ist. Die Fettfärbung zeigt die Oeltropfen in den Maschen des Maschenwerkes, in den Lymphgefässen der neugebildeten Bindegewebszüge und in den Lymphgefässen des subendothelialen Gewebes. Von hier aus bemerkt man eine strahlenartige Ausbreitung Oel führender Strassen in die oberen Bezirke des Leberparenchyms. Vom Maschenwerk aus ist also das emulgierte $\mathrm{Oel}$ in die Lymphgefässe des Leberparenchyms transportiert worden. Am Magen ist auch eine Wucherung der Endothelzellen erkennbar, aber kein Maschenwerk.

An der Lunge sieht man bei mit Sudan gefärbten Schnitten Fetttropfen in den Blutgefässen, hier und da in grösserer Menge. Pathologische Veränderungen sind aber an den Schnittpräparaten ebenso wenig: 
zu finden wie bei der makroskopischen Betrachtung der Lunge, nicht einmal eine Infiltration mit Leukozyten. Danach handelt es sich nicht um eine Fettembolie der Lunge, sondern um eine Lipämie.

Nr. 12. Männliches Kaninchen, $1320 \mathrm{~g}$ schwer. Oelinjektion: 30. IX. 1912. Menge des Kampferöls $7 \mathrm{ccm}$.

Verlauf: Nur einige Stunden war das Tier still, von da ab dauernd munter.

Sektion: 4. X. 1912, $1280 \mathrm{~g}$ schwer (40 g Gewichtsabnahme).

Befund: In der Bauchhöhle findet man ziemlich viel trübe ölhaltige Flüssigkeit, in der mikroskopisch reichlich Fettkugeln verschiedener Grösse, zahlreiche Leukozyten und spärlichere Endothelzellen enthalten sind. Das parietale und viszerale Peritoneum ist wie bei Nr. 11 überall wie von einem Schleier bedeckt. Auch die Hauptablagerungsstätten der dicken, weissen Beläge sind genau dieselben wie bei dem Paralleltier der Versuchsgruppe.

Die Pleura erscheint glatt und spiegelnd. Die Lunge zeigt keine Besonderheiten.

Die bakteriologische Prüfung der Bauchhöhle ergibt Keimfreiheit.

Die mikroskopische Untersuchung der Bauchserosa in ihren verschiedenen Abschnitten zeigt im wesentlichen dasselbe Bild wie bei Kaninchen Nr. 11. Nur ist am Netz und an der Milzoberfläche das Maschenwerk stärker entwickelt. Wie bei Nr. 11 ist gefässführendes Bindegewebe in die unteren Partien des Maschenwerkes eingedrungen. In dieser Schicht sind auch erweiterte mit Fett erfüllte Lymphgefässe vorhanden.

An der Abdominalseite des Zwerchfells findet man ein hochgradig. entwickeltes Maschenwerk, welches ebenso wie an den anderen Stellen strukturiert ist.

Der Befund der Lunge ist normal. Bei der Fettfärbung sieht man hier und da geringe Mengen von Fetttröpfchen in den Blntgefässen.

Epikrise. Bei beiden Tieren dieser Gruppe sind die reaktiven Veränderungen der Bauchserosa stark ausgeprägt, also 4 Tage nach der intraperitonealen Kampferölinjektion. Das Maschenwerk zeigt sich von reichlichen Fibrinmassen durchsetzt, während die Leukozyten an Zahl abgenommen haben. Auffallend und von grosser Bedeutung ist das Eindringen von Blut- und Lymphgefässen in Begleitung von Bindegewebszügen tief in das Maschenwerk hinein. Die oberen Partien des Maschenwerkes sind noch frei von den organisierenden und die Oelresorption fördernden Vorgängen.

\section{Gruppe.}

Tötung der beiden Tiere (Nr. 13 und 14) 5 Tage nach der intraperitonealen Kampferölinjektion.

Nr. 13. Männliches Kaninchen, $1550 \mathrm{~g}$ schwer.

Oelinjektion 30. IX. 1913. Menge des Kampferöls $8 \mathrm{~cm}$.

Verlauf: Zuerst war das Tier munter; in den beiden letzten Tagen war es still, sah elend aus und frass nicht.

Sektion 5. X. 1912, $1320 \mathrm{~g}$ schwer (230 g Gewichtsabnahme). 
Befund: Nach der Eröffnung der Bauchhöhle findet man darin eine geringe Menge trüber ölhaltiger Flüssigkeit, die mikroskopisch Oeltropfen verschiedener Grösse, Leukozyten und spärliche Endothelzellen aufweist. Adhäsive Veränderungen bestehen nicht.

An der ganzen Oberfläche des parietalen und viszeralen Bauchfells bemerkt man wieder einen feinen weisslichen Ueberzug. Der dicke, weisse, feucht glänzende Belag findet sich an der abdominalen Seite des Zwerchfells, am Netz, an der Leber, am Dickdarm, an der hinteren Bauchwand und am Mesenterium. Am Zwerchfell sieht man den Belag inselartig, in besonders grosser Menge am Centrum tendineum, weniger reichlich am muskulären Abschnitt des Zwerchfells.

An der Milz, am Dünndarm und an der vorderen Bauchwand sieht man nur wenig Belag. Pleura.

Die Pleura diaphragmatica ist glatt und spiegelnd wie die übrige

Die Lunge zeigt an ihrer Oberfläche vielfach Flecke von dunkelroter Farbe. Die hier angelegte Schnittfläche lässt dunkelrote, leicht prominierende Herde im Lungengewebe erkennen.

Die bakteriologische Kontrolluntersuchung der Bauchhöhle ergibt Keimfreiheit.

Mikroskopische Untersuchung: Am Parietalperitoneum findet man im allgemeinen eine starke Wucherung der Endothelzellen. An vielen Stellen sieht man das Bekannte Maschenwerk, teils mehr polypös, teils mehr diffus ausgebreitet. Die Hohlräume des Maschenwerkes werden ron Endothelzellen und netzförmig angeordnetem Fibrin begrenzt. Der Leukozytengehalt des Maschenwerkes ist stark vermindert. Blutgefässand lymphgefässhaltiges, junges Bindegewebe ist reichlich, namentlich in den unteren Partien zu erkennen. Die Oeltropfen und das Fibrin im Maschenwerk verhalten sich wie bei den Tieren der vorigen Gruppe. Manchmal zeigt auch das subseröse Bindegewebe selbst eine polypöse oder zottenartige Wucherung an ihrer Oberfäche mit gequollenen oder mehrschichtigen Endothelzellen belegt.

An der Milz und an der Leber sieht man starke reaktive Veränderungen, analog den Veränderungen in Gruppe VI. Man sieht mehrschichtige Zellwucherungen und Maschenbildung. der Endothelzellen. In den Hohlräumen des Masehenwerkes findet man gleichfalls Fetttröpfehen in grosser Menge. Es ist auch intra- und interzellulär in feinen Tröpfchen vorhanden. In den der Oberfläche benachbarten Partien des Leberparenchyms sieht man bei der Sudanfärbung strahlenförmige, rote Streifen, welche die mit Fett erfüllten Lymphgefässe darstellen. In der Grundpartie des Maschenwerkes bemerkt man ebenfalls eine Infiltration mit Leukozyten, wie ich sie bei Gruppe VI an der Leber genau schilderte.

Netz und Mesenterium verhalten sich genau wie bẹi den Tieren der Gruppe VI, ebenso Dickdarm und Dünndarm.

An der Abdominalseite des $Z$ werchfells sind die Auflagerungen noch stärker als bei Gruppe VI, sonst aber zeigt der Befund keine Abweichung von jenem.

Die Lunge zeigt in ausgedehntem Maasse die Gefässe mit Fett erfüllt, sowie eine Durchsetzung des interalveolären Gewebes mit Leukozyten und roten Blutkörperchen, namentlich in der Umgebung der Gefässe. Auch die Alveolen selbst enthalten viele Leukozyten und vielfach abgestossene Alveolarepithelien. Die in der Nähe der In- 
filtrationsherde liegenden Alveolen sind kompensatorisch hochgradig erweitert. Es kann nicht zweifelhaft sein, dass es sich hier um fettembolische Herde handelt.

Nr. 14. Männliches Kaninchen, $1300 \mathrm{~g}$ schwer.

Oelinjektion 30. IX. 1912. Menge des Kampferöls $=7 \mathrm{ccm}$.

Verlauf: Ungestört.

Sektion: 5. X. 1912. $1300 \mathrm{~g}$ schwer.

Befund: In der Bauchhöhle findet man reichliche, emulgiertes Oel einschliessende Flüssigkeit, die denselben mikroskopischen Befund zeigt wie Nr. 13. Der diffuse, weissliche, schleierartige und der streckenweise dicke Belag sind in noch stärkerem Grade als in Nr. 13 vorhanden. Freie Flöckchen, losgelöste Belagteile, finden sich besonders reichlich zwischen der hinteren Bauchwand und dem Darm.

An der Abdominalseite des Zwerchfells sieht man einen sehr stark entwickelten diffusen Belag entsprechend dem Centrum tendineum, in geringerer Ausdehnung und Stärke an den muskulären Partien des Zwerchfells. Am Netz sind dicke, weisse Auflagerungen mit vielen polypösen Fortsätzen vorhanden. Am Mesenterium ist der Belag ebenfalls stark, besonders deatlich an der Radix mesenterii, ebenso an dex Leber, an der Milz, an der Bauchwand und am Dickdarm, geringer am Dünndarm.

Die Pleura diaphragmatica ist glatt und spiegelnd wie die übrige Pleura. An der Lunge ist keinerlei Besonderheit wahrzunehmen.

Mikroskopisch verhalten sich die reaktiven Veränderungen am Parietal- und Viszeralperitoneum, genau so wie bei Kaninchen Nr. 13, weshalb ich auf die dortige Beschreibung verweisen kann. Die Lunge lässt dagegen auch mikroskopisch nichts Pathologisches erkennen.

Epikrise: Bei beiden Tieren dieser Gruppe, also 5 Tage nach der intraperitonealen Kampferölinjektion, ist die Oelreaktion an der ganzen Bauchserosa sehr deutlich und stark ausgeprägt. Die Organisations- und Resorptionsbestrebungen durch Hineinwachsen von blutgefäss- und lymphgefässhaltigem jungen Bindegewebe in das von Fibrin durchsetzte aber leukozytenärmer gewordene Maschenwerk sind unverkennbar.

Auffallend sind die fettembolischen Herde in der Lunge des Kaninchens Nr. 13, das darunter sichtlich gelitten hat (vergl. Kaninchen Nr. 6 in Versuchsgruppe III).

\section{Gruppe.}

Tötung der beiden Tiere (Nr. 15 u. 16) 6 Tage nach der intraperitonealen Kampferölinjektion.

Nr. 15. Männliches Kaninchen, $2110 \mathrm{~g}$ schwer.

Oelinjektion 30. IX. 1912. Menge des Kampferöls $=11 \mathrm{ccm}$.

Verlauf: Ungestört.

Sektion: 6. X., $1810 \mathrm{~g}$ schwer (300 g Gewichtsabnahme).

Befund: Keine freie Flüssigkeit und keine adhäsiven Veränderungen in der Bauchhöhle. Den feinen weisslichen Ceberzug kann man wieder an der ganzen Oberfläche des parietalen und vis- 
zeralen Peritoneums nachweisen. Auch der weisse, dicke, feucht glänzende Belag ist an der Bauchserosa weit verbreitet, besonders am Centrum tendineum des Zwerchfells. Die Pleuraseite des Zwerchfells ist glatt und spiegeInd wie die übrige Pleura. Die Lunge ist normal. freiheit.

Die bakteriologische Untersuchung der Bauchhöhle ergibt Keim-

Mikroskopische Untersuchung: An der Abdominalseite des Zwerchfells sieht man in dem hier stark entwickelten Maschenwerk viele, prall gefüllte Kapillargefässe. Die Gefässe liegen in den Septen des Maschenwerkes und lassen sich jetzt auch in die oberen Partien desselben verfolgen. Sie sind begleitet von Bindegewebszügen, die in den basalen Abschnitten des Maschenwerkes reichlich, spärlicher in den mittleren hervortreten, aber auch schon in die oberen Partien vorgedrungen sind. Fibrin zeigt sich im Maschenwerk in kleinen Klümpchen oder als Netz von Fäserchen. Die Oberfläche des Maschenwerkes ist bedeckt von gewucherten Endothelzellen, die verschieden geformte Fortsätze bilden. In den unteren Partien des Maschenwerkes, wo es bindegewebsreich und fibrinarm ist, bemerkt man stark erweiterte Lymphgefässe und prall gefüllte Blutgelässe. Bemerkenswert ist bei diesem Tier, dass die Lymphgefässe bis zur pleuralen Seite des Zwerchfells hin erweitert sind und bei der Fettfärbung resorbiertes Oel aufweisen. Eine Wucherung der Endothelzellen ist aber an der Pleura diaphragmatica nirgends zu entdecken,

In dem Maschenwerk der Leberoberfläche zeigt sich ein verschiedenes Verhalten, je nachdem die Organisation durch Einwachsen jungen Bindegewebes fortgeschritten ist. Im allgemeinen kann man hier in diesem Stadium 2 Schichten unterscheiden, eine obere fibrinreiche mit einem Ueberzug gewucherter Endothelzellen und eine untere, deren von grösseren und kleineren Oeltropfen erfüllte Maschen durch gefüsshaltiges Bindegewebe getrennt sind. Die Dicke der beiden Schichten wechselt an den verschiedenen Stellen sehr, bald ist die eine Schicht, bald die andere die breitere. Da, wo die Organisation des Maschenwerkes am weitesten entwickelt ist, verwischt sich auch die Grenze zwischen dem Leberparenchym und dem Maschenwerk, so dass das Leberparenchym gleichsam einbezogen ist in das organisierende Gewebe des unteren Maschenwerkes. Die Spalträume zwischen benachbarten Leberlappen sind zum Teil vollkommen vom Maschenwerk ausgefülltt.

Am Netz findet man an der Oberfläche starke mehrschichtige Zellwucherung und Maschenwerkbildung der Endothelzellen mit wenig Fibrin und spärlichen Leukozyten.

An den übrigen mikroskopisch untersuchten Stellen der Peritonealserosa (Mesenterium, Dickdarm, Dünndarm, Milz, Parietalperitoneum) beschränken sich die reaktiven Veränderungen bei diesem Tier meist auf eine mehr oder weniger starke Wucherung der Endothelzellen.

An der makroskopisch normal erscheinenden Lunge findet man hier und da einen kleinen fettembolischen Herd, wo die Blutgefässe reichlich resorbiertes Oel anfweisen und die benachbarten Lungenalveolen kompensatorisch erweitert sind.

Nr. 16. Männliches Kaninchen, $1830 \mathrm{~g}$ schwer.

Oelinjektion 30. IX. 1912. Menge des Kampferöls $=6 \mathrm{ccm}$.

Verlauf: Ungestört.

Sektion: 6. X. 1912, $1720 \mathrm{~g}$ schwer (110 g Gewichtsabnahme). 
Befand: Keine freie Flüssigkeit in der Bauchhöhle und keine Verklebungen oder Verwachsungen.

Am ganzen parietalen und viszeralen Peritoneum sieht man wieder einen schleierartigen weisslichen Ueberzug. Der weisse dicke Belag findet sich besonders an der hinteren Bauchwand, am Dickdarm, am Jesenterium und am stärksten an der abdominalen Seite des Zwerchfells und am Netz, in geringer Ausdehnung an der Leber und an der Milz.

An Lunge und Pleura ist nichts Auffälliges zu bemerken, auch nicht am Pleuraüberzuge des Zwerchfells.

Eine bakteriologische Kontrolle der Bauchhöhle ergibt Keimfreiheit.

Der mikroskopische Befund entspricht mit ganz unwesentlichen Abweichungen dem bei $\mathrm{Nr} .15$ beschriebenen, so dass ich darauf verweisen kann.

Die Lunge weist auch mikroskopisch keine Besonderheiten auf.

Epikrise: Die Oelreaktion der Peritonealserosa ist auch bei beiden Tieren dieser Gruppe, also 6 Tage nach der intraperitonealen Kampferölinjektion, sehr deutlich. Der Befund unterscheidet sich nur unwesentlich von dem bei Gruppe VII beschriebenen. Das gefässhaltige Bindegewebe ist streckenweise schon bis in die oberen Partien des Maschenwerkes vorgedrungen. Die Lymphgefässe der basalen Maschenwerkschicht sind sehr stark erweitert and mit Oeltropfen erfüllt, besonders am Zwerehfell und an der Leber.

\section{Gruppe.}

Tötung der beiden Tiere (Nr. 17 und 18) 7 Tage nach der intraperitonealen Kampferölinjektion.

Nr. 17. Nännliches Kaninchen, $1320 \mathrm{~g}$ schwer.

Oelinjektion 20. IX. 1912. Menge des Kampferöls $7 \mathrm{ccm}$.

Verlauf: Nur wenige Stunden nach der Oelung war das Tier still, von da ab aber sehr munter.

Sektion 27. 1X. 1912, $1390 \mathrm{~g}$ schwer (70 g Gewichtszunahme). Keine freie Flüssigkeit, keine Adhäsionen in der Bauchhöhle. Parietales und viszerales Peritoneum zeigen weit verbreitete Oelreaktion in verschiedener Stärke. Dicker weisser Belag findet sich an der Abdominalseite des Zwerchfells, vor allem am Centrum tendineum, an grossen Abschnitten der Leberoberfläche, sowohl an der Konvexität als auch an der Konkavität, an der Milz, am Parietalperitoneum, am Magen, am Netz, an der Radix mesenterii und an der Serosa des Dickdarms, während die Serosa des Dünndarms an den reaktiven Veränderungen sehr viel weniger beteiligt ist.

Lunge und Pleura sind frei von Veränderungen. Auch die Pleura diaphragmatica ist glatt und spiegelnd.

Die bakteriologische Prüfung der Bauchhöhle ergibt Keimfreiheit.

Mikroskopische Untersuchung: An der abdominalen Seite des Zwerchfells sieht man wohl die mehrschichtige Wucherung der Endothelzellen und eine Maschenwerkbildung, aber das Maschenwerk ist niedriger und seine Struktur ist dichter, so dicht, dass es bloss aus Haufen von 
Endothelzellen zu bestehen scheint. Mit Fett erfülte Hohlräume sind nur noch in geringer Anzahl vorhanden. Ausser in den spärlichen Hohlräumen des Maschenwerkes weist die Fettfärbung feine Tröpfchen intra- und interzellulär and in ziemlich grosser Menge in den Lymphgefässen des ganzen Zwerchfells bis zu den Lymphgefässen des subendothelialen Gewebes der Pleura diaphragmatica.

Auch an der Leber zeigt das Maschenwerk in seiner oberen Partie eine derart dichte Struktur, dass dort nur Haufen von Endothelzellen zu sehen sind. Die untere Sehicht des Maschenwerkes besteht aus fetterfüllten grossen und kleinen Hohlräumen, die durch gefässhaltige bindegewebige Septen voneinander getrennt sind. Fibrin ist im Maschenwerk nur in geringer Menge vorhanden. Bei der Fettfärbung findet man eine schmale Fettschicht auf der Oberfläche der Leber. An dem zunächst liegenden Parenchym der Leber sieht man das resorbierte Oel in strahlenförmigen roten Streifen angeordnet.

An der hinteren Bauchwand hat die Oberfläche des Maschenwerkes ein polypöses Aussehen infolge von Endothelzellenwucherung. Unter dem endothelialen Ueberzuge liegt ein breites Band von Fibrin. In den unteren Partien führen die Septen des Maschenwerkes deutlich gefässhaltiges Bindegewebe. Mit Oeltropfen erfüllte Hohlräume sind zwar deutlich in der mittleren Zone sowie in den Grundpartien des Maschenwerkes vorhanden, aber die Menge des Fettes ist doch im Vergleich zu den früheren Stadien der vorhergehenden Gruppen vermindert. In das anliegende subendotheliale Gewebe geht das Maschenwerk ohne erkennbare Grenze über, so dass das 'subendotheliale Gewebe ein Teil der basalen Naschenwerkzone zu sein șcheint.

Auch an der Milz, am Dickdarm enthält das mächtig entwickelte Maschenwerk mässige Mengen Fibrin, an Zahl sehr verminderte Leukozyten und namentlich in den unteren Partien bindegewebige Septen mit erweiterten und prall gefüllten Gefässen.

An der Lunge ist auch mikroskopisch nichts Pathologisches wahrzunehmen.

Nr. 18. Männliches Kaninchen, $1240 \mathrm{~g}$ schwer.

Oelinjektion 20. IX. 1912. Menge des Kampferöls $6 \mathrm{ccm}$.

Verlauf: Ungestört.

Sektion 27. IX. 1912, $1160 \mathrm{~g}$ schwer ( $80 \mathrm{~g}$ Gewichtsabnahme).

Befund: ln der eröffneten Bauchhöhle noch ziemlich reichlich emulgiertes Oel enthaltende Flüssigkeit, die mikroskopisch verschieden grosse Oelkugeln, Leukozyten und Endothelzellen enthält. Nirgends Adbäsionen oder auch nur Verklebungen. Am parietalen oder viszeralen Peritoneum deutliche Oelreaktion in Form des zarten schleierartigen Ueberzuges. Einen weissen, dicken Belag findet man an der Bauchwand, am Dickdarm, an der Leber, am Mesenterium, vor allem aber an der abdominalen Seite des Zwerchifells und an der Milz, während er am Dünndarm und am Magen fehlt.

Lunge und Pleura bieten keine Besonderheiten, speziell ist die Pleura diaphragmatica glatt und spiegelnd. wachstum.

Die bakteriologische Kontrolle der Bauchhöhle ergibt kein Bakterien-

Der mikrosk opische-Befund der stark ausgeprägten reaktiven Veränderungen am Parietal- und Viszeralperitoneum stimmt in allen wesentlichen Punkten mit dem bei Kaninchen Nr. 17 ephobenen Befunde überein. Die Lunge weist anch mikroskopisch nichts Pathologisches auf. 
Epikrise. Die reaktiven Veränderungen am Peritoneum der beiden Kaninchen sind auch 7 Tage nach der intraperitonealen Kampferölinjektion sehr deutlich. Wichtig ist das Fehlen von Adhäsionen trotz der ausgedehnten mächtigen Oelreaktion der Peritonealserosa. Ueberall ist das Maschenwerk von mehr oder weniger stark gewucherten Endothelzellen bedeckt. Der Fibrinund Leukozytengehalt wechselt an Menge im Maschenwerk, ist aber gegenüber den früheren Stadien entschieden wesentlich vermindert, während das Hineinwachsen blutgefäss- und lymphgefässführenden Bindegewebes in das Maschenwerk zugenommen hat.

\section{Gruppe.}

Tod des Tieres (Nr. 19) 10 Tage nach der intraperitonealen Kampferölinjektion.

Nr. 19. Männliches Kaninchen, $1270 \mathrm{~g}$ schwer.

Oelinjektion 19. IX, 1912. Menge des Kampferöls $6 \mathrm{ccm}$,

Verlauf: Gestorben am 29. IX. 1912, nachdem es einige Tage hindurch elend und sich ganz still verhalten hatte.

Sektion 29. IX. 1912, $1080 \mathrm{~g}$ schwer (190 g Gewichtsabnahme).

Befund: In der Bauchhöhle keine freie Flüssigkeit, keine adhäsiven Veränderungen. An dem parietalen und viszeralen Peritoneum ist ebenfalls ein tauartiger Ueberzug zu bemerken. Hauptablagerungsstätten des weissen, dicken Belages sind die Abdominalseite des Zwerchfells, das Netz, die Leber, die hintere Bauchwand und die Milz. Die Pleura diaphragmatica ist glatt wie die übrige Pleura.

Die Pleura zeigt auf der Oberfläche dunkelrote Flecke, die sich auf dem Durchschnitt als dunkelrote Herde in das Lungengewebe fortsetzen.

Die Bauchhöhle erweist sich als keimfrei.

Das mikroskopische Bild der reaktiven Veränderungen am Peritoneum stimmt bei diesem Tiere gut überein mit dem Befunde bei den nach 7 Tagen getöteten Kaninchen. Ein Unterschied liegt aber darin, dass das Maschenwerk in seinen oberen Partien noch überall eine deutliche Maschenbildung zeigt, während es bei der IX. Gruppe, besonders bei Kaninchen Nr. 17 eine sehr viel dichtere Struktur hatte. Das stark entwickelte Maschenwerk auf der Leberaberflä che ist von gewucherten Endothelzellen bedeckt. Fibrin liegt unter dieser Endothelwucherung: in Form eines breiten Bandes. Die Leukozyten sind im Maschenwerk nur noch in geringer Anzahl vorhanden. An anderen Stellen der Oberfläche der Leber, wo keine Maschenbildung vorhanden ist, zeigt sich auch eine Verdickung des subendothelialen Bindegewebes und an der Oberfläche stellenweise eine mehrschichtige Wucherung der Endothelzellen. Die Septen des Maschenwerkes bestehen in den basalen Abschnitten durchweg aus gefässhaltigem Bindegewebe.

An der Abdominalseite des $\mathrm{Z}_{\mathrm{w}}$ erchfells sieht man fast in seiner ganzen Ausdehnung ein beträchtlich entwickeltes Maschenwerk, welches wie bei der Leber aufgebaut ist. Bei der Fettfärbung findet man Fett in grossen und kleinen Kügelchen in den Hohlräumen des Maschenwerkes und als feine Tröpfehen intra- und interzellulär. In den 
erweiterten Lymphgefässen der unteren Zone des Maschenwerkes sowie in allen Schichten des Zwerchfellgewebes liegen viele Fetttropfen.

Die Milz zeigt eine durch Bindegewebswucherung deutlich verdickte Kapsel und ist von unregelmässig mehrschichtig gewucherten Endothelzellen bedeckt.

Am Netz sieht man deutliche Maschenbildung auf dẹr Oberfläche wie bei der Leber. Ihre Grundpartie ist bindegewebsreich, aber an anderen Stellen findet man eine starke Erweiterung der Lymphgefässe, so dass bei der Sudanfärbung diese ganze Partie nur aus Fett zu bestehen scheint.

An der Lunge sieht man mikroskopisch ansgebreitete Herde von Fettembolie. In diesen Herden sind die Blutgefässe mit dicht gelagerten Oellsugeln verschiedener Grösse erfüllt. In der Umgebung dieser Herde sind die Lungenalveolen kompensatorisch erweitert.

Epikrise. Die starke Oelreaktion am Peritoneum des Kaninchens Nr. 1910 Tage nach der intraperitonealen Kampferölinjektion ist im wesentlichen dieselbe wie bei den nach 7 Tagen getöteten Tieren der vorigen Versuchsgruppe. Die Fettembolie der Lunge ist bei diesem Tiere vielleicht die Todesursache gewesen.

\section{Gruppe.}

Tötung der beiden Tiere (Nr. 20 und 21) 2 Wochen nach der intraperitonealen Kampferölinjektion.

Nr. 20. Männliches Kaninchen, $1420 \mathrm{~g}$ schwer.

Oelinjektion 20. IX. 1912. Menge des Kampferöls $=7 \mathrm{ccm}$.

Verlauf: Ungestört.

Sektion: 4. X. 1912, $1450 \mathrm{~g}$ schwer (30 g Gewichtsabnahme).

Befund: In der Bauchhöhle zeigt sich eine geringe Menge emulgierten Oels; nirgends Adhäsionen.

An dem ganzen Peritoneum bemerkt man den gewohnten tanartigen, leicht weisslich aussehenden Ueberzug. Dicker weisser Belag, zum Teil polypös oder zottig, zum Teil als flachere Auflagerung, findet sich am Parietalperitoneum, an der Abdominalseite des Zwerchfells, vor allem am Centrum tendineum, in verschiedenen Bezirken der Leberoberfläche, sehr stark am Netz, ferner am Dickdarm und am Magen.

Die Pleuraseite des Zwerchfells ist glatt und spiegelnd, wie die übrige Pleura.

Die Lunge ist normal. freiheit.

Die bakteriologische Untersuchung der Bauchhöhle ergibt Keim-

Mikroskopische Untersuchung: An der Abdominalseite des $Z_{\text {werchfells sieht man im allgemeinen eine deutliche Verdickung }}$ des subendothelialen Bindegewebes und darin erweiterte Lymphgefässe. In der relativ niedrigen Auflagerung bemerkt man in den oberen und unteren Abschnitten grosse Hohlräume, die von langgestreckten Endothelzellen begrenzt werden. In den Septen sind prall gefüllte Kapillaren überall reichlich vorhanden, in der unteren Hälfte der Auflagerung in Bindegewebszügen liegend. An vielen Stellen zeigt die Auflagerung eine sehr dichte Struktur. Man sieht hier Haufen von Endothelzellen, 
die zuweilen noch zwischen sich kleine Hohlräume einschliessen. Leukozyten sind nur in mässiger Menge diffus eingestrent. Bei der Sudanfärbung des Zwerchfells sehen wir Oel als grosse Tropfen in den Hohlräumen, als feinere Tröpfchen intra- und interzellulär. Ausserdem findet man mit resorbiertem Oel vollgestopfte Lymphgefässe durch die ganze Dicke des Zwerchfells hindurch, bis zur Pleura diaphragmatica, deren Endothelüberzug aber unverändert ist. Fibrin ist nur in mässiger Menge, besonders in der eine dichtere Struktur zeigenden Partie des Maschenwerkes nachweisbar.

An der Oberfläche der Leber ist die Auflagerung relativ niedrig, wie am $\mathrm{Zwerchfell,} \mathrm{und} \mathrm{vielfach} \mathrm{von} \mathrm{derselben} \mathrm{dichten} \mathrm{Struktur.} \mathrm{Auch}$ das Verhalten von Fett und Fibrin ist wie am Zwerchfell. Eine leichte Verdickung der Leberkapsel ist unverkennbar.

Auf der deutlich verdickten Milzkapsel findet sich eine mehrschichtige Wucherung der Endothelzellen, aber kein Maschenwerk.

Die Netzoberfläche verhält sich in allen wesentlichen Punkten wie Zwerchfell und Leber. Auch am übrigen Peritoneum ist entweder Maschenwerk von der beschriebenen. Struktur vorhanden oder nur gewuchertes Endothel.

An der Lunge ist auch mikroskopisch nichts Pathologisches zu erkennen.

Nr. 21. Männliches Kaninchen, $1480 \mathrm{~g}$ schwer.

Oelinjektion 20. IX. 1912. Menge des Kampferöls $=7 \mathrm{ccm}$.

Verlauf: Nichts Besonderes.

Sektion: 4. X. 1912, $1560 \mathrm{~g}$ schwer ( $80 \mathrm{~g}$ Gewichtszunahme).

Befund: In der eröffneten Bauchhöhle findet man ziemlich reichlich ölhaltige Flüssigkeit, die mikroskopisch wie sonst Oelkügelchen verschiedener Grösse, Leukozyten und spärliche Endothelzellen enthält. Nirgends werden Adhäsionen gefunden.

Das Bild des tauartigen, weisslichen Ueberzuges, sowie der Befund bezüglich der Hauptablagerungsstätten des weissen, dicken Belages stimmen fast vollkommen mit den bei Kaninchen Nr. 20 notierten Veränderungen ẗberein. Die Lunge und die Pleura sind ganz normal.

Die bakteriologische Prüfung der Bauchhöhle ergibt Keimfreiheit.

Bei der mikroskopischen Untersuchung sind kaum Abweichungen von den Befunden des Paralleltieres zu bemerken. Die peritoneale Wucherung besteht aus einer bindegewebigen Grundschicht and dem endothelialen Ueberzug, der an vielen Stellen noch Haufen von Endothelzellen zeigt und kleine Hohlräume erkennen lässt. Die Kapillargefässe sind überall in den zottenartigen Fortsätzen reichlich vorhanden und mit Inhalt erfüllt. Das subseröse Gewebe ist deutlich durch die Wucherung des Bindegewebes verdickt. Hier sieht man vereinzelt ziemlich erweiterte Lymphgefässe, welche Fett enthalten. In den zottenartigen Wucherungen findet man Fett in den Hohlräumen, in den umgebenden Haufen von Endothelzellen und in den Lymphgefässen des Grundgewebes. Als feine Fetttropfen sieht man Fett in den Endothelzellhaufen intra- und interzellulär.

Epikrise: Bei beiden Tieren dieser Versuchsgruppe (Nr. 20 und 21) sind die reaktiven Veränderungen an der Peritonealserosa 14 Tage nach der intraperitonealen Kampferölinjektion noch deutlich vorhanden. Adhäsionen werden nicht gefunden. Die 
Wucherung des Bindegewebes verstärkt sich immer mehr und das Maschenwerk der Endothelzellen vermindert sich vielfach so, dass man statt eines solchen nur noch Haufen von Endothelzellen nachweisen kann, die eine relativ geringe Anzahl kleiner oder enorm grosser Hohlräume umschliessen.

\section{Gruppe.}

Untersuchung der beiden Tiere (Nr. 22 und 23) 3 Wochen nach der intraperitonealen Kampferölinjektion.

Nr. 22. Männliches Kaninchen, $1350 \mathrm{~g}$ schwer.

Oelinjektion 19. IX. 1912. Menge des Kampferöls $=7 \mathrm{ccm}$.

Verlauf: Zuerst ungestört; gestorben am 10. X. 1912, nachdem es seit 2 Tagen ein sehr elendes Aussehen gezeigt hatte.

Sektion: 10. X. 1912, $1050 \mathrm{~g}$ schwer (300 g Gewichtsabnahme).

Befund: In der eröffneten Bauchhöhle findet man eine geringe Menge einer klaren, leicht gelblichen Flüssigkeit, die nur spärlich Leukozyten enthält. Adhäsionen bestehen nicht. Das parietale und viszerale Peritoneum ist glatt und spiegelnd. Ein tauartiger Ueberzug oder ein weisser, dicker Belag ist nirgends nachweisbar. Das Zwerchfell ist sowohl an der Abdominalseite als auch an der Pleuraseite glatt. Die Lunge hat eine rötliche Farbe. Auf der Schnittfläche sieht man einen dunkelrot gefärbten Herd von grosser Ausdehnung. freiheit.

Die bakteriologische Untersuchung der Bauchhöhle ergibt Keim-

Mikroskopische Untersuchung: Das mikroskopische Bild am parietalen und viszeralen Peritoneum zeigt keine Abweichungen von der Norm. Wir haben also weder mehrschichtige Wucherung der Endothelzellen, noch Maschenwerkbildung. Das Zwerchfell ist normal. An der Jeber und an der Milz findet man gleichfalls keine Auflagerung.

Der schon makroskopisch in der Lunge gefundene grosse dunkelrote Herd erweist sich als Infiltrationsherd von Leukozyten. In den Alveolen sind ebenfalls reichlich Leukozyten vorhanden. Die Epithelien der Alveolen sind meistens abgelöst. Bei der Fettfärbung findet man nur spärliches Fett in den Gefässen. Bei diesem Tier handelt es sich also nicht um eine Fettembolie, sondern um eine erst in der 3 . Woche nach der Kampferölinjektion aufgetretene Pneumonie, der das Tier binnen wenigen Tagen erlag.

Nr. 23. Männliches Kaninchen, $1310 \mathrm{~g}$ schwer.

Oelbehandlung 19. IX. 1912. Menge des Kampferöls $=7 \mathrm{ccm}$.

Sektion: 10. X. 1912, $1410 \mathrm{~g}$ schwer (100 g Gewichtszunahme).

Befund: Keine freie Flüssigkeit und keine adhäsiven Veränderungen in der Bauchhöhle.

Am parietalen und viszeralen Peritoneum findet man weit verbreitet einen tauartigen Ueberzug. Ausserdem haftet an der Serosa des Dickdarms und an der hinteren Bauchwand massenhaft weisser, dicker Belag, bald mehr flach, bald von zottigem Aussehen. An der Leber indet man denselben Belag, nur weniger reichlich. An der Abdominal:eite des Zwerchfells ist ein mässiger Belag auf dem Centrum tendiıeum. Die Pleuraseite des Zwerchfells ist dagegen glatt, wie die übrige Ileura. 
Am Magen, am Dünndarm und an der Serosa der vorderen Bauchwand kann man weisse Auflagerungen überhaupt nicht erkennen. An dem fettreichen Netz ist der weisse Belag nur stellenweise, ebenso am Mesenterium.

Die Lunge ist normal.

Die bakteriologische Prüfung der Banchhöhle ergibt wie sonst Keimfreiheit.

Mikroskopische Untersuchung: Bei diesem Tier sind die reaktiven Veränderungen im allgemeinen nicht stark, wenn auch deutlich.

An der Leberoberfläche trifft man hier und da kleine polypöse Wucherungen, die ein zweifaches Bild zeigen: An einigen Stellen, wo die Wucherung nicht sehr beträchtlich ist, bildet das Bindegewebe den Grundstock und schliesst einige grosse Hohlräume ein. Die Oberfläche wird von Endothelzellen überzogen. An anderen Stellen aber zeigt die polypöse Wucherung eine dichtere Struktur und wird hauptsächlich von Endothelzellen gebildet, die nur vereinzelte kleine Hohlräume umschliessen. Bei der Sudanfärbung findet man Fett in den grossen und kleinen Hohlräumen und auch in feinen Tröpfchen intra- und interzellulär. Im allgemeinen ist eine Verdickung der Leberkapsel deutlich nachweisbar:

An der Milz ist die Kapsel auch stark verdickt. Einige Stellen der Oberfläche zeigen eine mehrschichtige Wucherung der Endothelzelles. Zuweilen sind auch kleine polypöse Wucherungen an der Oberfläche au bemerken, die aus einem bindegewebigen Grundgewebe und einen endothelialen Ueberzug bestehen. Nur hier und da sieht man in Grundgewebe Hohlräume, die mit Endothelzellen ausgekleidet sind und Oel enthalten.

An der Abdominalseite des Zwerchfells haben wir ein starke mehrschichtige Wucherung der Endothelzellen und auch ei1 Maschenwerk, das in dichter Struktur aus Haufen von Endothelzellen aufgebaut ist (vergl. Gruppe XI). Es sind also keine grösseren Hohlräume nachweisbar. Oeltropfen liegen in kleinen Hohlräumen, sowit intra- und interzellulär. Von der Grundschicht der Auflagerung bis zum subserösen Gewebe, das eine deutliche bindegewebige Verdickung zeigt, liegen ziemlich gleichmässig erweiterte Hohlräume, die wohl zumeist als erweiterte Lymphgefässe anzusprechen sind, Sie sind stark mit Oeltropfen gefüllt. In den grossen Lymphgefässen, welche zwischen dem Centrum tendineum und dem muskulären Teil des Zwerchfells liegen, beobachtet man ebenfalls resorbiertes Oel in grosser Menge. Prall gefüllte Kapillargefässe sind überall in der Auflagerung vorhanden. Fibrin wird nur noch sehr spärlich in der Auflagerung angetroffen.

An der Serosa der hinteren Bauchwand sieht man ebenfalls einige kleine polypöse Wucherungen. Das Grundgewebe dieser Wucherungen besteht gleichfalls aus gefässhaltigem Bindegewebe. Hier und da findet man Haufen von Endothelzellen. Der Ueberzug der Wucherung besteht aus Endothelzellen, die stellenweise noch stark und mehrschichtig. gewuchert sind.

An dem fettreichen Netz sieht man nur hier und da mehrschichtig gewucherte Endothelzellen, aber keine Maschenbildung. Das Grund. gewebe des Netzes zeigt keine nennenswerte Abweichung von de' Norm, nur ist es bindegewebsreicher. 
Die Lunge bietet auch mikroskopisch keine Besonderheiten. Bei der Fettfärbung findet man lediglich feine Oeltröpfchen in den Blutgefässen.

Epikrise: 3Wochen nach der intraperitonealen Kampferölinjektion zeigen die Auflagerungen auf der Peritonealserosa des Kaninchens Nr. 23 eine dichte Struktur und Reichtum an Bindegewebe. Das Fibrin ist bis auf spärliche Reste ganz verschwunden. Die Hohlräume in den Auflagerungen vermindern sich immer mehr. In den oberen Partien der Auflagerung sieht man nur noch kleine Hohlräume, und zwar nur stellenweise inmitten von Endothelzellenhaufen. Im basalen Abschnitt dagegen und im subserösen Gewebe trifft man gleichmässig erweiterte, mit Oel erfüllte Hohlräume. Auf Grund einer aufeinanderfolgenden Betrachtung der Befunde in den früheren und späteren Versuchsgruppen kann man mit Bestimmtheit schliessen, dass die gleichmässigen Hohlräume mindestens zum Teil als erweiterte Lymphgefässe aufgefasst werden müssen. Die Befunde möchte ich folgendermaassen erklären: In früheren Stadien liegen grosse Massen von Oel im Maschenwerk. Das Maschenwerk besteht aus Endothelzellen und Leukozyten. In. weiteren Stadien tritt an Stelle der Leukozyten Fibrin. Das eingescheidete Oel wird nach und nach in die Tiefe, und zwar in die Lymphgefässe, transportiert. So werden die Lymphgefässe in der Grundschicht der Auflagerung sowohl, als auch im subserösen Gewebe und sogar im Grundgewebe der Organe allmählich stark mit resorbiertem Oel erfüllt. Nun verkleinert sich das Maschenwerk an der oberen Partie der Auflagerung und besteht schliesslich zur Hauptsache aus Haufen von Endothelzellen, die dann nur noch kleine Hohlräume mit geringem Oelinhalt umschliessen.

Auffallenderweise zeigt das Paralleltier Nr. 22 gar keine reaktiven Veränderungen an der Bauchserosa (vergl. Gruppe V, Nr. 9).

\section{Gruppe.}

Untersuchung der 3 Tiere (Nr. 24, 25 u. 26) 30 Tage, 36 Tage und 36 Tage nach der intraperitonealen Kampferölinjektion.

Nr. 24. Männliches Kaninchen, $1650 \mathrm{~g}$ schwer.

Oelinjektion 4. IX. 1912, Menge des Kampferöls $=8 \mathrm{ccm}$.

Verlauf: Exitus am 4. X. 1912, nachdem das Tier 3 Tage sich ganz still verhalten und elend ausgesehen hatte.

Sektion: 4. X. 1912. $1040 \mathrm{~g}$ schwer (610 g Gewichtsabnahme).

Befund: Keine freie Flüssigkeit und keine adhäsiven Veränderungen 
in der Bauchhöhle. An dem parietalen und viszeralen Peritonerm findet man wieder einen tauartigen, leicht weisslich getrübten Ueberzug. Hauptablagerungsstätte des weissen, dicken Belags in der Reihenfolge seiner Stärke sind: Abdominalseite des Zwerchifells, Serosa der hinteren Bauchwand, Leber, Milz und Dickdarm. Am Magen, an der vorderen Bauchwand, am Diunndarm, am Netz und am Mesenterium sieht man weisse Auflagerungen leichteren Grades. Auch frei in der Bauchhöhle liegende Flöckchen werden gefunden. An der abdominalen Seite des Zwerchfells ist der Belag besonders stark auf dem Centrum tendineum, so dass diese Partie im ganzen weiss aussieht, während auf dem muskulären Zwerchiellabschnitt der Belag weniger stark entwickelt ist. Die Pleuraseite des Zwerchfells ist glatt wie die übrige Pleura.

Die Lunge zeigt dunkelrote Flecke auf der Oberfläche. Auf der Schnittfäche merkt man hier und da dunkelrote Herde in ziemlich grosser Ausdehnung.

Die bakteriologische Untersuchung der Bauchhöhle ergibt Keimfreiheit.

Mikroskopische Untersuchung: An der Oberfäche der Leber findet man im allgemeinen eine deutliche Verdickung der Kapsel. Die Endothelzellen überziehen wie normal als schmale Streifen in guter Anordnung die Oberfläche der Leber. An vielen Stellen der Oberfläche bemerkt man aber auch viele kleine knospenartige Fortsätze. Diese Fortsätze bestehen aus gefässhaltigem Bindegewebe und einem endothelialen Ueberzug, der stellenweise eine mehrschichtige Wucherung zeigt. In diesen kleinen bindegewebigen Fortsätzen bemerkt man kleine Hohlräume, die mit Fett erfüllt sind. An anderen Stellen der Leberoberfläche trifft man dagegen noch eine deutliche Maschenbildung, welche meistens mit schmalem Stiel an der Oberfläche der Leber primär haftet. Dieses Netzwerk besitzt noch grosse Hohlräume, welche stark mit Fett erfüllt sind. Die Septen der Hohlräume bestehen aus Bindegewebe. Die Kapillargefässe liegen massenhaft in diesen Septen, besonders mehr nach der Oberfläche zu sind sie an einigen Stellen sehr stark erweitert. Die Wand der Hohlräume wird aus den langgestreckten Endothelzellen, welche an vielen Stellen in Haufen liegen, gebildet. Zuweilen trifft man in diesen Haufen von Endothelzellen degenerative Vorgänge insofern, als die Zellen dort undeutliche Zellgrenzen zeigen und nur schwach und ungleichmässig gefärbte Kerne haben. Diese Haufen von Endothelzellen findet man auch reichlich an den oberen Partien der Auflagerung. Die Oberfläche der Auflagerung wird von Epithelzellen überzogen, welche stellenweise noch deutliche mehrschichtige Wucherung zeigen. Fibrin liegt spurenweise in der Auflagerung; an den kleinen knospenartigen Fortsätzen findet man Fibrin überhaupt nicht. Das Leberparenchym selbst zeigt keine nennenswerten Veränderungen. Leukozyteninfiltration ist an keiner Stelle mehr nachweisbar.

An der abdominalen Seite des Centrum tendineum des Zwerchfells sieht man noch eine starke Auflagerung, die beinahe die ganze Fläche desselben überzieht. Diese Auflagerung haftei teilweise mittels eines schmalen Stieles an der Oberfiäche des Zwerchfells. Am Stiel der Auflagerung sieht man eine bedeutende Entwickelung von Bindegewebsfasern, die eine Fortsetzung des subserösen Gewebes darstellen. 
Die Oberfläche der Auflagerung ist mit Endothelzellen überzogen, welche an manchen Stellen mehrschichtig gewuchert sind, An der oberen Partie der Auflagerung bemerkt man Haufen von Endothelzellen, welche mit deu die Oberfläche überziehenden mehrschichtigen Endothelzellen in direkter Verbindung stehen. In diesen Haufen sind noch kleine Hohlräume vorhanden, die ohne Zweifel ein Ueberbleibsel früherer von Endothelzellen und Fibrinnetz begrenzter grosser Hohlräume darstellen. Manchmal sind auch nur noch Haufen von Endothelzellen ohne HohIräume anzutreffen. Die Endothelien der Zellhaufen zeigen of degenerative Vorgänge; ihre Zellgrenzen sind undeutlich und ihre Kerne sind oft in Körnchen zerfallen sowie nur schwach und ungleichmässig gefärbt. Zuweilen sieht man riesenzellenartige Bildungen, offenbar durch Zusammenfliessen von Zellen entstanden. Bindegewebsreiche Partien mit vereinzelten ölerfüllten Hohlräumen wechseln ab mit regelmässig gebautem Maschenwerk, das in seinen vielen Hohlräumen emulgiertes Oel enthält. Die Septen des Maschenwerkes bestehen aus gefässhaltigem Bindegewebe. Die Innenfläche der Hohlräume ist von Endothelzellen ausgekleidet, die an manchen Stellen Zellhaufen bilden oder die beschriebene zottenartige Form angenommen haben. In den Septen des Maschenwerkes werden auch vereinzelt Haufen von Endothelzellen mit kleinen Hohlräumen sowie Riesenzellen beobachtet. Am muskulären Teil des Zwerchfells ist der Befund etwas anders als am Centrum tendineum. Man bemerkt hier eine starke Verdickung des subserösen Gewebes infolge von Bindegewebswucherung. An der Oberfläche haben sich viele zottige Anhänge gebildet, so dass die Oberfläche ihr glattes Aussehen verloren hat. Diese zottigen Wucherungen haben ein Gerüst gefässhaltigen Bindegewebes als Ausläufer des subserösen Gewebes und einon peritonealen Ueberzug. Selten trifft man am spitzen Teil der zottigen Wucherung noch ölhaltige Hohlräume an und daneben Haufen von Endothelzellen. An der Pleuraseite des Zwerchfells findet man auch mikroskopisch keine Veränderungen.

Das Netz ist im allgemeinen bindegewebsreich. Bei der Sudanfärbung zeigt das Grundgewebe desselben einen ziemlich reichlichen Fettgehalt, aber an der Oberfläche des Netzes liegt Fett in feinen Tröpfchen intra- und interzellulär. Die Oberfläche des Netzes zeigt nur stellenweise eine zotten- oder polypenartige Wucherung, die aus gefässhaltigem Bindegewebe und einem endothelialen Ueberzug besteht.

An der Serosa der Bauchwand trifft man ebenfalls kleine knospenartige bindegewebige Wucherungen mit endothelialem Ueberzug. Nur selten zeigen sich an der oberen Partie der Wucherung Haufen von Endothelzellen mit kleinen Hohlräumen, die noch nachweisbare Oeltropfen enthalten. Die Verdickung des subperitonealen Gewebes infolge von Binwegewebswucherung ist auch hier sehr deutlich.

Die Auflagerungen der Dickdarm- und Milzoberfläche bieten ein ähnliches Bild wie die der Leber. Die Milzkapsel ist durch Wucherung des Bindegewebes deutlich verdickt. Die Serosa des Magens und Dünndarms ist nicht nemnenswert verändert.

An der Lunge erweisen sich die schon mikroskopisch sichtbaren Herde als Infiltrationsherde von Leukozyten, welche zugleich auch die Alveolen ausfüllen. Bei der Fettfärbung findet man nur spärlich Fetttropfen in den Gefässen, so dass eine Fettembolie der Lunge bei diesem Tier ausgeschlossen werden kann. 
Nr. 25. Männliches Kaninchen, $1450 \mathrm{~g}$ schwer.

Oelinjektion 17. IX. 1912. Menge des Kampferöls $7 \mathrm{ccm}$.

Verlauf; Am 23. X. wurde das Tier tot im Stall gefunden, ohne dass ein vorhergehendes Kranksein bemerkt worden war.

Sektion: 23. X. 1912, $1480 \mathrm{~g}$ schwer (30 g Gewichtszunahme).

Befund: Keine adhäsiven Veränderungen und keine freie Flüssigkeit in der Bauchhöhle. Am parietalen und viszeralen Peritoneum ist gleichfalls ein schleierartiger Ueberzug zu sehen. An der Abdominalseite des $Z$ werchfells findet man einen stark entwickelten Belag, und zwar besonders hochgradig wieder auf dem Centrum tendineum. An der Leber findet man einen Belag auf der oberen und unteren Fläche derselben sowie in der Nähe des hinteren Leberrandes auffallend reichlich. Am Dickdarm und an der hinteren Bauchwand ist der Belag in geringerer Menge vorhanden, am Netz aber deutlich in die Augen fallend, an einigen Stellen mit polypöser Wucherung. Am Mesenterium, am Magen und am Dünndarm sieht man nur kleine punktförmige weisse Auflagerungen.

Die Pleuraseite des Zwerchfells ist glatt, ebenso wie die übrige Pleura.

Die Lunge zeigt keine Besonderheiten.

Mikroskopische Untersuchung: An der abdominalen Seite des Zwerchfells deckt das ganze Centrum tendineum, partiell auch auf den muskulären Teil übergreifend, ein stark entwickeltes, mit Oeltropfen erfülltes Netzwerk. Die Auflagerung haftet mit breiter Basis auf dem Zwerchfell. Haufen von Endothelzellen mit den beschriebenen degenerativen Vorgängen sind deutlich. In der Grundschicht der Auflagerumg bemerkt man regelmässig erweiterte, an der Innenfläche mit Endothelzellen ausgekleidete Hohlräume. Diese Grundschicht geht ohne scharfe Grenze in das subseröse Gewebe über, wo das Bindegewebe verdickt ist. An der muskulären Partie sieht man niedrige polypöse Wucherungen in grosser Ausdehnung. Diese Wucherungen bestehen wieder aus einem bindegewebigen Grundstock und einem endothelialen Ueberzug. Das Bindegewebe der polypösen Bildungen birgt kleine Haufen von Endothelzellen, die ihrerseits wiederum kleine mit Oeiresten erfüllte Hohlräume umschliessen.

Der Befund an der Leber, Milz, am Dickdarm und an der hinteren Bauchwand ist ganz analog dem bei Kaninchen $\mathrm{Nx} .24$ angegebenen Befunde.

An der lunge findet man auch mikroskopisch keine nennenswerten Veränderungen, nur hier und da lassen sich kleine Oeltropfen in den Blutgefässen nachweisen. Es ergibt sich überhaupt kein Anhaltspunkt dafür, dass die vor 5 Wochen erfolgte intraperitoneale Kampferölinjektion mit dem Tode des Tieres in ursächlichem Zusammenhange steht.

Nr. 26. Männliches Kaninchen, $1570 \mathrm{~g}$ schwer.

Oelinjektion 17. IX. 1912. Menge des Kampferöls 7,5 com.

Verlauf: Exitus an Enteritis am 23, X. 1912.

Sektion: 23. X. 1912, $995 \mathrm{~g}$ schwer (575 g Gewichtsverlust).

Befund: Keine treie Flüssigkeit und keine adhäsiven Veränderungen. Ein schleierartiger Ueberzug erstreckt sich über das ganze Peritoneum. Hochgradige, dicke, weisse Auflagerungen finden sich am Dickdarm, in geringerer Menge und Stärke am Dünndarm. An der Serosa der hinteren Bauchwan sieht man massenhaft zottige, weisse Auflagerungen. Auf 
dem Peritoneum findet man frei gewordene Flöckchen. Auf der Leber lagert ein weisser Belag, besonders auf der Oberfläche und Unterfläche in der Nähe des hinteren Randes. Hier ist der Belag gewöhnlich flach. An der Milz sieht man selten weisse Auflagerungen.

Die Abdominalseite des Zwerchfells zeigt einen inselartigen, weissen Belag, nicht nur auf dem Centrum tendineum, sondern auch sehr deutlich auf dem muskulären Abschnitt. Die Pleuraseite des Zwerchfells. ist glatt wie die übrige Pleura.

Die Lunge ist normal. freiheit.

Die bakteriologische Untersuchung der Bauchhöhle ergibt Keim-

Mikroskopische Untersuchung: Die Veränderungen sind fast die gleichen wie bei Kaninchen Nr. 25. Nur ein kleiner Unterschied besteht darin, dass die Auflagerung am Zwerchfell eine sehr deutliche. Maschenbildung mit zarten Septen zeigt. Die Septen bestehen zunächst aus den langgestreckten fadenartigen Ausläufern der Endothelzellen. Gefässhaltiges Bindegewebe ist in geringerer Menge als bei Nr. 25 vorhanden. In den oberen Bezirken des Maschenwerkes sieht man auch Haufen von Endothelzellen und Riesenzellen. Das Maschenwerk zeigt. in seiner Grundschicht regelmässige dichte Struktur, wie ich sie bei den anderen Kaninchen der Versuchsgruppe geschildert habe, während es an der oberen Partie der Auflagerung ungleichmässig ist. Auf dem. muskulären Teil des $Z$ werchfells bemerkt man eine niedrige bindegewebige Wucherung, welche einen endothelialen Ueberzug hat, und man trifft selten in diesem Grundgewebe ölhaltige kleine Hohlräume und Haufen von Endothelzellen. Das subseröse Gewebe des Zwerchfells ist im allgemeinen verdickt. Die Pleuraseite des Zwerchfells lässt. mikroskopisch keine Veränderungen erkennen.

An der Milz findet man eine deutliche Verdickung der Kapsel. Die sonstigen Veränderungen an den rerschiedenen noch nicht erwähnten Organen gleichen denen bei Kaninchen No. 25 völlig. Bei der. Sudanfärbung erkennt man eine geringe Menge von resorbiertem Oel in den Gefässen.

Epikrise: 4 bis 5 Wochen nach der intraperitonealen Kampferölinjektion sind die reaktiven Veränderungen am Peritoneum fast übercinstimmend mit denen bei Kaninchen Nr. 23 in der vorigen XII. Gruppe. Die Bindegewebsentwickelung in der Auflagerung ist immer stärker geworden; und damit geht parallel ein immer mehr zunehmender Untergang des Maschenwerkes. Die in Degeneration begriffenen Endothelzellen bilden Haufen von Riesenzellen. Oft präsentiert sich das Bindegewebe in Form von breiten Streifen.

Die Todesursache des ersten Tieres dieser Gruppe Nr. 24 war ohne Zweifel eine Pneumonie. Bei Kaninchen Nr. 25 war die Todesursache unklar und Kaninchen Nr. 26 litt an einer schweren Enteritis. Bei allen 3 Tieren konnte man Fettembolie der Lunge. als Todesursache ausschliessen. 


\section{Gruppe.}

Untersuchung der drei Tiere (Nr. 27, 28 und 29) 5 Wochen nach der intraperitonealen Kampferölinjektion.

Nr. 27. Männliches Kaninchen, $2000 \mathrm{~g}$ schwer.

Oelinjektion 18. IX. 1912. Menge des Kampferöls $=10 \mathrm{ccm}$.

Verlauf: Gestorben am 23. X. 1912, nachdem es seit einigen Tagen ganz still geworden war und ein schwerkrankes Aussehen gezeigt hatte.

Sektion: 23. X. $1912.1480 \mathrm{~g}$ schwer (520 g Gewichtsverlust).

Befund: Keine freie Flüssigkeit und keine adhäsiven Veränderungen in der Bauchhöhle. Das Peritoneum zeigt ein leicht weisshliches Aussehen. Weisser Belag mit einem Stich ins Gelbliche ist an der Serosa der hinteren Bauchwand zu beobachten, an der Leber, an der Milz und besonders stark am Centrum tendineum der Abdominalseite des Zwerchfells. An der Oberfläche des fettreichen Netzes sieht man ebenfalls den gelblich-weissen Belag, sowie spärliche polypöse Wucherungen.

Auf dem Dickdarm, dem Magen, Dünndarm und am Mesenterium haften weisse Auflagerungen von geringerer Dicke.

In der Pleurahöhle bemerkt man feste Verklebungen zwischen den beiden Pleurablättern, die sich anch anf die Pleura diaphragmatica erstrecken. Die Lunge zeigt an verschiedenen Stellen der Schnittläche ausgebreitete Infiltrationsherde.

Die bakteriologische Kontrolle der Bauchhöhle ergibt Keimfreiheit.

Mikroskopische Untersuchung: An der abdominalen Seite

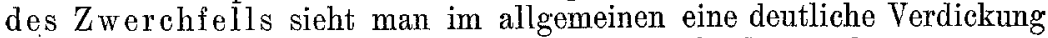
des subserösen Bindegewebes. An der Oberfläche lagert hier ein ausgedehntes Netzwerk stärker auf dem Centrum tendineum, als auf dem muskulären Zwerchfellabschnitt. Die Septen des Netzwerkes bestehen aus gefässhaltigem Bindegewebe. Hier und da trifft man in den Septen Haufen von Endothelzellen mit und ohne Hohlräume; die Zellen zeigen meist Degenerationserscheinungen, Kernzerfall und Neigung zur Riesenzellenbildung. Den allmählichen Uebergang vom Maschenwerk der Endothelzellen bis zur Riesenzellbildung findet man besonders an der oberen Partie der Auflagerung, deren Oberfläche wie sonst mit Endothelzellen überzogen ist. Unter dem endothelialen Ueberzug ist das Fibrin, das in den früheren Stadien an dieser Stelle regelmässig in grosser Menge zu finden war, durch breite Streifen von Bindegewebe ersetzt. Am muskulären Abschnitt des Zwerchfells treten die Veränderungen der Oberfläche gegenüber der Verdickung des subserösen Bindegewebes sehr zurück. Die Pleuraseite des Zwerchfells weist an der Oberfläche ein stark fibrinhaltiges, leukozytenreiches Granulationsgewebe auf. An der Serosa der Bauchwand ist das subperitoneale Gewebe infolge von Bindegewebswucherung stark verdickt und enthält dicht gelagerte Kapillargefässe. An die Oberfläche der Bauchwand hat das subperitoneale Bindegewebe vielfach mit Endothelzellen bekleidete zottige Fortsätze entsandt. In der bindegewebigen Grundsubstanz findet man auch Reste von Hohlräumen, die von degenerierten, meist zu Riesenzellen umgewandelten Endothelzellen begrenzt werden. In den Hohlräumen kann man noch Oel in geringer Menge nachweisen. Neben diesen Hohlräumen liegen stark erweiterte Blutgefässe und auch ölgefüllte Lymphgefässe. An anderen Stellen der Parietalserosa kann man auch 
noch deutliche Maschenbildung beobachten. Dieses Maschenwerk besteht aus einem gefässhaltigen Bindegewebsnetz mit vielen Hohlräumen verschiedenster Grösse. In den bindegewebigen Septen laufen überall stark gefüllte Blutgefässe, Die Innenfläche der Hohlräume ist mit verschieden geformten Endothelzellen überzogen. In den grösseren Hohlräumen sind die Endothelzellen lang gestreckt, an anderen Stellen bilden sie Haufen oder sind zu riesenzellenähnlichen oder synzytiumartigen Gebilden konfluiert. Besonders in den oberen Partien der Auflagerung sieht man meist kleinere Hohlräume, die von nebeneinander tiegenden, aufgequollenen und oft vakuolenhaltigen Endothelzellen begrenzt sind und noch Fett enthalten, Aber auch stärker verändertes Maschenwerk wird angetroffen, mit Schwund der Hohlräume nach erfolgter Resorption des dort eingekapselten Oelmaterials. Hier und da kann man zwischen den in Degeneration begriffenen, vakuolenhaltigen Zellen noch Zellgrenzen erkennen, während diese bei anderen Zellhaufen vollkommen fehlen, und so das Bild ron Riesenzellen resultiert (siehe Fig. 4). Stellenweise bemerkt man auch grosse Protoplasmamassen mit völligem Kernschwund. An der Oberfläche ist die Auflagerung auf der Parietalserosa mit einer schmalen Schicht mehrschichtigen Endothels iiberzogen.

Auf dem Dickdarm sieht man ebenfalls verschiedene Veränderungen. Im allgemeinen ist das subseröse Gewebe deutlich durch die Bindegewebswucherung verdickt. An einzelnen Stellen der Oberfläche bemerkt man eine mehrschichtige Zellwucherung; an anderen eine zotten- oder knospenartig Wucherung mit bindegewebeartigem Grundstock und endothelialem Ueberzug, an noch anderen Partien der Dickdarmserosa in grosser Ausdehnung ein stark entwickeltes Maschenwerk, vom Aufbau des am Zwerchfell und an der Bauchwand gefundenen Maschenwerkes.

Au der Milz sieht man eine stark verdickte Kapsel, an der Oberfiäche hier und da knospenartige Fortsätze, bestehend aus dichtem Bindegewebe und einem Ueberzuge von schmalen Endothelzellen, und nicht selten eine mehrschichtige Wucherung der Endothelzellen.

Das Netz ist zu einer dichten bindegewebigen Masse umgewandelt. Auf seiner Oberfläche sieht man ebenfalls viele bindegewebige Fortsütze mit endothelialem Ueberzug. In diesen Wucherungen sind auch noch kleine oder mittelgrosse Hohlräume mit verschieden geformten Endothelzellen zu erkennen.

An der Leberoberfläche haftet wie am Zwerchfell in grosser Ausdehnung Maschenwerk, zum kleineren Teil festsitzend mit einem Stiel, zum grösseren Teil locker angefügt, so dass es sich an vielen Stellen schon wieder von der Oberfläche abgelöst hat. Das Maschenwerk der Leberoberfläche ist ganz so gebaut, wie das des Zwerchfells und das der Bauchwandserosa.

Die reaktiven Veränderungen an der Serosa des Magens und des Dünndarms sind nur gering.

Die an der Lunge schon makroskopisch sichtbaren Infiltrationsherde weisen mikroskopisch Unmengen von Fibrin, Leukozyten und abgestossenen Alveolenepithelien auf. Die Sudanfärbung lässt in den Blutgefässen der Lunge mur ganz vereinzelte kleine Oeltröpfchen erkennen.

Nr. 28. Weibliches Kaninchen, $1350 \mathrm{~g}$. schwer.

Oelinjektion 19. IX. 1912. Menge des Kampferöls $=7 \mathrm{ccm}$.

Verlauf: Einige Stunden hindurch verhielt sich das Tier nach der Oelinjektion still, war aber dann in der Folgezeit sehr munter. 
Sektion: 24. X. 1912, $1510 \mathrm{~g}$ schwer (160 g Gewichtszunahme).

Befund: Keine adhäsiven Veränderungen und keine freie Flüssigkeit in der Bauchhöhle. Das Peritoneum ist etwas weisslich getrübt. Den bei Kaninchen Nr. 27. notierten gelblich-weissen Belag findet man bei diesem Tier am Dickdarm, an der Leber, an der hinteren Bauchwand und besonders stark an der abdominalen Seite des Zwerchfells. Zwischen den Belägen ist das Zwerchfell leicht weisslich getrübt. Am Netz sieht man auch eine ziemlich beträchtliche weisse Auflagerung, während Milz, Magen und Dümndarm wesentlich geringere Veränderungen zeigen.

Die Pleuraseite des Zwerchfells ist glatt, wie die übrigen Teile der Pleura. An der Lunge sind keine Besonderheiten zu bemerken.

Die bakteriologische Untersuchung der Bauchhöhle ergibt Keimfreiheit.

Mikroskopische Untersuchung: An der Abdominalseite des Zwerchfells haftet die ausgebreitete Auflagerung wie bei Kaninchen Nr. 27 teils fest mit einem Stiel, teils liegt sie der Zwerchfelloberfläche nur locker an. Díe Struktur der Auflagerung ist fast die gleiche wie bei Kaninchen $\mathrm{Nr} .27$.

An dem Maschenwerk kann man hier auch 2 Schichten unterscheiden. In der oberen Schicht. in der Nähe der Oberfläche sind sehr ungleichmässige kleine Hohlräume vorhanden, daneben stellenweise Haufen von Endothelzellen, die vielfach Degenerationserscheinuingen zeigen. Diese Zellhaufen umschliessen manchmal noch kleine Hohlräume. Oft trifft man auf riesenzellenartige Gebilde.

Die andere Art der Maschenbildung findet man nur in der Grundschicht der Auflagerung. lhre Wand wird von den langgestreckten Endothelzellen gebildet. Die Septen des Maschenwerkes bestehen aus gefässhaltigem Bindegewebe. Hier und da zeigen sich in den Septen Haufen von Endothelzellen, vielfach mit Degenerationserscheinungen. Unter dem endothelialen Ueberzuge der Auflagerung bemerkt man einen breiten Streifen von Bindegewebe, der noeh 'Reste des zurückgebildeten Maschenwerkes beherbergt. Besonderes Interesse bietet hier eine Beobachtung am Stiel der Auflagerung und an dem darunter gelegenen subserösen Gewebe. Man sieht hier, wie sich das Netzwerk in das Grundgewebe des Centrum tendineum direkt fortsetzt und an einigen Stellen bis in das subseröse Gewebe der Pleuraseite zu verfolgen ist. Dieses, das Zwerchfell in seiner ganzen Dicke durchsetzende, Netzwerk ist regelmässig aufgebaut, die Innenfläche der erweiterte Lymphgefässe darstellenden Hohlräume ist mit Endothelzellen gut ausgekleidet. Stellenweise sieht man aber auch hier Haufen von Endothelzellen and Riesenzellen an der Wand der Hohlräume.

Um Wiederholungen $\mathrm{zu}$ vermeiden, verweise ich bezüglich der mikroskopischen Befunde an der Serosa der Bauchwand, am Dickdarm, an der Milz, am Netz und an der Leber und bezüglich der sehr geringen reaktiven Veränderungen an der Serosa des Magens und Dünndarmes auf die genaue Beschreibung der vollkommen entsprechenden Befunde bei Kaninchen $\mathrm{Nr} .27$.

Der Lungenbefund bietet auch mikroskopisch nichts von der Norm Abweichendes. Nur spärliche Mengen von Oeltropfen zirkulieren in den Lymphgefässen.

Nr. 29. Männliches Kaninchen, $1230 \mathrm{~g}$ schwer.

Oelinjektion 19. IX. 1912. Menge des Kampferöls $6 \mathrm{ccm}$.

Verlauf: Ungestört.

Sektion: 24. X. 1912, $1250 \mathrm{~g}$ schwer (20 g zugenommen). 
Befund: In der Bauchhöhle zeigt sich eine ziemlich reichliche Menge klarer Flüssigkeit. Adhäsive Veränderungen sind nicht vorhanden. Von einem tauartig aussehenden Ueberzug am Peritoneum ist nichts mehr zu bemerken. Freilich sieht das Peritoneum gegenüber der Norm etwas weisslich getrübt aus.

Gelblich-weisser Belag findet sich in grosser Menge teils zottig, teils in flacher Form an der Abdominalseite des Zwerchfells, links besonders stark, ferner am Peritoneum der hinteren Bauchwand, am Dickdarm, an der Leber, am Netz und am Mesenterium, während an der. Milz geringere und am Magen und Dünndarm fast gar keine reaktiven Veränderungen wahrgenommen werden.

Die Pleuraseite des Zwerchfells ist glatt wie die übrige Pleura. Die Lunge bietet keinerlei Besonderheiten.

Die bakteriologische Untersuchung der Bauchhöhle ergibt ein negatives Resultat.

Der mikroskopische Befund an dem Parietal- und Viszeralperitoneum stimmt in allen wesentlichen Punkten mit den bei Kaninchen Nr. 27 und 28 beschriebenen Befunden überein.

Das Lungengewebe bietet auch mikroskopisch nichts Abnormes.

Epikrise. 5 Wochen nach der intraperitonealen Kampferölinjektion sind bei allen 3 Tieren dieser Versuchsgruppe die reaktiven Veränderungen am Peritoneum noch sehr stark ausgeprägt. Der tauartige Ueberzug ist im allgemeinen weisslich getriubt. Das Stadium der Auflagerungen ist an den verschiedenen Stellen der Peritonealserosa verschieden und auch in seinem Bezirk wechselod. Die Wucherung des Bindegewebes und der Untergang des Maschenwerkes an der oberen Partie der Auflagerung werden zusehends immer stärker. Der Oeltransport in die tiefer gelegenen Lymphbahnen hat zugenommen und damit hat sich die an der Peritonealoberfäche eingekapselte Oelmenge bedeutend vermindert. Mit dem Fortschaffen der aufgestapelten Oelmassen wird das einscheidende Gewebe überflüssig und fällt der Degeneration anheim. Immer sind die Auflagerungen von Endothel bekleidet, wodurch das Fehlen von Adhäsionen durchaus verständlich wird. Kaninchen Nr. 27 ist sicher einer Pleuropneumonie erlegen, die mit grosser Wahrscheinlichkeit keinen Zusammenhang hat mit der 5 Wochen früher vorgenommenen Oelinjektion.

\section{Gruppe.}

Tötung der beiden Tiere (Nr. 30 und 31) 6 Wochen nach der intraperitonealen Kampferölinjektion.

Nr. 30. Männliches Kaninchen, $1010 \mathrm{~g}$ schwer.

Oelinjektion 19. IX. 1913. Menge des Kampferöls $5 \mathrm{ccm}$.

Verlauf: Nur wenige Stunden hindurch war das Tier nach der Oelinjektion still, von da ab dauernd munter.

Sektion: 31. X. 1912, $1250 \mathrm{~g}$ schwer (240 g Gewichtszunahme). 
Befund: In der eröffneten Bauchhöhle findet man keine freie Flüssigkeit. Entsprechend der Operationswunde ist ein kleiner Narbenbruch entstanden, in dessen Bruchsack ein Netzabschnitt adhärent ist. Im übrigen ist die Bauchhöhle frei von adhäsiven Veränderungen. Das parietale und viszerale Peritoneum sind im allgemeinen leicht weisslich getrübt, nur hier und da hat das Peritoneum noch ein tauartiges Aussehen.

Gelblich weisser Belag haftet an der Bauchwandserosa, am Dickdarm, an der Leber, am Netz und besonders an der abdominalen Seite des Zwerchfells, stellenweise an der Milz und am Mesenterium.

Die Pleuraseite des Zwerchfells ist glatt wie die übrige Pleura. Die Lunge ist normal.

Mikroskopische Untersuchung: An der abdominalen Seite des Zwerchfells findet sich ein ausgedehntes Maschenwerk, dessen Septen aus gefässhaltigem Bindegewebe bestehen. An der oberen Partie der Auflagerung bildet das Bindegewebe einen breiten Streifen. Blutgefässe sind im ganzen Maschenwerk verbreitet: Die Oberfläche der Auflagerung ist von schmalen, selten mehrschichtig gewucherten Endothelzellen überzogen. Die Grundpartie der Auflagerung. bildet wieder ein regelmässig erweitertes Netzwerk mit endothelausgekleideten Maschen. Das Zwerchfell ist in seiner ganzen Dicke, also bis zur Pleuraseite, von erweiterten Lymphbahnen durchsetzt wie bei den Tieren der vorigen XIV. Versuchsgruppe, ohne dass der Endothelüberzug der Pleura diaphragmatica Veränderungen progressirer Art zeigt. Bei der Sudanfärbung sieht man Oel im Maschenwerk and in den erweiterten Lymphgefässen. In den oberen Bezirken der Auflagerung ist nur noch wenig Oel in kleinen Hohlräumen von Maschenwerkresten zu finden sowie intra- und interzellulär. Fibrin lässt sich im Naschenwerk überhaupt nicht mehr nachweisen.

An der Milz mit ihrer deutlich verdickten Kapsel hat die Auflagerung eine mehr flache Form und besteht aus dicht gefügtem Bindegewebe und einem endothelialen Ueberzug.

Das Netz mit seinem an vielen Stellen bindegewebsreichen Grundgewebe trägt an seiner Oberf̈äche zotten- oder knospenartige .Wucherungen aus endothelüberzogenem gefässhaltigem Bindegewebe.

Am Dickdarm ist das subseröse Gewebe durch die Bindegewebswucherung deutlich verdickt. An der Oberfläche haften zotten- oder knospenartige Wucherungen von dem bekannten Bau.

An der Leberoberfläche wechselt das mikroskopische Bild der Auflagerungen. Sie bilden zum Teil eine ganz flache Bindegewebslage mit kleineren und grösseren öIgefïllten Hohlräumen, an anderen Stellen haben sie die Form von zotten- oder knospenartigen Fortsätzen. Die Zotten und Knospen bestehen aus einem bindegewebigen Grundgewebe, das peripher dicht gefügt ist und Maschenwerkreste erkennen lässt, weiter nach dem Innern $z u$ aber ein lockeres Gefüge aufweist und erweiterte Lymphgefässe birgt. An noch anderen Stellen der Leberoberfäche stellt die Auflagerung ein Netzwerk dar, dessen obere Partie dichte Maschenbildung und Haufen degenerierter Endothelzellen und auch Riesenzellen zeigt, in dessen basalen Abschnitten aber grössere Hohlräume liegen. Gefässhaltiges Bindegewebe ist stellenweise in breiten Streifen, vor allem in der Nähe der endothelbekleideten Oberfläche vorhanden.

An der Bauchwandserosa bemerkt man deutliche Verdickung: des Bindegewebes und auf der Oberfläche viele zottige oder knospen- 
artige Auflagerungen verschiedener Grösse. Die grösseren Zotten und Knospen haben wieder, wie an der Leberoberfläche, ein peripher dicht angeordnetes Bindegewebe mit Resten eines frïheren Maschenwerkes (Endothelzellhaufen mit und ohne Hohlräume und Riesenzellen), in den zentralen Abschnitten dagegen ein lockeres Bindegewebe mit grossen Hohlräumen. Die grossen Hohlräume lassen sich in den Stiel der Auflagerung verfolgen und bis zu den resorbiertes Oel führenden erweiterten Lymphgefässen des subperitonealen Gewebes.

Im Lungengewebe werden auch mikroskopisch keine pathologischen Veränderungen wahrgenommen.

Nr. 31. Weibliches Kaninchen, $950 \mathrm{~g}$ schwer.

Oelinjektion 19. IX. 1912. Menge des Kampieröls $=5 \mathrm{ccm}$.

Verlauf: Ungestört.

Sektion: 31. X, 1912, $1090 \mathrm{~g}$ schwer (140 g Gewichtszunahme).

Befund: Nirgends adhäsive Veränderungen in der Bauchhöhle. Geringe Mengen einer klaren, gelblichen Flïssigkeit entleeren sich aus dem Bauchraum. Das Peritoneum ist glatt und nicht weisslich getrübt. Am Dickdarm, an der unteren Fläche der Leber, an der unteren Partie der Milz und an der Abdominalseite des Zwerchfells sieht man kleine fleckige, gelblich-weisse Auf lagerungen in geringer Zahl.

Pleura diaphragmatica und Lunge bieten keine Besonderheiten.

Die bakteriologische Untersuchung der Bauchhöhle ergibt Keimfreiheit.

Der mikroskopische Befund an den verschiedenen Stellen des Parietal- und Viszeralperitoneums gleicht dem von Nr. 30 fast vollkommen. Nur sind die reaktiven Veränderungen, wie schon bei der makroskopischen Beschreibung hervorgehoben ist, viel schwächer ausgeprägt.

Das Lungengewebe lässt auch mikroskopisch nichts Krankhaftes erkennen.

Epikrise: Die reaktiven Veränderungen an der Peritonealserosa sind auch 6 Wochen nach der intraperitonealen Kampferölinjektion noch deutlich ausgeprägt, stärker bei Kaninchen Nr. 30 als bei Nr. 31. Der Transport des Oels in die abführenden Lymphbahnen und der Ersatz des regressive Veränderungen durchmachenden zelligen Maschenwerkes durch Bindegewebe schreiten sichtlich fort. Auf die Oelinjektion zu beziehende Adhäsionen sind auch bei den beiden Tieren dieser Versuchsgruppe nicht gefunden. Die Netzadhäsion in einer kleinen Bauchnarbenhernie bei Kaninchen Nr. 30 hat natürlich mit der Oelinjektion ätiologiseh nichts zu tun.

\section{Gruppe.}

Tötung der beiden Tiere (Nr. 32, u. 33) 7 Wochen nach der intraperitonealen Kampferölinjektion.

Nr. 32. Männliches Kaninchen, $1270 \mathrm{~g}$ schwer.

Oelinjektion 18. X. 1912. Menge des Kampferöls $=6 \mathrm{ccm}$.

Verlauf: Ungestört.

Sektion: 6. XII. 1912, $1830 \mathrm{~g}$ schwer (560 g. Gewichtszunahme). 
Befund: Aus der eröffneten Bauchhöhle entleert sich eine geringe Menge einer klaren, gelblichen Flüssigkeit. Nirgends adhäsive Veränderungen. An der Abdominalseite des Zwerchfells ist auf eine grosse Strecke hin, sowohl auf dem Centrum tendineum als auch auf dem muskulären Abschnitt eine gelbgrau gefärbte, rauhe Auflagerung zu sehen.

Auflagerungen von gleicher Farbe und Beschaffenheit finden sich an der Bauchwandserosa, am Dickdarm, an der Leber und an der Milz.

Die Pleuraseite des Zwerchfells ist glatt wie die übrige Pleura.

Die Lunge ist normal.

Die bakteriologische Kontrolle der Bauchhöhle ergibt Keimfreiheit.

Mikroskopische Untersuchung: Die abdominale Oberfläche des Zwerchfells zeigt in grosser Ausdehnung eine bindegewebige Wucherung, teils zottenartig, teils mehr flach mit einem einzeiligen Ueberzug von Endothelzellen. Nur selten ist eine mehrschichtige Wucherung der Endothelzellen anzutreffen. In der bindegewebigen Grundschicht sieht man hier und da verschieden weite Hohlräume. Ihre Wände sind bekleidet mit niedrigen Endothelzellen, seltener von bandartigen oder riesenzellenartigen Zellgebilden. Die Gestalt der Hohlräume ist meist rundlich, oft aber auch länglich oder spaltförmig. Als letzte Reste des ursprünglichen Maschenwerkes sind nur noch sehr selten schattenartige Ueberbleibsel kleiner Endothelzellhaufen zu erkennen.

Bei der Sudanfärbung des Zwerchfells sieht man Oel in den Hohlräumen und in den erweiterten Lymphgefässen der Auflagerung, sowie in den Lymphbahnen des ganzen Zwerchfells sehr deutlich.

Am Dickdarm ist das subseröse Gewebe durch Bindegewebswucherung stark verdickt. Auf der Oberfläche sieht man zottige, bindegewebige Wucherungen, die denselben Bau zeigen wie die des Zwerchfells. Ebenso verhalten sich auch die bindegewebigen zottigen Wucherungen an der Bauchwandserosa. Reste von dem ursprünglichen Maschenwerk werden auch hier nur noch selten in Form von Riesenzellen angetroffen.

An der Leber und an der Milz ist die Kapsel deutlich verdickt. An der Oberfäuche dieser Organe sieht man kleine knospenartige Wucherungen. Sie bestehen aus Bindegewebe ohne Hohlräume und ohne Reste von Maschenwerk. Die Sudanfärbung lässt Oel im Bereiche der Auflagerung nur hier und da in ganz feinen Tröpfchen intra- und interzellulär erkennen. Auf der Oberfläche des bindegewebsreichen Netzes finden sich hier und da teils flache, teils knospenartige Wucherungen, deren Bindegewebe nur vereinzelt ungleichmässig erweiterte Hohlräume, aber keine Reste vom Maschenwerk mehr enthält.

Am Mesenterium, am Magen und Dündarm sind nur geringfügige Veränderungen zu konstatieren.

Das Lungengewebe zeigt auch mikroskopisch nichts Pathologisches. In den Lungengefässen kreisen nur kleine Oeltropfen (Sudanfärbung).

Nr. 33. Männliches Kaninchen, $1050 \mathrm{~g}$ schwer.

Oelinjektion 18. X. 1912. Menge des Kampferöls $=5 \mathrm{ccm}$.

Verlauf: Ungestört.

Sektion: 6. XII. $1912,1890 \mathrm{~g}$ schwer ( $840 \mathrm{~g}$ Gewichtszunahme).

Befund: Keine freie Flüssigkeit und keine adhäsiven Veränderungen in der Bauchhöhle. 
An der Abdominalseite des Zwerchfells sieht man rauhe Auflagerungen von gelbgrauer Farbe, in grossen Massen auf dem Centrum tendineum.

Aehnliche Auflagerungen befinden sich am Bauchwandperitoneum, am Netz, an der Leber, am Dickdarm, an der Milz und am Mesenterium, während sie am Dünndarm und am Magen fehlen. Pleura.

Die Pleura diaphragmatica ist glatt und spiegelnd wie die übrige

Die Lunge bietet keinen pathologischen Befund. freiheit.

Die bakteriologische Untersuchung der Bauchhöhle ergibt Keim-

Der mikroskopische Befund am Peritoneum gleicht dem bei dem Paralleltier Nr. 32 beschriebenen Befunde in allen wesentlichen Punkten, sowohl am Zwerchfell als auch an den übrigen untersuchten Stellen.

Am Lungengewebe wird auch mikroskopisch nichts Krankhaftes gefunden.

Epikrise: Die reaktiven Veränderungen am Parietal- und Viszeralperitoneum haben bei beiden Tieren dieser Versuchsgruppe (Nr. 32 und 33) 7 Wochen nach der intraperitonealen Kampferölinjektion eine starke Reduktion erfahren. Die Auflagerungen an den verschiedenen Organen, auch am Zwerchfell, bestehen durchweg fast lediglich aus Bindegewebe. Hohlräume, betreffs derer man nicht mehr unterscheiden kann, ob sie ein Rest des früheren Maschenwerkes sind oder als erweiterte zurückgebliebene Lymphgefässe aufzufassen sind, finden sich in nennenswerter Zahl nur noch am Zwerchfell. Ich halte diese Hohlräume der Mehrzahl nach für Lymphgefässe, weil daneben noch viele, aber kleine, in ganz gleicher Weise gebaute sicher als Lymphgefässe anzusprechende Räume beobachtet werden, und nicht nur in der Auflagerung, sondern auch überall in der Wand des Zwerchfells.

Adhäsionen wurden auch hier bei beiden Tieren in der Bauchhöhle nicht gefunden. Beide Tiere hatten an Gewicht sehr beträchtlich zugenommen.

\section{Gruppe.}

Tötung der beiden Tiere (Nr.34 u. 35) 8 Wochen nach der intraperitonealen Kampferölinjektion.

Nr. 34. Männliches Kaninchen, $1900 \mathrm{~g}$ schwer.

Oelinjektion 18. IX. 1912. Menge des Kampferöls $=9,5 \mathrm{ccm}$.

Verlauf: Ohne Störung.

Sektion: 13. XI. 1912, $2150 \mathrm{~g}$ schwer (250 g Gewichtszunahme).

Befund: Keine adhäsiven Veränderungen und keine freie Flüssigkeit in der Bauchhöhle. Das Peritoneum ist in weiter Ausdehnung etwas weisslich getrübt. Am parietalen Peritoneum findet man vielfach fest haftende, gelblichgraue Auflagerungen mit rauher Oberfäche. Gleichartige Auflagerungen von beträchtlicher Stärke bemerkt man an der 
abdominalen Seite des Zwerchfells, vor allem am Centrum tendineum, am Dickdarm und am Netz; grauweisse flache Auflagerungen am Leberrande und an der ganzen Konvexität der Milz.

Die Pleuraseite des Zwerchfells ist glatt wie die übrige Pleura. Die Lunge ist normal.

Mikroskopische Untersuchung: Das durch Bindegewebswucherung deutlich verdickte Wandperitoneum ist an vielen Stellen von gewuchertem Endothel bedeckt und zeigt vielfach kleinere und grössere knospen- oder polypenartige Wucherungen, die aus gefässhaltigem Bindegewebe und einem Endothelüberzug bestehen und nur noch selten Reste von Maschenwerk und kleine, endothelausgekleidete, ölhaltige (Sudanfärbung) Hohlräume erkennen lassen. In den Resten degenerierten Maschenwerkes wird auch noch intra- und interzellulär liegendes Oel, wenn auch nur in geringer Menge gefunden, ausserdem Zellen, die in ihrem Protoplasma feine gelb gefärbte Körnchen enthalten und ähnlich wie Luteinzellen aussehen.

An der Oberfläche der verdickten Dickdarmserosa sieht man wie am Wandperitonenm viele knospen- und polypenartige Wucherungen, freilich ohne Maschenwerkreste und ohne Oeltropfen.

Ebenso wenig werden noch Maschenwerkreste in den inselartigen Bindegewebswucherungen an der Oberfläche des äusserst bindegewebsreichen Netzes gefunden. Dagegen sind noch deutliche Maschenwerkreste mit und ohne Hohlräume, ferner Riesenzellen und als erweiterte Lymphgefässe anzusprechende Hohlräume mit Oelinhalt (Sudanfärbung) in den Auflagerungen der mässig verdickten Leberkapsel zu erkennen.

Die starken Auflagerungen an der Abdominalseite des $Z$ werchfells zeigen noch in grosser Ausdehnung ein deutliches von Endothel überzogenes Netzwerk, dessen Maschen sehr ungleichmässig gross, teilweise sehr gross sind. Daneben liegen in gefässreichem Bindegewebe auch Reste von Maschenwerk und Haufen in Degeneration begriffener Endothelzellen in allen Uebergängen bis zum Bilde von Riesenzellen. In den unteren Bezirken des Netzwerkes sind die Maschen von viel gleichmässigerer Grösse. Das regelmässig gebaute Netzwerk geht ohne scharfe Grenze in das Grundgewebe des Zwerchfells mit seinen erweiterten Lymphgefässen über, so dass sich die Hohlräume bis zum subserösen Gewebe der Pleuraseite verfolgen lassen. Fibrin ist nirgends mehr nachzuweisen. Bei der Sudanfärbung sieht man Oel in den Hohlräumen des Netzwerkes und reichlich in den erweiterten Lymphgefässen des Zwerchfellgrundgewebes bis hin zur Pleura diaphragmatica. Inter- und intrazellulär gelagerte Oeltropfen sind noch in den oberen, durch Maschenwerkreste dichter erscheinenden Bezirken der Auflagerung zu finden.

Auf der deutlich verdickten Milzkapsel bestehen die diffusen und die kleinen knospenartigen Wucherungen aus dicht angeordnetem Bindegewebe mit Maschenwerkresten und einem endothelialen Ueberzug.

Mesenterium, Dünndarm und Magen weisen weder in ihrem Gewebe noch an ihrer Oberfläche stärkere reaktive Veränderungen auf.

Das Lungengewebe bietet auch mikroskopisch nichts Pathologisches. Bei der Sudanfärbung sieht man geringe Mengen kleiner Oeltropfen in den Blutgefässen.

Nr. 35. Männliches Kaninchen, $2200 \mathrm{~g}$ schwer.

Oelinjektion 18. IX. 1912. Menge des Kampferöls $=10 \mathrm{ccm}$.

Verlauf: Ungestört, nur während einiger Stunden nach der Oelinjektion war das Tier still, von da ab sehr munter. 
Sektion: 13. XI. 1912, $2450 \mathrm{~g}$ schwer (200 g Gewichtszunahme).

Befund: Keine adhäsiven Veränderungen und keine freie Flüssigkeit in der Bauchhöhle. Das Peritoneum ist im allgemeinen etwas weisslich getrübt.

An dem Parietalperitoneum und am Dickdarm sieht man wie bei dem Paralleltier Nr. 34 gelblichgraue Auflagerungen mit rauher Oberfläche, ebenso an der abdominalen Seite des Zwerchfells und am Netz.

An der Leber zeigen sich streckenweise mehr flächenhafte dicke Beläge, sowohl an der Konvexität als auch an der Konkavität der Leber. Am Dünndarm, am Magen und am Mesenterium fehlen die beschriebenen Auflagerungen.

Die Pleura inklusive der Pleura diaphragmatica ist glatt. Die Lunge ist ebenfalls normal.

Die bakteriologische Untersuchung der Bauchhöhle ergibt wie sonst Keimfreiheit.

Die mikroskopischen Befunde an den verschiedenen Stellen des Parietal- und Viszeralperitoneums stimmen vollkommen mit den bei Kaninchen Nr. 84 erhobenen Befunden überein. Alle Veränderungen sind nur bei diesem Tier etwas schwächer ausgeprägt.

Das Lungengewebe erweist sich auch bei mikroskopischer Untersuchung als normal.

Epikrise: Reichliche Auflagerungen auf dem Parietal- und Viszeralperitoneum sind 8 Wochen nach der intraperitonealen Kampferölinjektion bei beiden Tieren der Versuchsgruppe, Nr. 34 und 35, noch deutlich erkennbar. Die Auflagerungen haben also immer mehr rein bindegewebigen Charakter angenommen, so am Netz, an der Bauchwandserosa, am Dickdarm und an der Leber, während am Zwerchfell noch ein Netzwerk mit ausgesprochener Maschenbildung gefunden wird.

\section{Gruppe.}

Tötung des Kaninchens (Nr. 36) 9 Wochen nach der intraperitonealen Kampferölinjektion.

Nr. 36. Männliches Kaninchen, $2920 \mathrm{~g}$ schwer.

Oelinjektion 18. IX. 1912. Menge des Kampferöls $=13 \mathrm{~cm}$.

Verlauf: Ungestört.

Sektion: 20. XI. 1912, $2920 \mathrm{~g}$ schwer.

Befund: Keine freie Flüssigkeit und keine adhäsiven Veränderungen in der Bauchhöhle.

An der Bauchwandserosa und am Netz findet man an manchen Stellen gelb-graue knötchenförmige Auflagerungen, stellenweise auch am Dickdarm.

Auf der Leberoberfläche haften gelblich-weisse Auflagerungen, besonders am vorderen und hinteren Rand. Aehnliche gelblich-weisse, flache Auflagerungen trifft man auch an der Milzoberfläche und an der abdominalen Seite des Zwerchfells, während im übrigen das Viszeralperitoneum kaum verändert aussieht. 
Der Befund an der Lunge und der Pleura, inklusive der Pleura diaphragmatica, ist normal.

Der Züchtungsversuch aus der Bauchhöhle fällt negativ aus.

Mikroskopische Untersuchung: Die bindegewebige Wucherung auf der Oberfläche des bindegewebsreichen $\mathrm{N}$ etzes birgt viele Kapillaren und nicht erweiterte Lymphgefässe, ausserdem aber vakuolenhaltige Riesenzellen, die in ihrem Protoplasma viele gelbgefärbte Körnchen enthalten. Manchmal lassen auch Lymphgefässe an ihrer Wand gelbliche Körnchen und vakuolenhaltige Endothelzellen erkennen, während an anderen Stellen die Wand mit normalen Endothelien bekleidet ist. An einigen Stellen der Netzoberfläche findet man kleine Fortsätze. Diese Fortsätze besitzen einige enorm erweiterte, mit Fett gefüllte Hohlräume, an anderen zahlreichen Stellen vakuolenhaltige oder auch gelbliche Körnchen einschliessende Riesenzellen, mit vielen Kernen und feinschaumigem Protoplasma. Den Grundstock der Fortsätze bildet ein dichtes Bindegewebe mit Blut- and Lymphgefässen.

An der Abdominalseite des Zwerchfells ist das subseröse Gewebe infolge von Bindegewebsvermehrung deutlich verdickt. Die mit einschichtigem, stellenweise anch mehrschichtigem Endothel bedeckte Oberfläche des Zwerchfells zeigt vielfach leichte Vorwölbungen, in denen meist ein oder zuweilen zwei grosse ölerfüllte Hohlräume angetroffen werden. Neben den Hohlräumen findet man Haufen von Zellen mit gelben Körnchen.

An der Leber ist die Kapsel etwas verdickt, die Oberfäche im allgemeinen mit normalen Endothelzellen überzogen. An vielen Stellen der Oberfläche findet man Auflagerungen, die zumeist fest an der Oberfläche haften, aus dichtem Bindegewebe bestehen und mit Endothelzellen gut bedeckt sind. In den bindegewebigen Auflagerungen, besonders in der Nähe der Oberfläche, sieht man Hohlräume von sehr ungleichmässiger Grösse, ausgekleidet von Endothelzellen, die an vielen Stellen Haufen bilden oder zu Riesenzellen zusammengeflossen sind, und neben den Blut- und Lymphgefässen vereinzelt Zellen mit gelben Körnchen.

Auf der Oberfläche der verdickten Dickdarmserosa zeigen sich massenhaft zottenartige Bildungen, die aus Bindegewebe bestehen und die mit Endothelzellen überzogen sind. Aehnliche zottige Bindegewebswucherungen ohne ölhaltige Hohlräume beobachtet man auch an der Oberfläche der verdickten Bauchwandserosa.

Am Mesenterium, am Magen und am Dünndarm findet man keine nennenswerten Veränderungen. erkennell.

Das Lungengewebe lässi auch mikroskopisch nichts Krankhaftes

Epikrise: Bei Kaninchen Nr. 36 ist 9 Wochen nach der intraperitonealen Kampferölinjektion, wie schon in früheren Stadien, eine ziemlich weit verbreitete Verdickung des Serosabindegewebes zu konstatieren, und sowohl am Parietal- wie am Viszeralperitoneum reichliche, teils mehr flache, teils polypös-zottige Auflagerungen, die aus endothelbekleidetem Bindegewebe mit Resten des untergehenden Maschenwerkes bestehen. Adhäsionen wurden, wie auch sonst, im Cavum peritonei nicht gefunden. 


\section{Gruppe.}

T'ötung der beiden Kaninchen (Nr. 37 und 38) 10 Wochen nach der intraperitonealen Kampferölinjektion.

Nr. 37. Männliches Kaninchen, $2100 \mathrm{~g}$ schwer.

Oelinjektion 18. IX. 1912. Menge des Kampferöls $=10^{1 / 2} \mathrm{ccm}$.

Verlauf: Ungestört.

Sektion: 27. XI. 1912, $2390 \mathrm{~g}$ schwer (270 g Gewichtszunahme).

Befund: Keine Adhäsionen, reichlich klare Flüssigkeit in der Bauchhöhle. An der Bauchwandserosa gelb-graue Auflagerungen. Die Serosa des Darmes, vor allem des Dickdarms, ist weisslich getrübt. Am Netz und am Mesenterium sieht man zahlreiche weissliche Herde, teils zirkumskript, teils mehr diffus. Fast die ganze Leberoberfläche ist wie von einem verschieden dicken weisslichen Rasen bedeckt. Am Leberrand bemerkt man mehr oder weniger breite weisslich-gelbe Streifen. Die Milz zeigt hier und da weisslich-gelbe Auflagerungen. An der Abdominalseite des Zwerchfells sieht man, besonders stark auf dem Centrum tendineum, weissliche Auflagerungen.

Die Pleuraseite des Zwerchfells ist glatt, wie die übrige Pleura.

Die Lunge ist normal retrahiert und überall lufthaltig.

Die bakteriologische Kontrolle der Bauchhöhle ergibt Keimfreiheit.

Mikroskopische Untersuchung: Die Oberfläche des bindegewebig verdickten Peritoneum diaphragmaticum ist von niedrigen, stellenweise aber auch von gequollenen und mehrschichtigen Endothelzellen überzogen. An manchen Stellen der Zwerchfelloberfläche werden noch vereinzelte Hohlräume verschiedener Grösse angetroffen. Sie liegen in gefässhaltigem Bindegewebe, das hier und da untergegangenes Maschenwerk, Haufen von degenerierten vakuolenhaltigen Endothelzellen, zum Teil mit kleinen ölgefüllten Hohlräumen und Riesenzellen aufweist. Während diese Hohlräume meist von undeutlich begrenzten Endothelien, von Endothelzellhaufen oder riesenzellartigen und bandförmigen Zellmassen ausgekleidet sind, sieht man neben den Blutkapillaren des bindegewebigen Stromas auch kleine spaltförmige Hohlräume mit einem Ueberzuge normaler Endothelien, die sich in die Lymphbahnen des Zwerchfells fortsetzen. Bei der Sudanfärbung findet man noch Oeltropfen in den Hohlräumen und in den Lymphspalten in ziemlich grosser Menge, auch intra- und interzellulär liegende Oeltröpfchen. Grosse Mengen resorbierten Oels lagern in den Lymphgefässen des Zwerchfellgrundgewebes, besonders an der Grenze des sehnigen und muskulären Teils. Auf diesem Grenzgebiete liegt noch eine dicke Auflagerung mit deutlicher Maschenbildung mannigfacher Art, überall bedeckt von einschichtigem oder auch mehrschichtigem Endothel. In der Richtung nach dem Centrum tendineum zeigt die Auflagerung eine dichte Struktur und enthält stellenweise grosse Hohlräume und daneben viele Endothelzellhaufen mit und ohne Hohlräume, sowie auch Riesenzellen. An anderen Stellen zeigt sie ein deutliches Maschenwerk, wie bei früheren Gruppen, teils weitmaschig, teils engmaschig. Da, wo das von degenerierten Endothelzellen gebildete kleinmaschige Maschenwerk beobachtet wird, findet man gleichzeitig Haufen von vakuolenhaltigen Endothelzellen, mit schwach gefärbten Kernen und riesenzellartigen Gebilden in grosser Menge.

Die Oberfläche der stark verdickten Serosa des Dickdarms hat ein verschiedenes Aussehen. An einigen Stellen ist die Oberfläche glatt mit 
schmalem endothelialem Ueberzug, an anderen Stellen sieht man viele zotten- oder knospenartige Wucherungen verschiedener Grösse. Das Grundgewebe der Wucherung besteht aus dichtem Bindegewebe mit vielen Blut- und erweiterten Lymphgefässen und mit spärlichen Haufen degenerierter Endothelzellen und mit vereinzelten Riesenzellen.

Die Oberfläche des verdickten Parietalperitoneums ist ebenfalls reichlich mit zotten- oder knospenartigen Wucherungen besetzt, an denen ein mehrschichtiges Deckendothel und ein bindegewebiger Grundstock mit Resten ursprünglichen Maschenwerkes beobachtet wird. Der Zustand der Auflagerungen auf der nur stellenweise verdickten Leberkapsel ist sehr verschieden. Teils präsentieren sie sich als Bindegewebsstreifen mit vielen Blutgefässen und Oeltropfen enthaltenden Lymphgefässen und mit vereinzelten Resten von Maschenwerk, teils als Maschenwerk mit Hohlräumen, die von degenerierten Endothelzellen und von Riesenzellen begrenzt werden, seltener als deutliches Netzwerk, das entsprechend früheren Stadien von langgestreckten Endothelzellen gebildet wird.

An der Oberfläche des sehr bindegewebsreichen Netzes sieht man vielfach nur eine rein bindegewebige Wucherung, an anderen Stellen jedoch auch in der bindegewebigen Wucherung noch ziemlich grosse Hohlräume, deren Wände bandförmige oder riesenzellenartige Gebilde zeigen und viele Haufen degenerierter, vakuolenhaltiger Endothelzellen, teils mit kleinen Hohlräumen, teils solide, sowie Riesenzellen in grosser Menge. Die Sudanfärbung weist in den Netzauflagerungen noch viel Oel im Maschenwerk und in den Lymphgefässen nach, auch intra- und interzellulär liegende Oeltropfen in den Maschenwerkresten.

Auf der sehr stark verdickten Milzkapsel werden kleine knospenartige bindegewebige Wucherungen ohne deutliche Reste von Maschenwerk gefunden.

Am Magen und am Dünndarm beobachtet man keine nennenswerten Veränderungen. Am Mesenterium ist das ganze Grundgewebe etwas bindegewebsreich; an seiner Oberfläche beobachtet man hier und da eine bindegewebige Wucherung ohne Maschenwerk.

Das Lungengewebe zeigt auch bei mikroskopischer Untersuchung nichts Pathologisches. Nur spärliche feine Oeltropfen zirkulieren in den Blutgefässen der Lunge.

Nr. 38. Männliches Kaninchen, $2270 \mathrm{~g}$ schwer.

Oelinjektion 18. IX. 1912. Menge des Kampferöls $=11 \mathrm{ccm}$.

Verlauf: Ohne Besonderheiten.

Sektion: 27. XI. 1912, $2700 \mathrm{~g}$ schwer (430 g Gewichtszunahme).

Befund: Keine Adhäsionen; reichlich klare Flüssigkeit in der Bauchhöhle. Ziemlich starke Injektion der Dickdarmserosa und der Mesenterialgefässe. Das parietale Peritoneum ist im allgemeinen glatt, doch an verschiedenen Stellen wie mit feinen Körnchen bestreut. Man sieht ferner eine Trübung am Netz, am Mesenterium und an der deutlich verdickten Serosa des Dickdarms. Die Leberoberfläche ist streckenweise von einem rahmartigen weisslichen Belag bedeckt. Ebensolche fleckigen Auflagerungen zeigt die Milz und teilweise der Magen. Die Zwerchfellserosa ist auf der peritonealen Seite stark belegt mit gelblich-weissen Massen, vor allem am Centrum tendineum, aber auch auf dem muskulären Teil.

Die Pleuraseite des Zwerchfells ist ebenso glatt wie die übrige Pleura. Die Lunge ist normal. 
Die bakteriologische Untersuchung der Bauchhöhle ergibt Keimfreiheit.

Das mikroskopische Bild der Peritonealserosa ist im allgemeinen das gleiche wie bei Kaninchen Nr. 37; Die gelblich-weissen Auflagerungen auf der abdominalen Seite des Zwerchfells sind teils niedrig. bindegewebig, teils enthalten sie Hohlräume und zeigen deutliche Maschenbildung, ausserdem eine dichte Schicht restierenden Maschenwerkes. Ueberall findet man ferner sehr ausgesprochen degenerative Vorgänge der Endothelzellen. Die Oberfläche wird meistens von einem schmalen, oft aber auch von einem mehrschichtigen endothelialen Ueberzug bedeckt.

Auf der verdickten Bauchwand serosa haften zottige Wucherungen, deren bindegewebiger Grundstock öltropfenenthaltende Lymphgefässe, aber keine Maschenwerkreste umschliesst und einen endothelialen Ueberzug besitzt.

Bei der weitgehenden Uebereinstimmung der bei diesem Tier ephobenen mikroskopischen Befunde mit denen des Kaninchens Nr. 37 erübrigt sich eine weitere Beschreibung.

Der Befund der Lunge ist auch mikroskopisch normal. Bei der Fettfärbung sieht man dann und wann feine Oeltropfen in den Blutgefässen.

Epikrise: 10 Wochen nach der intraperitonealen Kampferölinjektion ist bei beiden Kaninchen (Nr. 37 und 38) die Wucherung des Bindegewebes in den Auflagerungen so stark geworden, dass diese vielfach am Dickdarm, an der Bauchwand, an der Milz und an der Leber überhaupt nur noch aus Bindegewebe bestehen, abgesehen von den geringen Resten von Maschenwerk. Nur am Zwerchfell kann man noch ein deutliches Maschenwerk an einjgen Stellen der Auflagerung sehen, während an anderen zahlreichen Stellen schon eine starke bindegewebige Wucherung mit nur Resten des Maschenwerkes anzutreffen ist. Oel ist immer noch in den Maschen und den Resten des Maschenwerkes sowie auch intraund interzellulär liegend vorhanden, vor allem aber lagert es in den Lymphgefässen der Wand selbst in besonders grosser Menge im Zwerehfell.

Adhäsionen wurden bei beiden Tieren in der Bauchhöhle nicht gefunden.

\section{Gruppe.}

Untersuchung der beiden Kaninchen (Nr. 39 und 40) 11 Wochen nach der intraperitonealen Kampferölinjektion.

Nr. 39. Männliches Kaninchen, $1420 \mathrm{~g}$ schwer.

Oelinjektion 17. IX. 1912. Menge des Kampferöls $=7 \mathrm{ccm}$.

Verlauf: Cngestört.

Sektion: 3. XII. 1912, $2240 \mathrm{~g}$ schwer ( $820 \mathrm{~g}$ Gewichtszunahme).

Befund: In der Bauchhöhle finden sich keine adhäsiven Veränderungen, aber klare Flüssigkeit in reichlicher llenge. An der abdominalen Seite des Zwerchfells sieht man, besonders stark am Centrum 
tendineum, ausgedehnte gelblich-weisse Auflagerungen. Die Pleuraseite des Zwerchfells ist aber glatt wie die übrige Pleura.

Das Netz zeigt ebenfalls deutliche gelbliche Auflagerungen.

An der Bauchwandserosa bemerkt man gelbliche Auflagerungen in Form von Körnchen oder als flachen Belag mit rauher Oberfläche, ebenso am Dickdarm in grosser Menge, anf der Leberoberfläche einen noch umfangreicheren, mehr weisslichen Belag an der Fläche und auch am Rand, an der Milz gelbgraue Auflagerungen, am Mesenterium nur hiel und da leichte gelbliche Auflagerungen. Am Magen und am Dünndarm sieht man keine Auflagerungen. Die Lunge ist normal.

Die bakteriologische Untersuchung der Bauchhöhle fällt negativ aus.

Mikroskopische Untersuchung: In dem bindegewebig verdickten Peritoneum diaphragmaticum sind deutlich erweiterte Lymphgefässe. Auf dem muskulären Teil des Zwerchfells bemerkt man hier und da knospen-oder zottenartige kleine Wucherungen mit einem meist einschichtigen Endothelïberzug. Ihr Grundgewebe besteht aus gefässhaltigem Bindegewebe, in dem stellenweise verschieden geformte und verschieden grosse Zellen mit gelblichen Körnchen im Protoplasma und mit undeutlicher Kernstruktur liegen. Die Sudanfärbung weist innerhalb der Wucherungen noeh intra- und interzellulär liegende Oeltropfen und grössere Oeltropfen in den Lymphgefüssen nach, ferner sehr reichliche grosse Oeltropfen in den Lymphgefässen der Zwerchfellserosa und des Zwerchfellgrundgewebes. In dem Grenzgebiet zwischen dem sehnigen und muskulären Zwerchfellteil, sowie auch auf dem Centrum tendineum findet man ein stark entwickeltes Maschenwerk, in deren oberen Partien die Maschen durch sehr zarte, nur aus langgestreckten Endothelzellen gebildeten Septen geschieden werden, während an anderen Stellen die Septen aus feinen Bindegewebsfasern bestehen und die Innenfläche der Hohlräume mit schmalen Endothelzellen ausgekleidet sind.

Nur hier und da sieht man in den oberen Partien des Maschenwerks stärker entwickeltes, gefässhaltiges Bindegewebe. In den unteren Partien des Maschenwerkes herrscht die Bindegewebsentwickelung vor. Die Innenfläche der Maschen ist hier mit Endothelzellen ausgekleidet, die durch teilweises Zusammenfliessen ein bandähnliches oder riesenzellenartiges Aussehen erhalten haben. Leukozyten sind nur spärlich, Fibrin überhaupt nicht mehr im Maschenwerk vorhanden. Dagegen wird Oel noch in grosser Menge im Maschenwerk gefunden, aber auch in den Lymphgefässen des Zwerchfellgewebes bis hin zur Pleura diaphragmatica, die selbst auch mikroskopisch nicht verändert ist.

An der Leber sieht man auf weite Strecken der Oberfläche hin eine starke Maschenwerkbildung von gleichem Ban wie am Zwerchfell, doch bindegewebsreicher. Die Endothelzellen, die an der Wand der Maschen und in der bindegewebigen Wucherung verstrent oder in Haufen liegen, zeigen vielfach gelbe Körnchen in ihrem Protoplasma. Das Bindegewebe ist in den basalen Abschnitten der Auflagerung, also direkt auf dem Leberparenchym, besonders stark entwickelt, so dass hier eine mächtig verdickte Leberkapsel vorhanden zu sein scheint, während sonst an der Leberoberfläche die Kapselverdickung nicht gerade sehr ausgesprochen hervortritt. In dem verdickten Bindegewebe sieht man ziemlich gleichmässig weite Hohlräume, die mit Endothelzellen ausgekleidet sind oder Haufen von Endothelzellen und bandartige Zellmassen oder riesenzellenähnliche Bildungen zeigen. Das 
Verhalten von Fett im Maschenwerk ist ein gleiches wie beim Zwerchfell. An der oberen Schicht des Leberparenchyms, unter der Auflagerung, findet man Oeltroplen, die netzförmig, aber nicht strahlig, angeordnet sind.

Eine beträchtliche Maschenwerkbildung von demselben Bau wie auf der Leber deckt die sehr stark verdickte Milzkapsel.

An der Oberfläche des sehr bindegewebsreichen Netzes sieht man Verdickungen ans sehr dicht gefiigtem Bindegewebe und vereinzelt zottenartige Fortsätze aus endothelbekleidetem Bindegewebe, in dem hier und da endotheliale Hohlräume, mit Oeltropfen gefüllt, und Zellen mit gelben Körnchen verstreut liegen.

Auch in dem Bindegewebe der auf der verdickten Dickdarmserosa und auf dem Parietalperitoneum gefundenen zottigen Fortsätze werden nur vereinzelte Hohlräume von weclsselnder Grösse und selten Zellen mit gelben Körnchen angetroffen.

Die Oberfläche des etwas bindegewebsreicheren Mesentexium zeigt bindegewebige Verdickungen.

Die Lunge ist auch mikroskopisch normal. Bei der Sudanfärbung findet man geringe Mengen kleiner Oeltropfen in den Blutgefässen.

Nr. 40. Männliches Kaninchen, $2220 \mathrm{~g}$ schwer.

Oelinjektion 17. IX. 1912. Menge des Kampferöls $=11 \mathrm{ccm}$.

Verlauf: Tod an Enteritis am 5. XII. 1912 (79 Tage nach der Oelinjektion).

Sektion: 5. XII. 1912, $1270 \mathrm{~g}$ schwer (fast $1 \mathrm{~kg}$ Gewichtsabnahme).

Befund: Sehr starke Oelreaktion am Peritoneum parietale und viszerale. Am Zwerchfell, an der Leber, an der Milz, am Netz, am Dickdarm und am Mesenterium findet man überall starke Auflagerungen in Form von gelblich-weissen Flecken und Streifen. Keine adhäsiven Veränderungen in der Bauchhöhle.

Die Pleura und die Lunge sind normal.

Der Züchtungsversuch aus der Bauchhöhle ergibt wie sonst ein negatives Resultat.

Mikroskopische Untersuchung: Auf der Leber findet man wie bei Kaninchen Nr. 39 bindegewebsreiche Maschenwerkbildung. Ein besonders interessantes Bild zeigt sich in der oberen Partie des Leberparenchyms. Hier sieht man einige Hohlrăume zwischen den Leberzellen, ausgekleidet mit schmalen Endothelzellen. In einer noch tieferen Schicht werden nur wenig erweiterte Lymphgefässe sichtbar von genan demselben Aussehen, wie die ebengenannten Hohlräume. Die Leberzellen in der Umgebung der Hohlräume zeigen eine schwache und ungleichmässige Protoplasma- und Kernfärbung und sind manchmal vakuolenhaltig. Zuweilen trifft man schattenartige Zellleiber mit blassen Kernen. Leukozyten sind hier und da verstreut vorhanden (s. Fig. 5).

$\mathrm{Im}$ übrigen verweise ich bezüglich der mikroskopischen Befunde am Parietal- und Viszeralperitoneum auf die Befunde beim Paralleltier Nr. 39, die sich im wesentlichen decken. Nur ist bei dem Kaninchen Nr. 40 die Bindegewebsentwickelung eine noch stärkere.

Das Lungengewebe zeigt auch mikroskopisch nichts Krankhaftes. In den Lungengefässen zirkulieren wie sonst feine Oeltröpfchen. Als Todesursache ist mit Sicherheit die Enteritis anzusprechen.

Epikrise: 11 Wochen bzw. 79 Tage nach der intraperitonealen Kampferölinjektion bestehen die Auflagerungen auf der Peritoneal- 
serosa, abgesehen vom Zwerchfell, der Iueber und der Milz fast ausschliesslich aus Bindegewebe. Reste vom Maschenwerk sind hier nicht oder nur sehr spärlich nachzuweisen. Die Zellen mit gelben Körnchen halte ich für Endothelzellen, in deren Protoplasma die Körnchen im Verlaufe degenerativer Vorgänge aufgetreten sind. Sie finden sich nicht nur unter den Zellen des Maschenwerkes, sondern auch im Endothel von Lymphgefässen und im Serosabindegewebe neben Blutgefässen.

Besonders bemerkenswert ist die Erweiterung der Lymphgefässse an der oberen Partie des Leberparenchyms bei Nr. 40, in deren Nachbarschaft die Leberzellen regressive Erscheinungen zeigen.

Nach diesen Ausführungen kann man leicht verstehen, dass die Erweiterung der Lymphgefässe in den späteren Stadien zur Maschenbildung mit beiträgt. Zugleich erklärt dieses Bild die Menge der Fettropfen, die in der oberen Partie der Leber als massiges Lager und nicht in Strahlenform, wie in den früheren Stadien, erscheinen.

Adhäsionen wurden bei beiden Tieren in der Bauchhöhle nicht gefunden.

\section{Gruppe.}

Untersuchung des Kaninchens Nr. 41 Wochen nach der intraperitonealen Kampferölinjektion.

Nr. 41. Weibliches Kaninchen, $1900 \mathrm{~g}$ schwer.

Oelinjektion 17. IX. 1912. Menge des Kampferöls $=9,5 \mathrm{ccm}$.

Verlauf: Ohne Zwischenfall.

Sektion: 10. XII. 1912, $2560 \mathrm{~g}$ schwer (660 g Gewichtszunahme).

Befund: Keine adhäsiven Veränderungen, geringe Menge klarer Flüssigkeit in der Bauchhöhle. An der parietalen Bauchwand sieht man leicht gelbliche Flecke, ebenso am Dickdarm, am Mesenterium, an der Milz und an der Leber.

An der abdominalen Seite des Zwerchfells haften sowohl am Centrum tendineum wie am muskulären Abschnitt, gelb-weisse Auflagerungen. Wo die Auflagerungen fehlen, sieht das Peritoneum diaphragmaticum weiss ans. Die Pleuraseite des Zwerchfells ist glatt wie die übrige Pleura. Die Lunge ist normal.

Die Bauchhöhle erweist sich bei der bakteriologischen Kontrolle als keimfrei.

Mikroskopische Untersuchung: Entsprechend dem muskulären Abschnitt des $\mathrm{Z}$ werchfells ist das bindegewebig verdickte Peritoneum diaphragmaticum von einschichtigem, teilweise auch mehrschichtigem Endothel bedeckt. In dem Grenzgebiet zwischen muskulärem und sehnigem Abschnitt sieht man stark entwickelte Maschenwerkbildung mit grösstenteils einschichtigem Endothelüberzug. Das Maschenwerk zeigt an verschiedenen Stellen wechselnde Struktur, teils 
dicht mit degenerierten Zellen und spärlichen kleinen Hohlräumen, teils lockerer gefügt, mit grösseren Hohlräumen, die von langgestreckten feinen Endothelzellen begrenzt werden und oft Endothelzellhaufen, sowie Riesenzellen in ihrer Wand bergen. Dieselben Hohlräume findet man in dem Grundgewebe des Zwerchfells bis zum subserösen Gewebe der Pleura diaphragmatica. Die Leukozyteninfiltration ist in den Peritoneumauflagerungen bei diesem Tiere wesentlich stärker als bei den vorhergehenden Versuchsgruppen. Oeltropfen weist die Sudanfärbung sowohl in den Hohlräumen des Maschenwerkes und des Zwerchfellgrundgewebes bis zur Pleura nach, als auch intra- und interzellulär in der Auflagerung.

An der Leberoberfläche findet sich ein deutliches bindegewebsreiches Maschenwerk, wie bei Kaninchen Nr. 40, ebenso auf der stark verdickten Milzkapsel.

An der Oberfläche des sehr bindegewebsreichen Netzes trifft man an vielen Stellen bandartige bindegewebige Verdickungen, sehr häufig auch kleine knospen- oder zottenartige Wucherungen aus Bindegewebe, mit Resten degenerierten Maschenwerkes und mit Resten unresorbierten Oels in den kleinen Hohlräumen sowohl, wie intra- und interzellulär liegend.

Bezïglich der leichteren Veränderungen am Parietalperitoneum, am Dickdarm und am Mesenterium verweise ich auf die entsprechenden Befunde bei den Tieren der 20. Versuchsgruppe (Nr. 39 und Nr. 40).

Epikrise: 12 Wochen nach der intraperitonealen Kampferölinjektion zeigen sich bei Kaninchen Nr. 41 auf dem Zwerchfell massenhaft Reste degenerierten Maschenwerkes neben deutlich ausgeprägtem Netzwerk. Die Entwickelung von Bindegewebe ist bei diesem Tier am Zwerchfell geringer, als bei den Tieren der vorhergehenden Versuchsgruppen. Ausserdem findet man bei diesem Tiere noch eine ausgesprochene Leukozyteninfiltration und sogar noch Fibrin in den Auflagerungen des peritonealen Zwerchfellüberzuges. Am Zwerchfell beobachtet man überall eine starke Erweiterung der Lymphgefässe durch die ganze Dicke des Diaphragma hindurch, bis zur Pleura diaphragmatica. Die erweiterten Lymphbahnen sind mit Oeltropfen erfüllt. Die reaktiven Veränderungen an der übrigen Peritonealserosa zeichnen sich durch denselben Bindegewebsreichtum aus, wie bei den vorhergehenden Versuchsgruppen. Verwachsungen wurden in der Bauchhöhle auch bei diesem Tiere nicht gefunden.

\section{Gruppe.}

Untersuchung der beiden Kaninchen (Nr. 42 und 43) 13 Wochen nach der intraperitonealen Kampferölinjektion.

Nr. 42. Weibliches Kaninchen, $2350 \mathrm{~g}$ schwer.

Oelinjektion 4. IX. 1912. Menge des Kampferöls $=12 \mathrm{ccm}$.

Verlauf: Ungestört.

Sektion: 4. XII. 1912. $2440 \mathrm{~g}$ schwer (90 g Gewichtszunahme). 
Befund: Keine freie Flüssigkeit und keine adhäsiven Veränderungen in der Bauchhöhle. Das Peritoneum zeigt weit verbreitet ein leicht weissliches Aussehen. Ausserdem sieht man gelbliche oder weissliche Auflagerungen, diffus oder mehr inselförmig, in kleineren oder grösseren Flecken, flach oder auch stellenweise polypös oder rauh an der abdominalen Seite des Zwerchfells, an der Milz und Leberoberfläche, am Parietalperitoneum, am Netz, am Dickdarm und ganz vereinzelt am Mesenterium und am Dünndarm. Die Pleuraseite des Zwerchfells ist glatt, wie die übrige Pleura.

Die Lunge ist normal.

Die bakteriologische Prüfung der Bauchhöhle ergibt wie immer Keimfreiheit.

Mikroskopische Untersuchung: Auf dem bindegewebig verdickten Peritoneum diaphragmaticum trifft man endothelbekleidete knospenartige Fortsätze aus Bindegewebe, das hier und da noch einige ungleichmässig erweiterte Hohlrüume birgt. Die Hohlräume sind teils mit gut erhaltenen und gut färbbaren Endothelzellen ausgekleidet, zum Teil mit Endothelzellen, die sich in den verschiedenen Stadien der Degeneration befinden, und enthaiten noch deutliche Oelreste. Ausser den Hohlräumen findet man im bindegewebigen Stroma Haufen von vakuolenhaltigen Endothelzellen und Zellen mit feinen gelblichen Körnchen.

An anderen Stellen der abdominalen Zwerchfelloberfläche, besonders in dem Grenzgebiet zwisehen sehnigem und muskulären Teil haftet eine dicke Auflagerung von Netzwerk. Die das Netzwerk überziehenden Endothelzellen sind meist flach, an einigen Stellen aber noch aufgequollen und von zylinderförmiger Gestalt, hier und da auch mehrschichtig. Die Auflagerung zeigt ein sehr wechselndes Strukturbild. An vielen Stellen besteht sie aus reichlichem Bindegewebe mit Resten degenerierten Maschenwerkes, an anderen Stellen dagegen aus deutlichiem Netzwerk mit zahlreichen HohIräumen, deren Septen von langgestreckten Endothelzellen oder von aufgequollenen Endothelzellen gebildet werden, oder von bandförmigen Protoplasmamassen und Riesenzellen. Blutgefässe führende Bindegewebszüge sind überall reichlich in der Auflagerung vorhanden. Stellenweise bildet das Bindegewebe inselartige Klumpen, welche die Reste untergegangenen Maschenwerkes beherbergen. Unresorbiertes Oel ist noch ziemlich reichlich in den Maschen des Netzwerkes vorhanden. Auch intra- und interzellulär liegende feine Oelkïgelchen kann man mit der Sudanfärbung nachweisen. Ausserdem. findet man resorbiertes $0 \mathrm{el}$ in den Lymphgefässen des Zwerchfells bis zur Pleura diaphragmatica, die selbst keine Veränderungen aufweist. Die Lenkozyteninfiltration in der Auflagerung ist gering; Fibrin ist nicht mehr nachweisbar. Ueber die ganze Oberfläche des bindegewebsreichen Omentum ist ein Streifen von Bindegewebe ausgebreitet. Vielfach sieht man zottige Bindegewebswucherungen mit endothelialem Ueberzug, oft auch weite mit Oel erfüllte Hohlräume.

Die Oberfläche des verdickten Parietalperitoneums ist meist mit schmalen Endothelzellen überzogen. Einer Mlehrschichtung der Endothelzellen begegnet man seltener. Ebenfalls selten sieht man kleine knospenartige Bindegewebswucherungen mit Spuren degenerierten Maschenwerkes. Stellenweise sind eingestreut grosse Zellen mit gelblichen Körnchen oder Haufen solcher Zellen, die noch kleine Hohlräume mit Oelresten umschliessen. Auch in den etwas erweiterten Lymphgefüssen des sub- 
peritonealen Gewebes lässt sich mit der Sudanfärbung resorbiertes Oel nachweisen.

Die stark verdickte Milzkapsel zeigt vereinzelt Bindegewebswucherungen ohne Maschenwerkreste.

Auf der Oberfläche der Leber, deren Kapsel ebenfalls deutlich verdickt ist, sieht man flächenhafte bindegewebige Auflagerungen bedeckt von schmalen einschichtigen, selten von mehrschichtigen Endothelzellen. In den bindegewebigen Auflagerungen liegen die Hohlräume verschieden dicht und sind verschieden gross, erstrecken sich auch in die oberen Partien des Leberparenchyms und sind mit Oel erfüllt.

Während auf der stellenweise sehr stark verdickten Serosa des Dickdarms hier und da kleine zottenartige Bindegewebswucherungen angetroffen werden, zeigt die Oberfläche des etwas verdickten Mesenteriums nur geringe, die des Magens und Dünndarms kaum noch reaktive Veränderungen.

Der Befund der Lunge ist auch mikroskopisch völlig normal.

Nr. 43. Weibliches Kaninchen, $2570 \mathrm{~g}$ schwer.

Oelinjektion 4. IX. 1912. Menge des Kampferöls $=13 \mathrm{ccm}$.

Verlauf: Ungestört.

Sektion: 4. XII. 1912, $2680 \mathrm{~g}$ schwer (110 g Gewichtszunahme).

Befund: In der Bauchhöhle etwas klare gelbliche Flüssigkeit, keine adhäsiven Veränderungen. Das Peritoneum zeigt im allgemeinen ein weissliches Aussehen. Am Parietalperitoneum fallen gelbliche, flache Flecke mit glatter Oberfläche auf, an der Milz gelbbräunlich gefärbte, festhaftende Auflagerungen, an der abdominalen Zwerchfellfläche inselförmige gelbbraune Auflagerungen, ebenso am Leberrand und streckenweise auf der konvexen Fläche und auf der Unterfläche der Leber. Am. Netz, Mesenterium, am Magen und am Dünndarm sind keine nennenswerten Veränderungen bemerkbar. Die Pleuraseite des Zwerchfells ist glatt wie die übrige Pleura. Die Lunge ist normal.

Mikroskopische Untersuchung: Auf dem bindegewebig verdickten Peritoneum des Zwerchfells sieht man bald zottige, bald flache Bindegewebswucherungen, die mit einschichtigen schmalen Endothelzellen, hier und da mit mehrschichtigem Endothel iberzogen sind. Die Bindegewebswucherungen umschliessen noch vielfach Hohlräume verschiedener Grösse, deren Wand von zumeist degenerierten Endothelzellen, von synzytialen oder riesenzellenartigen Zellmassen gebildet wird. Neben den Oelreste enthaltenden Hohlräumen sind Ueberbleibsel degenerierten Maschenwerkes vorhanden. Gut erhaltenes Maschenwerk. findet sich an keiner Stelle des Peritoneums mehr. Bezüglich der Befunde am Netz, am Parietalperitoneum, an der Milz- und Leberoberfläche, am Dickdarm, am Mesenterium, am Magen und Dünndarm verweise ich auf die fast genau entsprechenden Befunde bei dem Paralleltier dieser Versuchsgruppe Kaninchen Nr. 42.

Von Fibrin ist nirgends mehr eine Spur zu erkennen. Der Befund der Lunge ist auch mikroskopisch ganz normal. Nur geringe Mengen feiner Oeltröpfchen zirkulieren in den Blutgefässen der Lunge.

Epikrise: 13 Wochen nach der intraperitonealen Kamplerölinjektion sind immer noch deutliche reaktive Veränderungen an dem Peritoneum vorhanden. Die Auflagerungen am Parietalperitoneum, am Dickdarm, an der Milz und am Netz sind in diesem 
Stadium fast bindegewebig und enthalten nur noch spärliche Reste von Maschenwerk. Dagegen trifft man an der Leberoberfläche und vor allem am Zwerchfell streckenweise noch deutliche Maschenwerkbildung. Am Zwerchfell geht offenbar die Rückbildung des Maschenwerkes am langsamsten vor sich. Ueberall sind die Auflagerungen von Endothel bekleidet. Wie sonst zeigen sich nirgends in der Bauchhöhle Adhäsionen.

\section{Ueberblick über die Resultate sämtlicher 22 an 43 Kaninchen angestellten Versuche.}

Wenn man die 22 Versuche überblickt, so ergibt sich als eine unbestreitbare Tatsache, dass das Peritoneum des Kaninchens auf die intraperitoneale Kampferölinjektion hin typische Veränderungen in gesetzmässiger Folge erkennen lässt. Makroskopisch zeigt das Peritoneum ein tauartiges Aussehen und später eine weissliche Färbung, sowie auch weisse, dicke, mattglänzende Auflagerungen. Die Gefässe der Serosa sind besonders am Mesenterium stark injiziert. In der Bauchhöhle sieht man kurze Zeit nach der Oelbehandlung noch klares, nicht emulgiertes Oel, während später nur emulgiertes Oel gefunden wurde, das sich noch nach 2 Wochen nachweisen liess. Mikroskopisch sieht man in sehr frühen Stadien eine deutliche Injektion der Blutgefässe und eine starke Infiltration mit Leukozyten in der Serosa und Subserosa. Manchmal trifft man dort kleine Blutungsherde. Auf dem parietalen and viszeralen Peritoneum bemerkt man eine starke Wucherung der Endothelzellen und in derselben eine anfangs enorme Infiltration mit Leukozyten und Fibrinbildung. Das Peritoneum wird an vielen Stellen mit dieser Schicht bedeckt, die emulgiertes Oel in grossen Mengen einschliesst. Später wird das durch Endothelproliferation und Leukozytenemigration erzeugte, zur Einscheidung der emulgierten Oelmassen dienende Maschenwerk ron der Serosa her organisiert. Organisation des Maschenwerkes und langsame Oe]resorption beherrschen die weiteren Stadien der Entwicklung, bis schliesslich nur noch geschrumpftes Bindegewebe mit Resten von Maschenwerk und mit Resten noch nicht zur Resorption gelangten Oels übrig bleibt.

Aus diesen Befunden schliesse ich mit Sicherheit, dass die reaktiven Veränderungen am Peritoneum in einer proliferierenden, mit enormer Leukozytenansammlung und Fibrinbildung einhergehenden, im wesentlichen aber trockenen Peritonitis bestehen. 
Dieser Vorgang, bei welchem durch Endothelproliferation, Leukozytenemigration und Fibrinbildung emulgiertes Oel eingeschlossen wird und durch den eine mehr oder weniger dicke Auflagerungsschicht auf der Peritonealserosa entsteht, passt gut zu dem Bilde der „Fremdkörperperitonitis". Ueber die Fremdkörperperitonitis hat C. Ruge interessante Mitteilungen gemacht. Ruge unterscheidet unter den bei der Laparotomie gesetzten Reizen zwei Arten, nämlich einen rein mechanischen Reiz und einen Fremdkörperreiz. Er hatte nach den operativen Eingriffen leichte körnchenartige Wucherungen am Peritoneum nachgewiesen. Bei der mikroskopischen Untersuchung sah er, dass diese Wucherungen nichts anderes waren, als eine peritoneale Reaktion auf kleine und kleinste Fremdkörper. In der Mitte der Granulation fand er stets feine, kleine Leinwandfasern bzw. kleinste Partikel von Tupfern und Servietten. Er hielt diesen Befund für eine Dissemination von Fremdkörpern, die als peritoneale Reaktion eine granulierende Entzündung hervorrufen.

Diese Dissemination und Einkapselung von Fremdkörpern am Peritoneum ist eine allgemein bekannte Tatsache. Um meine Resultate mit der Fremdkörperperitonitis vergleichen zu können, habe ich auch an 4 Kaninchen Versuche vorgenommen, und zwar in der Weise: Ich habe ganz fein geschnittene Seidenfäden und Serviettenstückchen, die in physiologischer Kochsalzlösung aufgeschwemmt worden waren, in die Bauchhöhle des Kaninchens hineingegossen. 24 Stunden, 4 Tage und 6 Tage später habe ich die Tiere durch Nackenschlag getötet und sofort seziert. Bei der Sektion fand ich, dass die Fremdkörper nicht auf der ganzen Oberfläche des Peritoneums verteilt waren, sondern vorn zwischen dem Dickdarm und der vorderen Bauchwand eingeschlossen lagen. In der Nähe dieser Stelle findet man aber am Dick- und Dünndarm sowie an der parietalen Bauchwand kleine Partikelchen von Fremdkörpern, welche fest am Peritoneum haften. Gleichzeitig vorgenommene bakteriologische Untersuchungen der Bauchhöhle ergaben Keimfreiheit. Die mikroskopische Betrachtung zeigt in der Serosa, wo auf der Oberfläche der Fremdkörper haftet, eine starke Injektion der Blutgefässe and eine starke Infiltration mit Leukozyten. An der Oberfläche derselben Stelle findet man eine starke Wucherung der Endothelzellen, welche den Fremdkörper eingekapselt hat. Die Infiltration der Wucherung mit Leukozyten ist auch beträchtlich. Bei einem Kaninchen, bei dem die Unter- 
suchung am 6. Tage nach Einbringung der kleinen Fremdkörper in die Bauchhöhle vorgenommen wurde, fand ich in der Wucherung bereits einen starken Untergang von Leukozyten und Endothelzellen. Man bemerkt in der Wucherung Hanfen von degenerierten Zellen und auch riesenzellenartige Gebilde. Auch Fibrin ist in der Wucherung deutlich zu sehen. Dieses Resultat stimmt also ganz mit dem Befund bei den mit Kampferöl behandeiten Tieren überein, und daraus schliesse ich, dass die von Hoehne in seinen verschiedenen Arbeiten beschriebene reaktive aseptische Peritonitis nach der intraperitonealen Kampferölinjektion in der Tat aufzufassen ist als Fremdkörperperitonitis. Es wird also, wie Hoehne angegeben hat, das emulgierte Oel durch den reaktiven Entzündungszustand des Peritoneums eingekapselt. Eine eitrige Peritonitis mit Bildung eines eitrigen Exsudates habe ich bei Anwendung von Kampferöl als Reizmittel ebensowenig beobachtet, wie Hoehne. Ich stimme auch mit Hoehne darin überein, dass in den ersten Wochen das emulgierte Oel ron einer streckenweisen sogar mächtigen Fibrinschicht eingescheidet wird.

Wenn man die reaktiven Veränderungen nach der intraperitonealen Kampferölinjektion, die ich ebenso wie Hoehne als Fremdkörperperitonitis deute, genauer überblickt, so kann man 3 verschiedene Stadien unterscheiden, die regelmässig wiederkehren:

Im 1. Stadium zeigt sich eine deutliche Proliferation des Serosaendothels and eine sehr hochgradige Leukozyteninfiltration. 6 Stunden nach der Kampferölinjektion ist đie Endothelproliferation schon auffällig, aber noch nicht bedeutend. Nach 12 Stunden wird die Proliferation und Infiltration hochgradig. Gefässhaltiges Bindegewebe fehlt zu dieser Zeit in der Wucherung noch vollkommen. Fibrin findet man erst in spärlicher Menge. Oeltropfen liegen massenhaft im Maschenwerk, das zunächst lediglich von gewucherten Endothelzellen und von Leukozytenmassen gebildet ist. In diesem Stadium wird also das in die Bauchhöhle eingebrachte Oel durch Endothelproliferation und Leukozytenemigration eingekapselt und dadurch eine schnelle und gefährliche Massenresorption von Oel verbindert. Die Lymphgefässe der Serosa und Subserosa enthalten in dieser Zeit in der Regel nur wenig resorbiertes Oel.

Ich möchte dieses auf etwa 24 Stunden nach der intraperitonealen Kampferölinjektion sich erstreckende Stadium als das Stadium der Endothelproliferation und der Leukozyteninfiltration bezeichnen. 
Im 2. Stadium gehen die Leukozyten allmählich zugrunde. 48 Stunden nach der intraperitonealen Kampferölinjektion beginnt schon in den Leukozyten die Nekrose bemerkbar zu werden: am 4. Tage sind die Leukozyten in dem der Serosa aufgelagerten Maschenwerk schon an Zahl rermindert. Ganz parallel mit dem Untergang und der Verminderung der Leukozyten geht die Zunahme von Fibrin. Es tritt zuerst am 2. Tag nach der Oelinjektion im Maschenwerk auf und bildet am 4. Tage bereits ein deutliches Netz und breite Streifen in der oberen Partie der Auflagerung. Diese Fibrinvermehrung hält deutlich bis zum 7 . Tage an. Vom 9. Tage ab aber beginnt das Fibrin sich wieder zu vermindern, und zwar zucrst in der unteren Sehicht der Auflagerung sobaid dort gefässhaltiges Bindegewebe von unten her eindringt. Die ersten Gefässsprossen gelangen 48 Stunden nach der Oelinjeltion in die Grundpartie der Auflagerung hinein. Aber auch am 6. Tage nach der Oelinjektion haben die immer weiter vordringenden Blutgefässe noch nicht die oberen Partien des Maschenwerkes erreicht. Die Lymphgefässe erweitern sich am 3. Tage nach der Oelinjektion, und zwar am Grund der Auflagerung. 6 Tage später dringen sie mit den Blutgefässen und dem Bindegewebe in die unteren Partien des Maschengewebes hinein. Den Zeitraum ron 48 Stunden bis zum 7. Tage nach der intraperitonealen Kampferölinjektion möchte ich das Stadium der Fibrinbildung nennen.

Die Zwischenzeit von 24-48 Stunden stellt die Uebergangszeit vom ersten zum zweiten Stadium dar.

Das 3. Stadium endlich beginnt mit dem. 9. Tage nach der Oelinjektion. Zwischen dem 2. und 3. Stadium liegt ebenso wie zwischen dem 1. und 2. Stadium eine Uebergangszeit. Das 3. Stadium ist charakterisiert durch lebhafte Wucherung des Bindegewebes, durch das Verschwinden des Fibrins und durch den Untergang der gewucherten Endothelzellen. Das Fibrin vermindert sich, wie schon gesagt, vom 9. Tage der Oelinjektion ab, zuerst in der unteren Partie der Auflagerung, sobald hier Bindegewebe eindringt und ist nach 3 Wochen schon fast vollkommen verschwunden. Umgekehrt ist das mit dem 9. Tage in die untere Partie des Maschenwerkes einwachsende Bindegewebe nach 3 Wochen schon in der ganzen Auflagerung verbreitet. Von der 4 . Woche ab bildet das Bindegewebe da, wo früher Fibrin als eine dicke Schicht vorhanden war, d. h. in dem oberen Bezirk der Auflagerung, einen breiten Streifen. Von nun an nimmt das Bindegewebe an Masse immer 
mehr zu, so dass an einzelnen Stellen der Peritonealserosa die Auflagerungen der Hauptsache nach nur noch aus Bindegewebe bestehen, das Reste degenerierten Maschenwerkes in Gestalt von Zellhaufen und Riesenzellen umschliesst. Gleichzeitig mit der Bindegewebswucherung zeigen die Endothelzellen im Maschenwerk schon in der 2. Woche Degenerationserscheinungen. Diese werden im Verlaufe der 3. Woche noch stärker, so dass dann das Maschenwerk der Endothelzellen in seiner oberen Partie nur noch Zellhaufen mit kleinen Hohlräumen und mit Riesenzellen darstellt und führen von der 4 . Woche ab zu mehr oder weniger vollständigem Schwund des Maschenwerkes an verschiedenen Stellen der Peritoneajserosa, besonders am Parietalperitoneum, am Dickdarm, am Netz und zum Teil an der Leber sowie an der Milz.

Die 3 genannten Stadien der reaktiven Kampferölperitonitis halten sich aber nicht immer an scharfbegrenzte Zeitabschnitte. Bald verläuft der reaktive Prozess am Peritoneum schneller, bald langsamer, und auch an den verschiedenen Abschnitten der Peritonealserosa desselben Tieres zeigen sich grosse graduelle Unterschiede. So tritt die Bindegewebsentwicklung z. B. an der Bauchwand; am Dickdarm und am Netz stärker und frühzeitiger auf als an der Leber und der Milz. Am Zwerchfell erfolgt die bindegewebige Umwandlung der Auflagerung, besonders im Grenzgebiet zwischen dem sehnigen und muskulären Teil am schwächsten und spätesten. Hier bleibt das Maschenwerk am längsten erhaiten und ist auch nach 13 Wochen noch sehr deutlich.

Blutgefässe findet man in diesem 3. Stadium überall in der Auflagerung. Leukozyten sind schliesslich nur zerstreut hier und da vorhanden. Das Bindegewebe der Serosa wird fast regelmässig im Verlaufe der entzündlichen Reaktion verdickt. Die Lymphgefässe bilden in der Grundpartie der Auflagerung infolge ihrer Erweiterung ein System von Hohlräumen und beteiligen sich auf diese Weise an der Bildung von Maschen in der Auflagerung. Man kann erweiterte Lymphgefässe noch in den bindegewebigen Fortsätzen der späteren Wochen erkennen. Dass sich die Lymphgefässe auch unter der Auflagerung stark erweitert haben, kann man in Fig. 5 an der Leber deutlich erkennen.

Am Zwerchfell erstreckt sich die Lymphgefässerweiterung und die entsprechende Lymphbahnfüllung mit resorbiertem Oel allmählich durch die ganze Dicke des Diaphragma hindurch bis zur Pleura hin, ohne dass die Pleuraoberfläche verändert wird. Zuerst 
findet man also auch noch im 3. Stadium das Oel hauptsächlich eingekapselt im Bereiche der Auflagerung, in späterer Zeit aber auch in den Lymphgefässen des darunter liegenden Gewebes, so dass z. B. am Zwerchfell auch im subpleuralen Gewebe Oeitropfen in grosser Menge nachweisen kann. Je mehr von dem Oel durch langsame Resorption in die Tiefe rückt, um so mehr vermindert sich das in den Maschen der Auflagerung eingekapselte und aufgespeicherte Oeldepot. Auch die inter- und intrazellulär gelegenen Oeltröpfchen zeigen später eine starke Verminderung.

Abgesehen von diesen mikroskopisch wahrnehmbaren starken Veränderungen in der Auflagerung kann man auch schon makroskopiseh Umwandlungen der Serosabeläge wahrnehmen. Der Belag, welcher in den ersten Wochen eine weisse Farbe zeigte, sieht von der 6. Woche ab gelbgrau aus, haftet mehr oder weniger an der Peritonealserosa und hat eine rauhe Oberfläche. Am Parietalperitoneum sieht man statt des Belages schliesslich nur noch gelbe Flecke. An der Leber und am Zwerchfell behält der Belag aber noch längere Zeit einen mehr weisslichen oder gelblichweissen Farbenton.

Was nun den Zustand der Kaninchen nach der intraperitonealen Kampferölinjektion betrifft, so wird derselbe durch die Menge von $1 / 2 \mathrm{ccm}$ auf je $100 \mathrm{~g}$ des Körpergewichts nicht gestört, abgesehen davon, dass einige Tiere nach dem kleinen Eingriff eine Zeitlang sich still verhielten.

Von den 43 Versuchstieren sind im Verlaufe der 13 Wochen danernden Beobachtungszeit 7 gestorben, und zwar 1 aus unklarer Ursache am 36. Tage nach der Injektion, 5 an interkurrenten Krankheiten, davon 2 an schwerer Enteritis 36 Tage und 79 Tage post injectionem, 2 an Pneumonie (sicher obne Fettembolie) 3 Wochen und 30 Tage nach der Injektion und an Pleuropneumonie nach 5 Wochen. Nur 1 der Versuchstiere starb mit grösster Wahrscheinlichkeit an Fettembolie der Lunge am 10. Tage nach der Oelinjektion (Nr. 19 Versuchsgruppe X). Fettembolische Herde fanden sich aber in der Lunge ausserdem noch bei 3 getöteten Kaninchen, 2 mal stärker nach 24 Stunden und nach 5 Tagen und 1 mal geringer nach 6 Tagen. Mässige Mengen resorbierter Oeltropfen finden sich in den Lungengefässen regelmässig. Solche Lipämie verursacht aber keine pathologischen Veränderungen des Lungengewebes.

Emulgiertes Oel trifft man bis zu 2 Wochen nach der intra- 
peritonealen Oelinjektion im Bauchraum. Entsprechend der Emulgierung des injizierten Oels erscheint das Peritoneum wie mit Oeltropfen betaut. Dies tauartige Aussehen erhält die Peritonealoberfläche etwa nach 12 Stunden. Die wie ein Oeltau aussehenden auf der Peritonealoberfläche verteilten Oeltropfen wirken auf die Serosa wie kleine Fremdkörper und rufen die beschriebenen Reaktionserscheinungen hervor (cf. Hoehne: Verh. d. VI. internat. Kongr. f. Geb. u. Gyn. Berlin 1912). Nach 5 Wochen zeigt das Peritoneum stat des tauähnlichen Bildes eine leichte Trübung, die auf die stärkere Bindegewebsentwicklung in der Auflagerung und in der Serosa zurückzuführen ist.

Sehr wichtig ist nun die Frage nach etwaigen im Anschluss an die intraperitoneale Kampferölinjektion auftretenden Adhäsionen im Bauchraum. Bei meinen 43 Versuchstieren habe ich nennenswerte Adhäsionen überhaupt nicht gefunden. 1 mal fand sich eine Netzadhäsion in einer kleinen Bauchnarbenhernie. Offenbar war diese auf sekundäre Heilung der Operationswunde zu beziehen. Ausserdem bemerkte ich nur noch 1 mal eine unwesentliche Netzadhäsion an einer Milz, die besonders stark mit gelbweissem Belag überzogen war. Dass bei den 43 geölten Kaninchen nicht ein einziges Mal eine Darmverwachsung beobachtet worden ist, trotz der zumeist recht langen Beobachtungszeit, halte ich für besonders bemerkenswert. Ich muss mich also dem Urteil von Hoehue anschliessen, der den Standpunkt vertritt, dass zwar das Oel nicht mit Sicherheit die Entstehung von Adhäsionen verhütet, aber auch trotz der starken reaktiven Veränderungen am Peritoneum keine Adbäsionen veranlasst.

Beachtenswert ist auch die Beobachtung, dass von den 43 Kaninchen 2 trotz der regelrechten wohlgelungenen Kampferölinjektion weder makroskopisch noch mikroskopiseh reaktive Veränderungen am Peritoneum aufwiesen, und ausserdem 1 weiteres nur mikroskopisch deutliche Endothelzellenwucherung zeigte. Bei den beiden Kaninchen, die gar keine reaktive Peritonitis erkennen liessen, konnte jch aber Fett in den Lymphgefässen der Serosa und Subserosa, sowie in den Blutgefässen der Lunge nachweisen. Das Oel war also bei diesen Tieren ohne jede Reaktion seitens des Peritoneums resorbiert worden. Das Peritoneum hat demnach auch bei Tieren der gleichen Rasse eine ganz verschiedene Empfindlichkeit und Reaktionsfähigkeit. Ausserdem möchte ich noch einmal betonen, dass die reaktiven Veränderungen keineswegs überall gleich- 
mässig über das ganze Peritoneum verbreitet gefunden werden. Die ganz starken Beläge finden sich meist nur herdweise an den verschiedenen Stellen der Peritonealserosa, besonders am Zwerchfell, manchmal nur spärlich und können auch bisweilen ganz fehlen. Leichtere Veränderungen aber, vor allem in Form der Endothelzellenwucherung oder dünner Beläge finden sich in den früheren Stadien fast ausnahmslos sehr weit verbreitet über die Peritonealserosa. Natürlich können kleine Veränderungen auch unter den verschiedenen technischen Manipulationen leiden oder gar schwinden, so dass man im mikroskopischen Präparate weniger findet, als in Wirklichkeit vorhanden war.

Nachdem ich an einer grossen Versuchsreihe nachgeprüft hatte, wie das Kaninchenperitoneum auf die intraperitoneale Kampferölinjektion reagiert, wandte ich mich der weiteren Frage zu, ob das Peritoneum anderer Tiergattungen in derselben Weise und in derselben Stärke auf die Oelinjektion antwortet. Wenn das Peritoneum bei einer Tiergattung auf intraperitoneal injiziertes Oel gar nicht reagiert, dann darf man solche Tiergattung für experimentelle Untersuchungen über Oelprophylaxe nicht verwenden, weil man sonst in seinen Schlussfolgerungen mit Bezug auf den Menschen zu einem durchaus fehlerhaften Resultat gelangt.

Um diese 'Frage zu klären, habe ich Versuche an Meerschweinchen und an weissen Mäusen angestellt. Die Versuchsanordnung war bei diesen beiden Versuchsreihen die gleiche wie bei den Kaninchen (vgl. diese). Um eine Nachprïfung zu ermöglichen, führe ich meine Versuchsprotokolle an, und zwar berichte ich zuerst über meine am Meerschweinchenperitoneum angestellten Versuche.

\section{Experimente an Yeerschweinchen:}

\section{Gruppe.}

Tötung der beiden Meerschweinchen (Nr. 1 und 2) 3 Tage nach der intraperitonealen Kampferölinjektion.

Nr. 1. Männliches Meerschweinchen, $460 \mathrm{~g}$ schwer.

Oelinjektion 28. X. 1912. Menge des Kampferöls $=2,3 \mathrm{ccm}$.

Verlauf; Ungestört.

Sektion: 31. X. 1912, $500 \mathrm{~g}$ schwer.

Befund: Keine freie Flüssigkeit und keine adhäsiven Veränderungen in der Bauchhöhle. Am parietalen und viszeralen Peritoneum findet man stellenweise ein leicht tauartiges Aussehen. Weisse, feucht glänzende Auflagerungen sieht man nur spurenweise an der Abdominalseite des Zwerchfells, am Dickdarm und an der Milz. Das Netz ist 
fettreich und seine Oberfläche ist deutlich mit einem Oeltau bedeckt. Die Pleura und die Lunge sind normal.

Der Züchtungsversuch aus der Bauchhöhle fällt negativ aus.

Mikroskopische Untersuchung: Am parietalen und viszeralen Peritoneum findet man gar keine Maschenbildung, die ja beim Kaninchen sehr deutlich war. Nur hier und da haben wir eine mehrschichtige Wucherung der Endothelzellen. Besonders deutlich sind sie an der abdominalen Seite des Zwerchfells. Im subserösen Gewebe sieht man im allgemeinen erweiterte und stark gefüllte Blutgefässe. Letztere enthalten bisweilen eine geringe Ansammlung von Leukozyten. Bei der Sudanfärbung sieht man selten in der Endotheizellenwucherung feine intra- und interzellulär gelegene Fetttröpfchen, Fibrin ist nicht vorhanden.

Die Lunge ist auch mikroskopisch normal. Hier und da bemerkt man geringe Mengen feiner Oeltropfen in den Blutgefässen der Lunge.

Nr. 2. Männliches Meerschweinchen, $380 \mathrm{~g}$ schwer.

Oelinjektion 28. X. 1912. Menge des Kampferöls $=2 \mathrm{ccm}$.

Verlauf: Nichts Besonderes zu bemerken.

Sektion: 31. X. 1912, $410 \mathrm{~g}$ schwer.

Befund: Keine freie Flüssigkeit und auch keine adhäsiven Veränderungen in der Bauchhöhle. Das Peritoneum ist überall glatt. Weisse Auflagerungen sieht man nur am Zwerehfell und am Netz. Am Dickdarm, an der Milz und an der Leber zeigt.die Serosa ein etwas weissliches Aussehen, aber keinen Belag. Die Lunge und die Pleura sind normal.

Die Bauchhöhle erweist sich bei der bakteriologischen Prüfung als keimfrei.

Mikroskopische Untersuchung: Am Zwerchfell und am Netz zeigen sich deutliche Veränderungen. An der Abdominalseite des Zwerchfells bemerkt man besonders auf dem Centrum tendineum an einigen Stellen eine Auflagerung in dünner Schicht. Diese Auflagerung. besteht hauptsächlich aus stark gewucherten Endothelzellen, die kleine Hohlräume einschliessen. Die Hohlräume sind laut Sudanfärbung mit Oeltropfen erfüllt. Auch intra- und interzellulär liegende feine Oeltropfen in der Auflagerung kann man sehr deutlich erkennen. Fibrin ist in geringer Menge als feines Netz nachweisbar. Wo die Auflage rungen am Peritoneum diaphragmaticum fehlen, findet man aufgequollene und mehrschichtig gewucherte Endothelzellen. Die Lymphgefässe der Zwerchfellserosa und Subserosa sind deutlich erweitert und enthalten resorbiertes Oel. Die Pleura diaphragmatica ist spiegelnd und glatt.

An der Oberfläche des Netzes bemerkt man ebenfalls eine starke Wucherung der Endothelzellen, die ebenso wie am Zwerchfell grosse und kleine HohIräume bilden und mit Leukozyten ziemlich stark durchsetzt sind. Fibrin ist ebenfalls in spärlicher Menge vorhanden. Im Grundgewebe des Omentum fallen die beträchtlich erweiterten und prall gefüllten Blutgefässe auf, besonders dicht unter der Auflagerung, sowie eine hochgradige Infiltration mit Leukozyten. Im Maschenwerk der Auflagerung sind noch keine Blutgefässe nachweisbar, nur selten findet man an der Grundschicht einige vom Grundgewebe eindringende Kapillarsprossen.

An anderen Organen findet man keine nennenswerten Veränderungen.

Die Lunge ist auch mikroskopisch normal. Feine Fetttroplen in den Lungengefässen sind in geringer llenge nachweisbar. 


\section{Gruppe.}

Tötung der beiden Meerschweinchen (Nr, 3 und 4) 5 Tage nach der intraperitonealen Kampferölinjektion.

Nr. 3. Männliches Meerschweinchen, $280 \mathrm{~g}$ schwer.

Oelinjektion 28. X. 1912. Menge des Kampferöls = 1,4 ccm.

Verlauf: Ohne Störung.

Sektion: 2. XI. 1912, $300 \mathrm{~g}$ schwer.

Befund: Oel ist in geringer Menge frei in der Bauchhöhle nachzuweisen. Adhäsive Veränderungen finden sich nicht. Der charakteristische Oeltau ist am Peritoneum deutlich. Die Mesenterialgefässe sind ziemlich stark injiziert. Weisse, feucht glänzende Auflagerungen sieht man nur in Form kleiner Punkte auf der Leber und auf der abdominalen Zwerchfellseite. An der Oberfläche von Netz und Mesenterium sieht man kleine weissliche Auflagerungen, am Netz zum Teil polypöse Wucherungen.

Pleura und Lunge bieten nichts Besonderes.

Die bakteriologische Untersuchung der Bauchhöhle ergibtKeimfreiheit.

Mikroskopische Untersuchung: Die reaktiven Veränderungen der Peritonealserosa beschränken sich bei diesem Tier auf eine starke mehrschichtige Wucherung der aufgequollenen Endothelzellen. Das Serosabindegewebe zeigt eine ziemlich deutliche Erweiterung und Füllung der Blutgefässe und auch eine geringe Ansammlung von Leukozyten. Nur an der Oberfläche des Netzes bemerkt man eine ausgesprochene Maschenwerkbildung. Das Maschenwerk besteht aus gewucherten aufgequollenen Endothelzellen genau so, wie ich es am geölten Peritoneum der Kaninchen geschildert habe. Die Durchsetzung mit Leukozyten ist auch ziemlich deutlich, aber nicht so stark wie beim Kaninchen. Fibrin ist gleichfalls in geringer Nlenge vorhanden. Die Maschen der Auflagerung sind natürlich von emulgiertem Oel erfüllt.

Die Lunge weist auch mikroskopisch keine Besonderheiten auf.

Nr. 4. Männliches Meerschweinchen, $390 \mathrm{~g}$ schwer.

Oelinjektion 28. X. 1912. Menge des Kampferöls $=2 \mathrm{ccm}$.

Verlauf: Ungestört.

Sektion: 2. XI, $1912,400 \mathrm{~g}$ schwer. häsionen.

Befund: Keine freie Flüssigkeit in der Bauchhöhle. Keine Ad-

Das Peritoneum zeigt im allgemeinen ein tauartiges Aussehen. Am Parietalperitoneum der hinteren Bauchwand findet man weisse kleine Auflagerungen, an der Oberfläche der Leber und Milz hier und da kleine fleckige Beläge, an der Abdominalseite des Zwerchfells ebenfalls ganz kleine weisse, fleckige Auflagerungen und am Netz einige poly. pöse Wucherungen. Die Pleuraseite des Zwerchfells ist glatt, wie die übrige Pleura. Die Lunge bietet keine Besonderheiten.

Die Bauchhöhle erweist sich als keimfrei.

Mikroskopische Untersuchung: An der Oberfläche des Netzes findet man, wie bei Meerschweinchen Nr. 3, eine starke Maschenwerkbildung von derselben Struktur. Leukozyteninfiltration ist in mässigem Grade vorhanden. Fibrin wird nur spärlich gefunden. Im übrigen beschränken sich die reaktiven Veränderungen an der Peritonealserosa fast durchweg auf Mehrschichtung der aufgequollenen Endothelzellen. 


\section{Gruppe.}

Tötung der beiden Neerschweinchen (Nr. 5 und 6) 7 Tage nach der intraperitonealen Kampferölinjektion.

Nr. 5. Männliches Meerschweinchen, $510 \mathrm{~g}$ schwer.

Oelinjektion 28. X. 1912. Menge des Kampferöls $=2,5 \mathrm{ccm}$.

Verlauf: Keine besonderen Störungen.

Sektion: 4. XI. 1912, $580 \mathrm{~g}$ schwer.

Befund: In der Bauchhöhle keine freie Flüssigkeit. Keine adhäsiven Veränderungen. Das parietale und viszerale Peritoneum zeigt ein tanartig, leicht getrübtes Aussehen. Ausserdem werden am Netz an einigen Stellen weisse Auflagerungen bemerkt und am Centrum tendineum des Zwerchfells weissliche Flecke.

Die Lunge ist normal. Die Pleura diaphragmatica ist glatt und spiegelnd, wie die übrige Pleura.

Bei der bakteriologischen Untersuchung zeigt sich die Bauchhöhle frei von Keimen.

Mikroskopische Untersuchung: An der Oberfläche des Netzes findet man etwas Maschenwerk, bestehend aus aufgequollenen, feinschaumigen Endothelzellen mit grossen Kernen. Die Leukozyteninfiltration des Maschenwerkes ist mässig stark. Oel liegt in den Maschen in Form von grossen und kleinen Tropfen, aber auch intra- und interzellulär. Fibrin ist in geringer Menge nachweisbar. An der oberen Partie des Grundgewebes entsenden die stark erweiterten und gefüllten Blutgefässe einige Ausläufer in die hier mit Leukozyten stark durchsetzte basale Schicht der Auflagerung. Im übrigen zeigt sich an der Peritonealserosa nur mehrschichtige Wucherung der aufgequollenen Endothelzellen, sowie Erweiterung und starke Füllung der Blutgefässe im Serosabindegewebe.

Nr. 6. Männliches Meerschweinchen, $380 \mathrm{~g}$ schwer.

Oelinjektion 28. X. 1912. Menge des Kampferöls $=2 \mathrm{ccm}$.

Verlauf: Ungestört.

Sektion: 4. XI. 1912, $400 \mathrm{~g}$ schwer.

Befund: Peritoneum parietale und viszerale ist glatt und spiegelnd. Kein tauartiges Aussehen, keine Auflagerungen. Keine freie Flüssigkeit in der Bauchhöhle.

Die Pleura und die Lunge sind ganz normal.

Die Bauchhöhle ist keimfrei.

Auch mikroskopisch zeigen sich an der Peritonealserosa keine Veränderungen.

Die Sudanfärbung lässt in den Lymphgefässen der Zwerchfellserosa und Subserosa resorbierte Oeltropfen erkennen, ebenso in den Blutgefässen des nicht veränderten Lungengewebes.

Wenn wir uns die bei den Meerschweinchenversuchen gefundenen Resultate noch einmal vergegenwärtigen, so ist zu konstatieren, dass auch bei dieser Tiergattung eine Veränderung des Peritoneums nach intraperitonealer Kampferölinjektion zweifellos auftritt, und zwar in ähnlicher Weise, wie beim Kaninchen. Doch 
zeigen nur 4 der 6 Meerschweinchen eine nennenswerte Maschenwerkbildung, während bei 1 Meerschweinchen lediglich mehrschichtige Wucherung der Serosaendothelien und bei einem anderen gar keine Veränderungen beobachtet wurden. Ein negativer Befund am Peritoneum scheint beim Meerschweinchen viel häufiger zu sein als beim Kaninchen. Und sehr gross scheint auch der Unterschied zwischen Kaninchen und Meerschweinchen hinsichtlich der Stärke der reaktiven Veränderungen. Während die Veränderungen beim Kaninchen sehr hochgradig und fast überall auf dem parietalen und viszeralen Peritoneum verbreitet waren, findet man beim Meerschweinchen nur geringe Wacherungsvorgänge und Leukozyteninfiltration und nur auf einzelne Strecken der Peritonealserosa beschränkt. Fibrin ist nur in geringer Menge nachweisbar, während beim Kaninchen nach der gleichen Versuchsdauer Fibrin in grosser Menge gefunden wurde. Das Peritoneum des Mcerschweinchens reagiert also allem Anschein nach wesentlich schwächer als das Kaninchenperitoneum auf das intraperitoneal injizierte Kampferöl, und ausserdem auch an verschiedenen Organen sehr viel ungleichmässiger. Freilich wären vielleicht die reaktiven Veränderungen stärker ausgefallen, wenn ich mehr Kampferöl angewendet hätte. Krankhafte Erscheinungen wurden an den Meerschweinchen nach der intraperitonealen Kampferölinjektion nicht beobachtet.

Fettembolien der Lunge kamen nicht vor.

Meine weiteren Untersuchungen erstreckten sich noch auf die Reaktionsfähigkeit des Peritoneums von weissen Mäusen.

\section{Experimente an weissen Mäusen.}

Für die Versuche an Mäusen habe ich gleichfalls 1 proz. Kampferöl verwendet. Nachdem die Bauchhaut mit Alkohol und Jodtinktur desinfiziert war, habe ich mit der Pravazschen Spritze auf Körpertemperatur erwärmtes steriles Kampferöl langsam in die Bauchhöhle eingespritzt. Für eine Laparotomie, wie ich sie beim Kaninchen und Meerschweinchen angeführt habe, sind natürlich diese Tiere zu klein. Weil ich befürchten musste, dass eine zu kleine Menge des Kampferöls sich in der Bauchhöhle nicht überall verteilen würde, habe ich nicht, wie bei Kaninchen und Meerschweinchen, $1 / 2 \mathrm{ccm}$ auf je $100 \mathrm{~g}$ Körpergewicht gerechnet, sondern die doppelte Menge, also 0,1 ccm auf je $10 \mathrm{~g}$ Körpergewicht. 


\section{Gruppe.}

Tötung der beiden Mäuse (Nr. 1 u. 2) 2 Tage nach der intraperitonealen Kampferölinjektion.

Nr. 1. Männliche weisse Maus, $20 \mathrm{~g}$ schwer.

Oelinjektion 28. X. 1912. Menge des Kampferöls $=0,2 \mathrm{ccm}$.

Verlauf: Anfangs zeigt das Tier einige Minuten lang heftige Zuckungen. Nach 1 Stunde erholt es sich wieder und frisst.

Sektion: 30. X. 1912.

Befund: Peritoneum im allgemeinen glatt und spiegelnd. Auch das Zwerchfell zeigt makroskopisch keine Besonderheiten.

Pleura und Lunge sind normal. Bakterien werden in der Bauchhöhle nicht gefunden.

Mikroskopisch sieht man an vielen Stellen des Parietal- und Viszeralperitoneums gar keine Veränderungen. Mehrschichtige Wucherung aufgequollener Endothelzellen findet sich an einzelnen Partien der Milzoberfläche, am Netz und vor allem an der Leberoberfläche. Die Leukozyteninfiltration und die Gefässerweiterung im Serosabindegewebe ist nur mässig ausgeprägt, Fibrin nur in Spuren nachzuweisen. Der Lungenbefund ist auch mikroskopisch normal.

Nr. 2. Weibliche, weisse Maus, $20 \mathrm{~g}$ schwer.

Oelinjektion 28. X. 1912. Menge des Kampieröls $=0,2 \mathrm{ccm}$.

Verlauf: Ein leichter Krampf danerte einige Minuten, dann lag das Tier still da. Nach 1 Stunde wurde es wieder munter, frass.

Sektion: 30. X. 1912.

Befund: Das Peritoneum bietet überall ein tauartiges Aussehen. Auf lagerungen werden nicht gefunden. Pleura und Lunge sind normal. Die Bauchhöhle ist keimfrei.

Mikroskopisch zeigt das Parietal- und Viszeralperitoneum inkl. der Zwerchfelloberfläche keine nennenswerten Veränderungen.

\section{Gruppe.}

Tötung der beiden Mäuse (Nr. 3 u. 4) 3 Tage nach der intraperitonealen Kampferölinjektion.

Nr. 3. Männliche, weisse Maus, $20 \mathrm{~g}$ schwer.

Oelinjektion 28. X. 1912. Menge des Kampferöls $=0,2 \mathrm{ccm}$.

Verlauf: Nach der Oelung tritt ein leichter, einige Minuten dauernder Krampf auf, dann ist das Tier für 1 Stunde ganz ruhig und frisst nicht. Später erholt es sich und bleibt weiterhin munter.

Sektion: 31. X. 1912.

Befund: Starke Injektion der Mesenterialgefässe. An der abdominalen Seite des Zwerchfells sieht man kleine weisse Flecke, besonders deutlich auf dem Centrum tendineum, am Parietalperitoneum und am Dickdarm feinste weisse Auflagerungen. Im übrigen ist das Peritoneum glatt. Pleura und Lunge sind normal.

Die Bauchhöhle erweist sich als keimfrei.

Auch die mikroskopische Untersuchung ergibt bei dieser Maus sehr deutliche Veränderungen, besonders am Zwerchfell and am Dickdarm.

An der abdominalen Seite des Zwerchfells findet man eine ausgesprochene Wucherung aufgequollener Endothelzellen mit Bildung vieler grösserer und kleinerer Hohlräume. Die Leukozyteninfiltration 
im Maschenwerk und im Serosabindegewebe ist mässig stark, die Lymphgefässerweiterung und Hyperämie ausgesprochen. Fibrin wird noch in Spuren gefunden. Im Sudanpräparat bemerkt man Oel in kleinsten Tröpfchen intra- und interzellulär liegend in den gewucherten Endothelzellen. Grössere Tropfen von Oel füllen die Hohlräume des Maschenwerkes. Auch in den erweiterten Lymphgefässen der Serosa und Subserosa werden reichliche Mengen von Oeltropfen gefunden (s. Fig. 6).

An der Dickdarmserosa sieht man weit verbreitet eine deutliche Wucherung der aufgequollenen Endothelzellen, aber ohne Hohlraumbildung mit intra- und interzellulär liegenden Oelkügelchen. Weniger ausgesprochen ist die Endothelzellenwucherung am Netz und an der Milzoberfläche. Doch fehlt auch hier nicht die Leukozyteninfiltration und die Gefässerweiterung.

Der Lungenbefund bietet auch mikroskopisch keine Besonderheiten. Die Lipämie in den Lungenblutgefässen ist gering.

Nr. 4. Männliche, weisse Maus, $20 \mathrm{~g}$ schwer.

Oelinjektion 28. X. 1912. Menge des Kampferöls $=0,2 \mathrm{ccm}$.

Verlauf: Nach der Oelung treten leichte Zuckungen auf, aber das Tier erholt sich bald wieder.

Sektion: 31. X. 1912. Keine freie Flüssigkeit im Bauchraum.

Befund: Das Peritoneum zeigt überall ein tauartiges Aussehen, kleine weissliche Auflagerungen.

Pleura und Longe sind normal.

Auch mikroskopisch werden weder am Parietal- noch Viszeralperitoneum nennenswerte Veränderungen gefunden.

\section{Gruppe.}

Tötung der beiden Mäuse (Nr. 5 u. 6) 5 Tage nach der intraperitonealen Kampferölinjektion.

Nr. 5. Männliche, weisse Maus, $20 \mathrm{~g}$ schwer.

Oelinjektion 28. X. 1912. Menge des Kampferöls $=0,2 \mathrm{~cm}$.

Verlauf: Heftiger Krampf nach der Oelung. Nach 1 Stunde erholt sich das Tier wieder.

Sektion: 2. XI. 1912 .

Befund: In der Bauchhöhle findet man etwas emulgiertes Oel. Das Peritoneum zeigt im allgemeinen ein tauartiges Aussehen. Mesenterialgefässe sind deutlich injiziert. Einen geringen weissen Belag findet man deutlich am Leberrand, am Dickdarm, an der Milz und an der Abdominalseite des Zwerchfells. Am Netz bemerkt man viele kleine weisse Knötchen.

Pleura und Lunge sind normal.

Die Bauchhöhle ist keimfrei.

Mikroskopische Untersuchung: An der Oberfläche des Netzes sind die Endothelzellen deutlich gewuchert. In dieser Wucherung zeigen sich im Sudanpräparat mit Oeltropfen erfüllte Hohlräume. Die Leukozyteninfiltration ist im Maschenwerk und in dem Serosabindegewebe stark ausgeprägt. Fibrin wird nur in spärlicher Menge gefunden.

An der abdominalen Seite des Zwerchfells, am Dickdarm und an einigen anderen Stellen der Peritonealserosa beschränken sich die reaktiven Veränderungen im wesentlichen auf eine Wucherung und 
Mehrschichtung der aufgequollenen Endothelzellen mit leichter Leukozyteninfiltration ohne deutliche Maschenbildung.

In den Lungengefässen zirkulieren wohl resorbierte Oeltropfen, aber pathologische Veränderungen des Lungengewebes werden nicht wahrgenommen.

Nr. 6. Weibliche, weisse Maus, $20 \mathrm{~g}$ schwer.

Oelinjektion 28. X. 1912. Menge des Kampferöls $=0,2 \mathrm{ccm}$.

Verlauf: Ein leichter Krampf nach der Oelung schwindet nach 2 Stunden.

Sektion: 2. XI. 1912.

Befund: Keine freie Flüssigkeit im Abdomen. Der Oeltau wird am ganzen Parietal- und Viszeralperitoneum bemerkt. Feine weisse Auflagerungen finden sich an der Abdominalseite des Zwerchfells, am Dickdarm und an der Leber.

Pleura und Lunge zeigen keine Besonderheiten.

Die Bauchhöhle ist keimfrei.

Mikroskopisch bestehen die reaktiven Veränderungen am Parietalund Viszeralperitoneum in mässig starker Wucherung und Mehrschichtung des aufgequollenen Serosaendothels, besonders an der Abdominalseite des Zwerchfells, am Netz und am Dickdarm, aber ohne Maschenbildung. Das Lungengewebe bietet auch mikroskopisch nichts Pathologisehes.

Wenn jch auch aus den wenigen Versuchen an 6 weissen Mäusen keine bindenden Schlüsse ziehen will, so glaube ich doch sagen zu können, dass das Mäuseperitoneum noch weniger intensiv und noch ungleichmässiger als das Meerschweinchenperitoneum auf die intraperitoneale $\mathrm{Kampfer-}$ ölinjektion reagiert, wenn auch qualitativ sich die Veränderungen nicht unterscheiden von denen beim Meerschweinchen und beim Kaninchen. Hauptsächlich zeigten sich von den reaktiven Veränderungen betroffen Zwerchfell, Netz und Dickdarm. Diese Beobachtung stimmt mit dem Befund beim Meerschweinchen fast überein.

Noch eine Tatsache ist bei den Versuchen an weissen Mäusen erwähnenswert. Alle 6 Mäuse zeigten nach der intraperitonealen Kampferölinjektion Zuckungen oder Krämpfe, wie ich sie bei den Meerschweinchen und Kaninchen nach Injektion der von mir gewählten Kampferöldosis nie beobachtet habe. Es scheinen mir die weissen Mäuse gegen Kampferöl besonders empfindlich zu sein.

Ein Blick auf die Versuchsresultate bei den 3 verschiedenen Tiergattungen ergibt ohne weiteres, dass die reaktiven Veränderungen am Peritoneum bei Kaninchen, Meerschweinchen und weissen Mäusen dem Grade nach sehr verschieden sind. Offenbar ist der Intensitätsunterschied auf die verschiedene Empfindlichkeit des Peritoneums gegen Kampferöl zurückzuführen. Wenn das Peri- 
toneum bei einer Tiergattung gegenüber dem Oel sehr empfindlich ist, so zeigt es starke Veränderungen, ist aber bei einer anderen Gattung das Peritoneum gegen das Oel weniger empfindlich, dann reagiert es schwach oder gar nicht. Trit nur eine schwache oder gar keine Reaktion ein, so wird das emulgierte Oel ohne weiteres in die Lymphbahnen resorbiert, während es bei einer starken Reaktion durch die gewucherten Endothelzellen und die massenhaft. angesammelten Leukozyten eingekapselt und zunächst auf dem Peritoneum festgehalten wird. Es wird also unter diesen $\mathrm{Um}$ ständen die Oelresorption in die Lymphbahnen wesentlich gehemmt, um so mehr, je stärker die reaktiven Veränderungen an der Peritonealserosa ausfallen. Natürlich erfolgt auch dann die Resorption des Oels, nur in geringerem Grade und sehr allmählich, bis schliesslich nach vielen Wochen das eingekapselte Oel aus der Auflagerung schwindet.

Da die verschiedengradige Reaktionsfähigkeit des Peritoneums bei den verschiedenen Tiergattungen eine feststehende Tatsache ist, muss man sehr vorsichtig sein, wenn man einen Tierversuch mit der Oelinjektion vornimmt. Wenn man für den Versuch eine Tiergattung wählt, die auf Kampferöl peritoneal sehr unregelmässig, gering und ungleichmässig reagiert wie Meerschweinchen und weisse Mäuse, dann wird man viele negative und sehr ungleichmässige Resultate bekommen, während bei anderen Tiergattangen, wie z. B. bei dem Kaninchen, die Resultate in den allermeisten Fällen positiv und wesentlich gleichmässiger ausfallen.

Will man also brauchbare und möglichst verwertbare Versuche mit intraperitonealen Kampferölinjektionen anstellen, so empfiehlt es sich, eine Tiergattung zu benutzen, die bezüglich der Empfindlichkeit des Peritoneums gegen Kampferöl der des Menschen möglichst nahekommt. Es wäre vielleicht am besten, Affen zu diesen Versuchen heranzuziehen. Nach meinen Versuchsergebnissen genügen aber wohl dazu Kaninchen, da ich ebenso wie Hoehne bei dieser Tiergattung fast regelmässig starke und übereinstimmende reaktive Veränderungen erhalten habe. Besonders für diese Versuche, für die man viele Tiere gebraucht, sind gerade die leicht $\mathrm{zu}$ beschaffenden Kaninchen sehr geeignet. Natürlich ist die Empfindlichkeit des Peritoneums beim Kaninchen an seinen verschiedenen Bezirken auch recht verschieden und abhängig von der Struktur des von ihm bedeckten Gewebes, vor allem von dessen Gehalt an Blut- und Lymphgefässen. 
Versuche mit der intraperitonealen Kampferölinjektion an Meerschweinchen und weissen Mäusen möchte ich auf Grund meiner Untersuchungen für ungeeignet und für sehr wenig vergleichbar halten mit den Verhältnissen beim Menschen. Sehr wünschenswert, ja notwendig ist es, für einen Versuch immer mehrere Tiere zu benutzen. Auch wenn man mit den gut reagierenden Kaninchen arbeitet, soll man doch mindestens 2 oder 3 Tiere in einer Gruppe verwenden, wie ich es auch gehalten habe.

\section{Schlussfolgerungen.}

I. Durch intraperitoneale Kampferölinjektion wird beim Kaninchen fast regelmässig die von Hoehne beschriebene, reaktive Peritonitis ausgelöst (Versuche an 43 Kaninchen). In Uebereinștimmung mit Hoehne fasse ich diese reaktive Peritonitis als Fremdkörperperitonitis auf.

II. Bei der Entwickelung der reaktiven Veränderungen am Peritoneum nach intraperitonealer Kampferölinjektion kann man 3 aufeinanderfolgende Stadien unterscheiden: 1. Das Stadium der Endothelproliferation und der Lenkozyteninfiltration, 2. das Stadium der Fibrinbildung und 3. das Stadium der Organisation und der langsamen Oelresorption.

III. 1 proz. Kampferöl in einer Menge von $1 / 2$ cem auf je $100 \mathrm{~g}$ Körpergewicht wirkt bei Kaninchen nicht giftig. Fettembolie der Lunge ist bei dieser 0 elmenge, die rein gewichtsmässig auf einen Menschen von $60 \mathrm{~kg}$ Körpergewicht berechnet $300 \mathrm{ccm}$ betragen würde, nicht absolut ausgeschlossen.

IV. Darmadhäsionen habe ich bei einer Beobachtungszeit von vielen Wochen nach der intraperitonealen Kampferölinjektion nie beobachtet.

V. Die Reaktionsfähigkeit des Peritoneums gegenüber dem Kampferöl ist bei verschiedenen Tiergattungen sehr verschieden. Selbst bei ein und derșelben Tiergattung reagiert das Peritoneum der einzelnen Tiere keineswegs immer gleichmässig. In den verschiedenen Bezirken der Peritonealserosa zeigt die Reaktion eine verschiedene Stärke. Das Peritoneum des Kaninchens reagiert fast ausnahmslos sehr stark und regelmässig, während bei Meerschweinchen und bei weissen Mäusen die Reaktion nur geringfügig und unregelmässig, sowie aucb an den verschiedenen Peritonealabschnitten recht ungleichmässig auftritt. 


\section{Literatir.}

1. Martin, Die Krankheiten der Eileiter. Leipzig 1895.

2. Glimm, Deutsehe Zeitschr. f. Chir. 1906.

3. Pfannenstiel, XIII. Kongress in Strassburg 1909.

4. Hoehne, Verhandl. d. Deutschen Gesellsch. f. Gyn., XIII. Kongr. in Strassburg 1909. S. 281--287. - Münchener med. Wochenschr. 1909. S. 2508-2511. - Dieses Archiv. 1911. Bd. 93. H. 3. S. 563-648. Verhandl. d. Deutschen Geselisch. f. Chir. 1911. Bd. 40. - Klinischtherapeutische Wochenschr. 1911. Nr. 40. - Zentralbl, f. Gyn. 1911. Nr. 32. S. 1145-1149. - Zentralbl. f. Chir. 1911. Nr. 30. - Verhandl. d. Deutschen Gesellsch. f. Gyn., XIV. Kongress in München 1911. S. 324-331. - Zentralbl. f. Gyn. 1912. Nr. 9. - Münchener med. Wochenschr. 1912. Nr. 16. - Verhandl. d. VI. Internat. Kongr. f. Geb. u. Gyn. Berlin 1912. - Therapeutische Monatshefte. 1912. Novemberheft.

5. Burkhardt, Zentralbl. f. Gyn. 1911. Nr. 33.

6. Krecke, Münchener Gyn. Gesellsch. 1911.

7. Hirschel, Bruns: Beiträge. 1907. Bd. 56. Chirurgenkongress 1910. Münchener med. Wochenschr. 1910. Nr. 15.

8. Holzbach, Naturforscherversammlung in Karlsruhe 1911.

9. Rübsamen, Zentralbl. f. Gyn. 1912. Nr. 31.

10. Esser, Niederrheinische Gesellsch. f. Natur- u. Heilkunde. Bonn vom 17. VI. 1912.

11. Happich, Münchener med. Wochensehr. 1912. Nr. 12 u. 23.

12. Wilkie, Surgery, Gynecology and Obstetrics. February 1910. p. 126-132.

13. Rehn, Verhandl. d. Deutschen Gesellsch. f. Chir. zu Berlin, 40. Kongress vom 19.-22. November 1911.

14. Novak, Wiener klin. Wochenscbr. 1912. Nr. 29.

15. C. Ruge, Verhandl. d. Gesellsch. f. Geb. u. Gyn. zu Berlin vom 14. Juli bis zum 27. Oktober 1911. Ref. Zeitschr. f. Geb. u. Gyn. 1912. Bd. 70. H. 1 .

16. Heimann, Zeitschr. f. Geb. u. Gyn. Bd. 71. H. 3.

\section{Erklärung der Abbildungen auf Tafel VII--VIII.}

Fig. 1. Auflagerung am Dickdarm bei schwacher Vergrösserung: Zeiss Obj. A, Ok. 3 (Kaninchen Nr. 3). a = Maschenbildung der Endothelzellen. $\mathrm{b}=$ Serosa und Subserosa. $\mathrm{c}=$ stark erweiterte Blutgefässe. $\mathrm{d}=$ Infiltration mit roten Blutkörperchen und mit Leukozyten. $\mathrm{e}=$ Längsmuskulatur. $\mathrm{f}=$ Ringmuskulatur. $\mathrm{g}=$ Schleimhaut.

Fig. 2. Untere Partie von Fig. 1 bei stärkerer Vergrösserung: Zeiss Obj. E., Ok. 4. $\mathrm{a}=$ Maschenbildung der Endothelzellen. $\mathrm{b}=$ Hyperämie und Leukozyteninfiltration der Serosa. $c=H o h l r a ̈ u m e . ~ d=$ Endothelzellen. $\mathrm{e}=$ Leukozyten. $\mathrm{f}=$ Bindegewebszellen der Serosa. $\mathrm{g}$ = Leukozyten im Bindegewebe der Serosa. $\mathrm{h}=$ rote Blutkörperchen. $\mathrm{i}=$ stark erweiterte Blutgefässe. 
180 Kawasoye, Veränderungen der Bauchorgane nach Kampferölinjektion.

Fig. 3. Fibrin im Maschenwerk: Zeiss A, Ok. 2 (Kaninehen Nr. 11). $a=$ breiter Streifen von Fibrin in der oberen Partie der Auflagerung. $b=$ Fibrinnetz in der Auflagerung. $: c=$ Auflagerung. $\mathrm{d}=$ Lebergewebe.

Fig. 4. A uflagerung am Dünndarm. Zeiss Obj: E., Ok. 3 (Kaninchen N. 27). $a=$ Endothelialer Ueberzug auf der Auflagerung. $\mathrm{b}=$ Hohlräume in der Auflagerung. $\mathrm{c}=$ bandartig konfluierte Endothelzellen. $\mathrm{d}=$ Zellklumpen. $\mathrm{e}=$ riesenzellenartiges Bild konfluierter Endothelzellen. f = Endothelzelthaufen an einer Stelle des Hohlraumes. $\mathrm{g}=$ Bindegewebe. $\mathrm{h}=$ langgestreckte Endothelzellen.

Fig. 5. Lebergewebe, das gerade unter der Auflagerung liegt. Zeiss Obj. E, Ok. 4 (Kaninchen Nr. 40). a = Normale Leberzellen. $\mathrm{b}=\operatorname{sch} w a c h$ tingierte Leberzellen. $\mathrm{c}=$ erweiterte Lymphgefässe. $d=$ stark erweiterte Lymphgefässe. $\theta=$ Blutgefässe.

Fig. 6. Sudanfärbung des Zwerchfells (weisse Maus Mr. 3). Zeisś E, 0k. 2. a = Auflagerung. $b=$ Grundgewebe des $Z$ werchfells. $\mathrm{c}=$ Fett in grossen Kugeln. $\mathrm{d}=$ Fett in feineren Tropfen, welche intra- und interzellulär liegen. 